\title{
Fusion Materials Research at Oak Ridge National Laboratory in Fiscal Year 2018
}

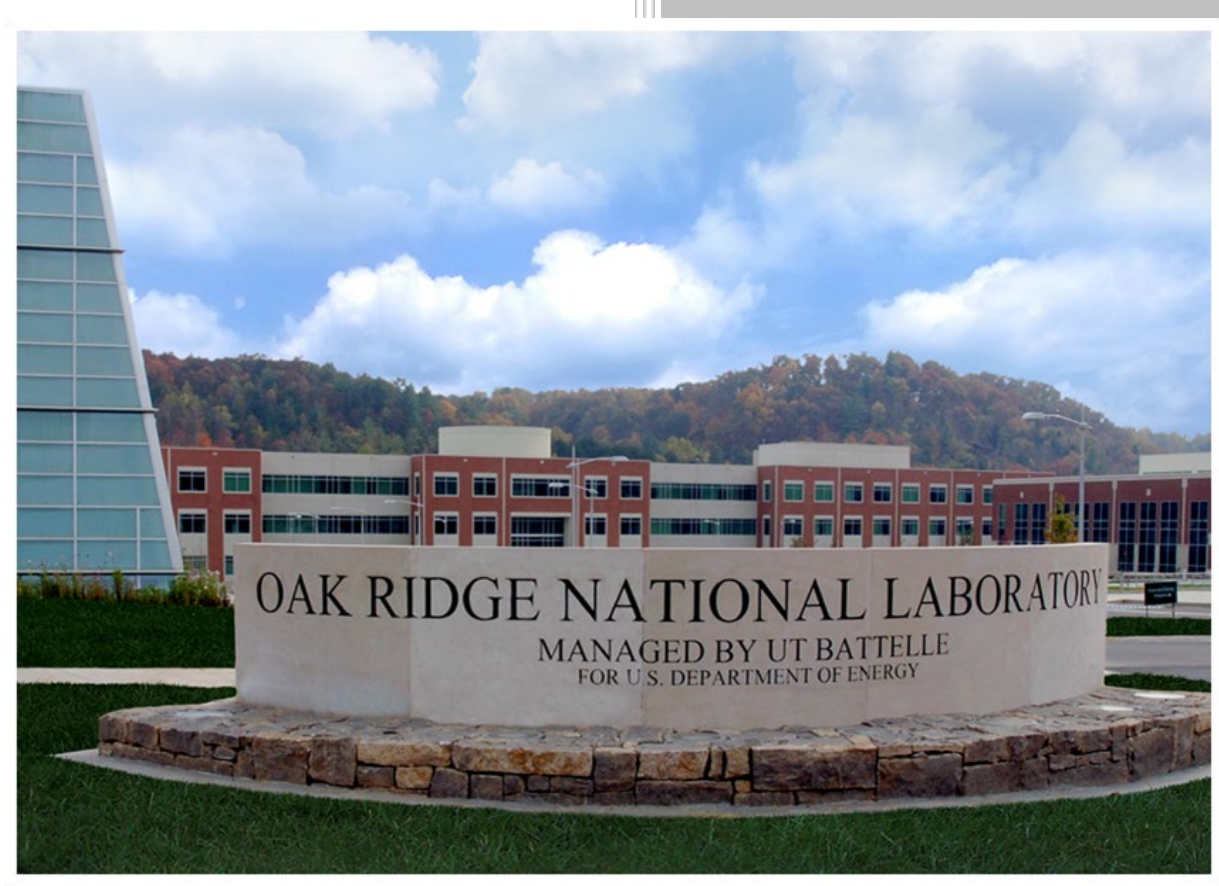

Approved for public release.

F.W. Wiffen

Y. Katoh

S. Melton

Distribution is unlimited.

November 2018 


\section{DOCUMENT AVAILABILITY}

Reports produced after January 1, 1996, are generally available free via US Department of Energy (DOE) SciTech Connect.

Website www.osti.gov

Reports produced before January 1, 1996, may be purchased by members of the public from the following source:

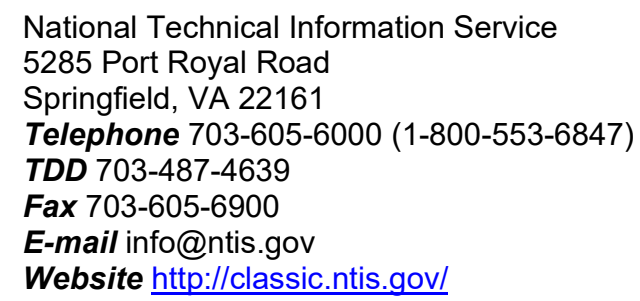

Reports are available to DOE employees, DOE contractors, Energy Technology Data Exchange representatives, and International Nuclear Information System representatives from the following source:

Office of Scientific and Technical Information

PO Box 62

Oak Ridge, TN 37831

Telephone 865-576-8401

Fax 865-576-5728

E-mail reports@osti.gov

Website http://www.osti.gov/contact.html

This report was prepared as an account of work sponsored by an agency of the United States Government. Neither the United States Government nor any agency thereof, nor any of their employees, makes any warranty, express or implied, or assumes any legal liability or responsibility for the accuracy, completeness, or usefulness of any information, apparatus, product, or process disclosed, or represents that its use would not infringe privately owned rights. Reference herein to any specific commercial product, process, or service by trade name, trademark, manufacturer, or otherwise, does not necessarily constitute or imply its endorsement, recommendation, or favoring by the United States Government or any agency thereof. The views and opinions of authors expressed herein do not necessarily state or reflect those of the United States Government or any agency thereof. 
Materials Science and Technology Division

FUSION MATERIALS RESEARCH AT OAK RIDGE NATIONAL LABORATORY IN FISCAL YEAR 2018

\author{
Compiled by: \\ F.W. Wiffen \\ Y. Katoh \\ S. Melton
}

Date Published: November 2018

\title{
Prepared by
}

OAK RIDGE NATIONAL LABORATORY

Oak Ridge, TN 37831-6283

managed by

UT-BATTELLE, LLC

for the

US DEPARTMENT OF ENERGY

under contract DE-AC05-00OR22725 


\section{CONTENTS}

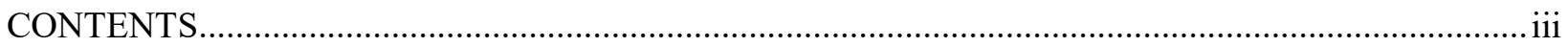

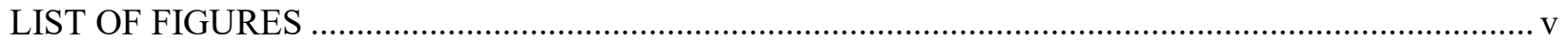

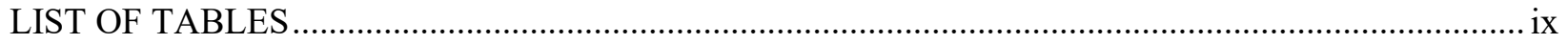

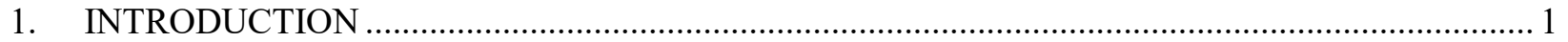

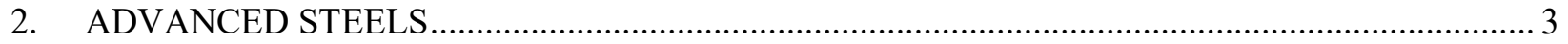

2.1 DEVELOPMENT OF ADVANCED RAFM STEELS - CASTABLE

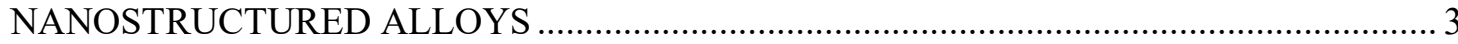

2.2 PRE-IRRADIATION CHARACTERIZATION OF EUROFUSION PROJECT

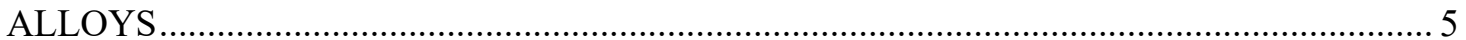

2.3 DEVELOPMENT OF TRANSFORMATION ENHANCED ODS Fe-Cr ALLOYS ............... 8

2.4 Fe-Cr-Al ODS ALLOYS FOR FUSION REACTOR APPLICATIONS …........................... 10

2.5 BAINITIC STEEL DEVELOPMENT FOR FUSION APPLICATIONS ............................. 14

2.6 MICROSTRUCTURAL CHARACTERIZATION OF RAFM STEELS IN HFIR JP28

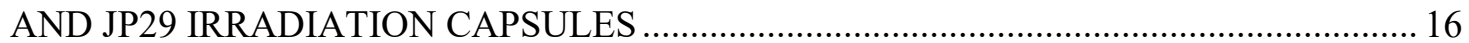

2.7 IRRADIATION CREEP OF F82H PRESSURIZED TUBES …..................................... 19

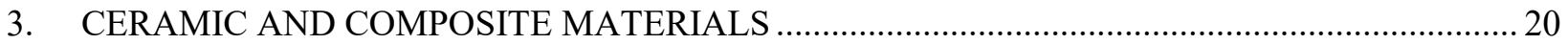

3.1 HIGH DOSE NEUTRON IRRADIATION EFFECTS ON MECHANICAL

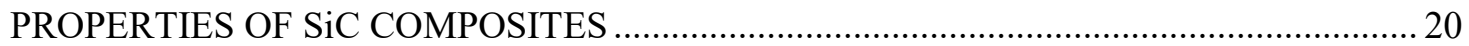

3.2 ADVANCED CHARACTERIZATION OF IRRADIATION DEFECTS IN SILICON

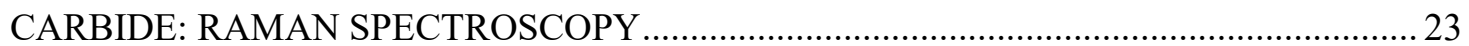

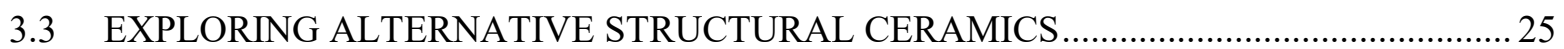

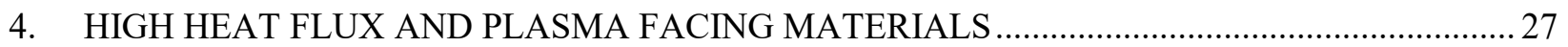

4.1 NEUTRON IRRADIATION EFFECTS IN TUNGSTEN …............................................... 27

4.2 TRANSMUTATION-INDUCED PRECIPITATION IN TUNGSTEN IRRADIATED

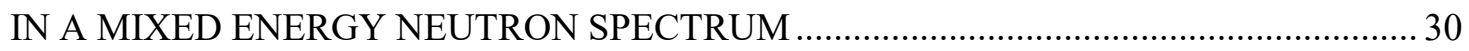

4.3 MECHANICAL PROPERTIES OF TUNGSTEN IRRADIATED IN THE PHENIX

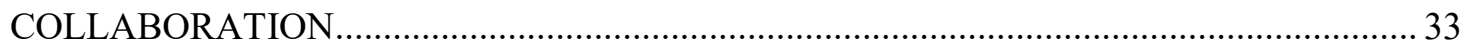

4.4 THERMAL PROPERTIES OF PHENIX COLLABORATION NEUTRON

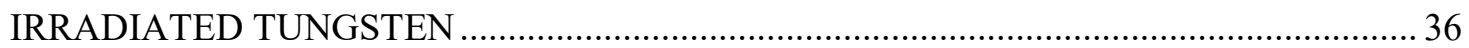

4.5 NEUTRON IRRADIATION EFFECTS IN TUNGSTEN-COPPER COMPOSITES .............. 39

4.6 W-Re-Os ALLOYS FOR THE FUSION PROGRAM ......................................................... 41

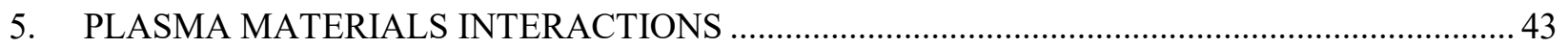

5.1 DAMAGE-MECHANISM INTERACTIONS AT THE PLASMA-MATERIALS

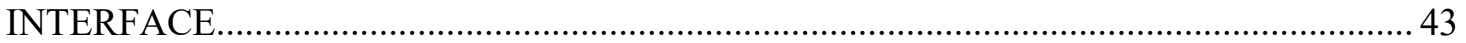

5.2 GAS-DEFECT INTERACTIONS IN FUSION MATERIALS ............................................ 46

5.3 HIGH-HEAT FLUX TESTING OF FUSION MATERIALS …........................................... 48

5.4 HIGH HEAT FLUX TESTING OF NEUTRON IRRADIATED TUNGSTEN .................... 51

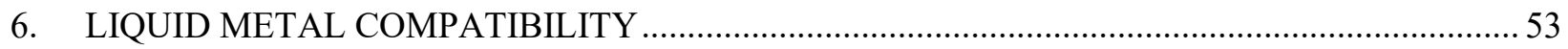

$6.1 \quad$ LIQUID METAL COMPATIBILITY IN FLOWING SYSTEMS........................................ 53

6.2 LIQUID METAL COMPATIBILITY IN STATIC Li, Sn AND Sn-Li ................................ 55

7. EXPLORATORY, UNIQUE AND INNOVATIVE MATERIALS ............................................... 57

7.1 PROPERTIES AND CHARACTERIZATION OF NOVEL COPPER ALLOYS FOR

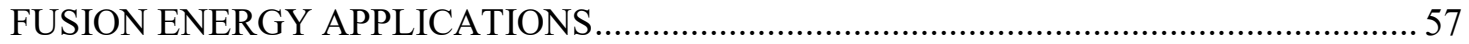

7.2 NEUTRON AND ION IRRADIATION EFFECTS IN 312 AND 211 Ti-BASED MAX PHASES...

7.3 EFFECT OF GAMMA IRRADIATION ON SECOND-GENERATION HIGH TEMPERATURE SUPERCONDUCTORS 
8. COMPUTATIONAL MATERIALS SCIENCE.

8.1 MECHANICAL PROPERTIES AND RADIATION EFFECTS IN MATERIALS FOR FUSION

8.2 ANALYSIS OF PHASE STABILITY OF PRECIPITATES IN TUNGSTEN ALLOYS .......66

8.3 THERMODYNAMICS OF COMPLEX MULTI-PHASE FUSION ALLOYS.......................... 68

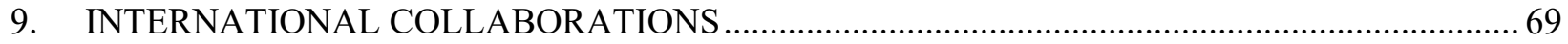

9.1 US-JAPAN COLLABORATIONS ON STRUCTURAL MATERIALS …............................ 69

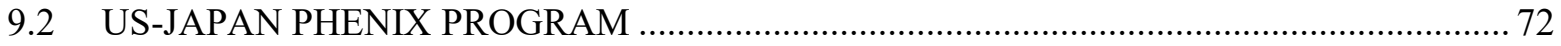

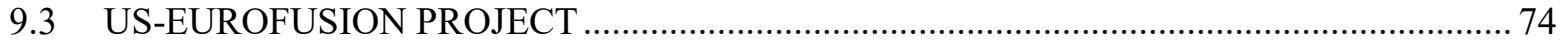

9.4 IAEA - STANDARDIZATION OF SSTT FOR FUSION APPLICATIONS ….................... 75

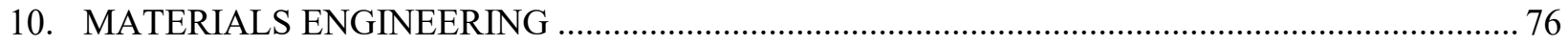

10.1 MATERIALS ENGINEERING SUPPORTING THE FNSF CONCEPTUAL DESIGN ........ 76

11. EXPERIMENTAL TECHNIQUES AND LABORATORY SYSTEMS ….................................. 78

11.1 MECHANICAL TEST SYSTEMS FOR IMET HOT CELLS ........................................... 78

11.2 FINITE ELEMENT ANALYSIS OF TUNGSTEN COMPOSITE TENSILE

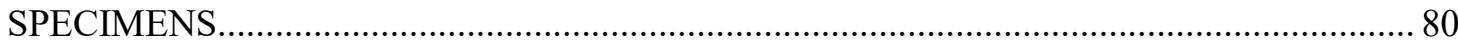

11.3 THE GD-OES TECHNIQUE TO MEASURE THE COMPOSITION OF TUNGSTEN

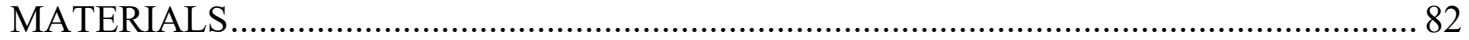

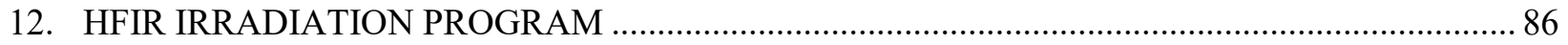

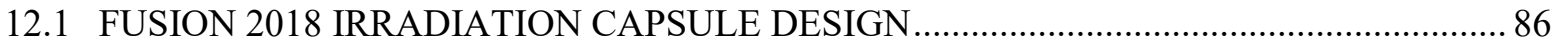

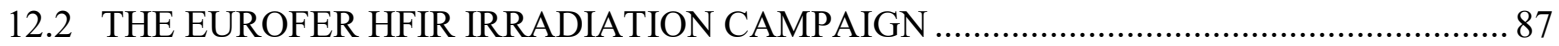

12.3 A HYDROGEN-CHARGED IRRADIATION CAPSULE FOR HFIR ............................... 88

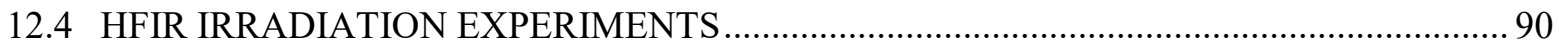

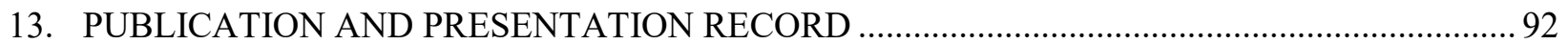

13.1 PAPERS PUBLISHED IN FY 2018

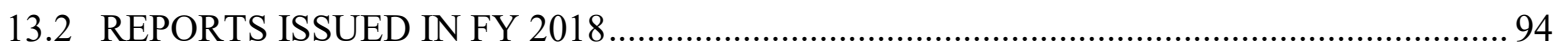

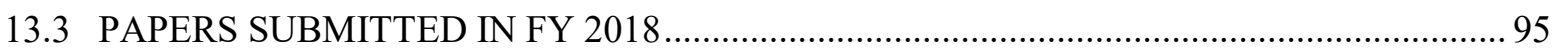

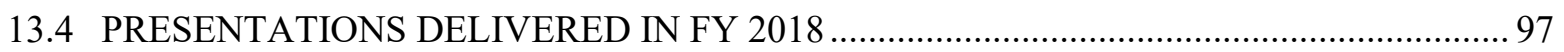




\section{LIST OF FIGURES}

Figure 1. Representative (a) high-density nanoprecipitates and dislocations in a CNA and (b) creep curves of CNAs and reference T91.

Figure 2. (a) Three types of microstructures developed in CNA5 and (b) the effect on helium thermal desorption behavior.

Figure 3. (a) Fine-grain $\mathrm{CNA} 7$ after annealing at $900^{\circ} \mathrm{C}$ and (b) dilatometry determined phase transformation temperatures of CNA7.

Figure 4. Vickers hardness values from tests performed on SS-J3 head/grip sections of the different Eurofer97 steels.

Figure 5. Engineering stress-strain curves for the Eurofer97 steel variants. SS-J3 samples, strain rate $: 10^{-3} \mathrm{~s}^{-1}$. Elongation measured from machine stroke.

Figure 6. SEM secondary electron images of very coarse precipitates in reference $\mathbf{E}$ series Eurofer97 steel.

Figure 7. Transition temperature $T_{0}$ of ten Eurofer 97 variants, compared to the $T_{0}$ range of standard Eurofer97.

Figure 8. Neutron scattering intensities measured between 200 and $900^{\circ} \mathrm{C}$ during the in-situ SANS experiments.

Figure 9. APT maps illustrating the evolution of the nano precipitate size during annealing/extrusion at $1000-1100^{\circ} \mathrm{C}$ for durations ranging from $15 \mathrm{~min}$ to $500 \mathrm{~h}$.

Figure 10. Creep-rupture test results at $550^{\circ} \mathrm{C}$ of the original $3 \mathrm{Cr}-3 \mathrm{WVTa}$ steel (black symbols: base metal [1]; blue symbols: cross-weld) and the MSLC2 (open red symbols: as-normalized, base metal and cross-weld; filled red symbols: normalizedand-tempered, base metal and cross-weld).

Figure 11. (a) Charpy impact test results of as-normalized and tempered materials $(3 \mathrm{Cr}$ $3 W V T a$ base and newly proposed $3 \mathrm{Cr}-3 \mathrm{WV}$ base steels), and (b) as-GTAW 3Cr$3 W V$ base steel plates with original $3 \mathrm{Cr}-3 \mathrm{WVTa}$ steel weld filler metal.

Figure 12. Schematic of a cutting fixture for highly radioactive SS-J type specimens (red in image): (a) mounted in the open position and (b) mounted in the closed position both shown above the cutoff blade.

Figure 13. STEM-EDS map showing $\mathrm{Cr}$-rich clusters (blue images) in the Eurofer97 matrix irradiated near $300^{\circ} \mathrm{C}$. A 3 by 3 pixel smoothing filter was used.

Figure 14. Typical flexural behavior of non-irradiated and neutron irradiated (11 dpa at $500{ }^{\circ} \mathrm{C}$ and $44 \mathrm{dpa}$ at $590-640^{\circ} \mathrm{C}$ ) $\mathrm{SiC}$ composites with various fiber matrix interfaces. HNS fiber reinforced CVI-SiC matrix composites with $\mathrm{PyC}$ monolayer and $\mathrm{PyC} / \mathrm{SiC}$ multilayer are referred to as HNS-C and $\mathrm{HNS}-\mathrm{C} / \mathrm{ML}$, respectively. In a similar manner, SA3 fiber reinforced CVI-SiC matrix composites with monolayer and multilayer were denoted as $\mathrm{SA3}-\mathrm{C}$ and $\mathrm{SA3}-\mathrm{C} / \mathrm{ML}$, respectively.

Figure 15. Typical specimen surface images of $\mathrm{SiC}$ composites before and after neutron irradiation at 590-640 ${ }^{\circ} \mathrm{C}$ to 44 dpa. HNS-C and SA3-C indicate single layer PyC interfaces with HNS and SA3 SiC fiber reinforcement, respectively. The images show significant differential swelling between HNS fiber and matrix, but limited differential swelling between SA3 fiber and matrix.

Figure 16. Irradiation temperature dependence of longitudinal optical peak position and swelling of $\beta-\mathrm{SiC}$ neutron irradiated to 1.4-11.8 dpa. This image will be shown in a cover of the Journal of Raman Spectroscopy.

Figure 17. Micro-cracks in $\mathbf{T i}^{11} \mathrm{~B}_{2}$ irradiated in HFIR at $(\mathrm{A}) \sim 200^{\circ} \mathrm{C}$ and $(\mathrm{B}) \sim \mathbf{6 0 0}^{\circ} \mathrm{C} \ldots \ldots \ldots \ldots \ldots \ldots . . . . . . . . . .26$ 
Figure 18. Tensile properties of single-crystal tungsten with $<110>$ crystal direction along the tensile axis (a) irradiated at $360-460^{\circ} \mathrm{C}$ and tested at $300^{\circ} \mathrm{C}$, (b) irradiated at $690-800^{\circ} \mathrm{C}$ and tested at $500^{\circ} \mathrm{C}$, and (c) irradiated at $800-830^{\circ} \mathrm{C}$ and tested at $650^{\circ} \mathrm{C}$. Curves are offset by $5 \%$ strain with the same scale used for all curves................... 28

Figure 19. Summary of microstructures from tungsten irradiated in the TITAN/PHENIX programs compared with previous data from JMTR, JOYO, and HFIR irradiations reported by Hasegawa et al. [2]. Selected microstructures have been evaluated in more detail in recent articles: (a) from Hu et al. [3], (b)-(c)-(d) this work, (e) Fukuda et al. [4], and (f) Hu et al. [3].

Figure 20. STEM dark field images and $X$-ray maps of neutron-irradiated single crystal tungsten (110): (a) $0.02 \mathrm{dpa}, 460^{\circ} \mathrm{C}$; (b) $0.09 \mathrm{dpa}, 7^{\circ} 7^{\circ} \mathrm{C}$; (c) $0.44 \mathrm{dpa}, 7^{\circ} 5^{\circ} \mathrm{C}$; (d) $1.80 \mathrm{dpa}, 770^{\circ} \mathrm{C}$.

Figure 21. (a) STEM bright-field images taken at the same location in sample OW158 $\left(1.5 \mathrm{dpa}, 8^{\circ}{ }^{\circ} \mathrm{C}\right)$ using different sample tilts; (b) computer generated model of acicular precipitates (purple straight lines) and voids (black circles); (c) snapshots of movie showing the correlation of precipitates and voids. 32

Figure 22. Unirradiated microstructure of thick plate unalloyed tungsten, orientation "A."......... 34

Figure 23. Vickers microhardness of thick plate unalloyed tungsten, orientation " $A$ ", before and after irradiation at the nominal temperatures indicated.

Figure 24. Tensile tests at the approximate irradiation temperature of the thick plate tungsten, orientation " $A$ ". Curves are offset on the $x$-axis for clarity.

Figure 25. Sample size comparison measured with the LFA 467 and analyzed with the instrument software. Literature values are from Ref. [1].

Figure 26. Thermal diffusivity of unirradiated tungsten materials intended for high heat flux testing.

Figure 27. Thermal diffusivity of irradiated tungsten the materials intended for high heat flux testing.

Figure 28. Tungsten-copper sintered composite irradiated at $630-780^{\circ} \mathrm{C}$ and tested at (a) room temperature and (b) the irradiation temperature. Only the plastic strain is shown and approximately the same scale is used for all tensile curves..

Figure 29. (a) As fabricated W-5Re-Os ingot and specimens cut using EDM; (b) GD-OES elemental distribution profile.

Figure 30. Tungsten-ion-irradiated tungsten, imaged by transmission electron microscopy........... 43

Figure 31. Example of analysis of the tendril / substrate interface, using a speciallydeveloped experimental method.

Figure 32. The local strain tensor measured around a nanoindent in (001) single crystal tungsten, as determined by high-resolution EBSD. Inset is the measured density of geometrically necessary dislocations.

Figure 33. Sink strength of RAFM, CNA, ODS steels (bar plot) and normalized deuterium retention rate (normalized to that of pure iron) of the six steels (scattered data points with right $y$-axis). The individual sink strength of various microstructural features is also shown (left axis). The arrow shown in the figure is included as a guide to the eyes.

Figure 34. Incident heat flux from the plasma-arc lamp: numerical simulation results for new, line-focus reflector, and measured data for old uniform heat-flux reflector.

Figure 35. Measured incident heat flux and estimated absorbed heat flux into $W$ from the new PAL line-focus reflector and old uniform heat-flux reflector.

Figure 36. Heat flux evolution during HHFT and measured temperature: (a) control PAL shut-down with regular HHFT cycle and (b) temperature data (PAL shut-down after HHF ended).

Figure 37. Images of as-polished, unirradiated K-doped W-3Re sample A00C. 
Figure 38. K-doped W-3Re sample A000 after neutron irradiation and before HHF exposure.

Figure 39. Specimen mass change of APMT specimens in three TCL experiments as a function of estimated temperature in the flowing $\mathrm{Pb}$ - $\mathrm{Li}$ after $1,000 \mathrm{~h}$ exposures. Higher mass losses were typically observed for specimens that were not pre-oxidized prior to exposure.

Figure 40. Examples of oxide thickness measurement on APMT specimens using TEM images: (a) bright-field image of pre-oxidized scales with no exposure and (b) darkfield image of $\mathrm{Pb}-\mathrm{Li}$ exposed oxide scale. The two-way arrows indicate individual thickness measurements.

Figure 41. Specimen mass change data for specimens exposed for $1000 \mathrm{~h}$ in isothermal capsule experiments.

Figure 42. Solubility of $\mathrm{Fe}, \mathrm{Cr}$ and $\mathrm{Ni}$ in liquid $\mathrm{Li}, \mathrm{Pb}$ and $\mathrm{PbLi}$ up to $1000^{\circ} \mathrm{C}$. Dashed lines connect median solubilities.

Figure 43. Yield strength (upper) and creep life (lower) of $\mathrm{Cu}-\mathrm{Cr}-\mathrm{Nb}-\mathrm{Zr}$ compared to $\mathrm{Cu}$ $\mathrm{Cr}-\mathrm{Zr}$ alloy literature values.

Figure 44. (a)-(b) Low magnification optical image of the CCZ and CCNZ alloys in the asreceived condition. (c)-(d) High magnification optical image of the $\mathrm{CCZ}$ and $\mathrm{CCNZ}$ alloys in the as-received condition. (e) SEM-EDS on spherical particles in the CCZ alloy. (f) SEM-EDS on facet particles in the CCNZ alloy. (g) TEM image at the tab location of the creep-tested $\mathrm{CCZ}$ sample at $500^{\circ} \mathrm{C}, 90 \mathrm{MP}$ for $79 \mathrm{~h}$. (h) TEM image at the tab location of the creep-tested CCNZ sample at $500^{\circ} \mathrm{C}, 90 \mathrm{MP}$ for $113 \mathrm{~h}$.

Figure 45. Aging of $4 \mathrm{~nm}$ He-bubble with initial $\mathrm{He} / \mathrm{VAC}=2$ : crystal temperature and bubble volume increase are plotted vs modeling time. Sudden volume increase occurred when bubble emits an interstitial loop. Formation and emitting of loops is a stochastic and random process and loops may have different shape and Burgers vector: Left - two segments of $1 / 2<111>$ loops of $\sim 450$ SIAs, Right $-<100>$ loop of -530 SIAs. This modeling is suggested for comparison with targeted in situ TEM experiments.

Figure 46. Near equilibrium (left) and over-pressurized (right) bubbles after interaction with a moving $1 / 2<111>$ edge dislocation in bec Fe. Note a significant increase in the total dislocation network after interaction with the over-pressurized bubble.

Figure 47. Interactions of $1 / 2<111>$ edge dislocation with $6 \mathrm{~nm}$ impenetrable, rigid inclusion for different interaction geometries. Top: dislocation slip plane intersects the inclusion along its equator. Shear Orowan is formed around the inclusion. This geometry results in near the maximum strengthening.

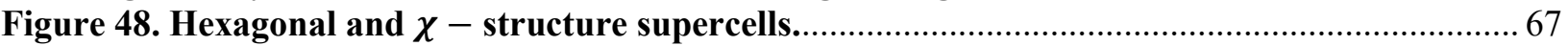

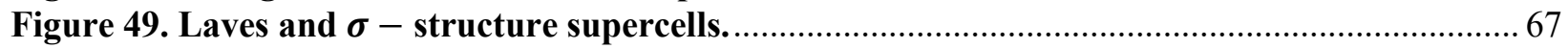

Figure 50. Eurofer97: (a) Cr-rich clusters distributed in the matrix, with an average size of $3.1 \pm 0.8 \mathrm{~nm}$ and number density of $1.7 \times 10^{23} \mathrm{~m}^{-3}$, (b) Elemental segregation $(\mathrm{Cr}$ and $\mathrm{Ni}$ enrichment, Fe and $\mathrm{V}$ depletion) and helium bubbles were observed at the lath boundaries.

Figure 51. General layout of fracture toughness test setup.

Figure 52. (a) M5CVN multi-notch bend bar test fixture and (b) a close up photo of the indenter.

Figure 53. Temperature response of major reactor components to loss-of-cooling event, and vacuum vessel materials issues that could be tackled in the Fusion Materials research program.

Figure 54. Front view of the high temperature vacuum test frame ready for installation in the IMET hot cells of ORNL Building 3025E. 
Figure 55. New Mitutoyo HV-120B Vickers hardness tester for installation in the Building $3025 \mathrm{E}$ hot cells.

Figure 56. Tests use the SSJ-2 samples (left), and the FEA model focuses on the gauge section (right).

Figure 57. Example of tungsten foil modeled with a fixed support and induced motion on one end (top), and the resulting strain profile (bottom).

Figure 58. Cross section of experimental tungsten-steel laminate (left). Simulated tungstensteel laminate layers with $\mathbf{5 7} \boldsymbol{\mu \mathrm { m }}$ individual layer thickness (right).

Figure 59. Exploded view of centering ring and sample mount on GD-OES $4 \mathrm{~mm}$ anode with DiP.

Figure 60. Examples of several sample types for GDOES are shown: (a) $3 \mathrm{~mm}$ disc in square sample mounting tab shown with the centering ring, (b) $6 \mathrm{~mm}$ sample in mounting tab, (c) tensile bar, (d) silver paint coated mount, (e) W ZrC material with two $4 \mathrm{~mm}$ and one $2 \mathrm{~mm}$ craters, (f) $10 \mathrm{~mm}$ disc of W PIM material with a $2 \mathrm{~mm}$ crater.

Figure 61. Example of sputtered crater depth profile. The slope at the bottom of the crater was because the original sample was not mounted flat in the mount.

Figure 62. The same material, $\mathrm{W}-10 \% \mathrm{ZrC}$, was measured with the $2 \mathrm{~mm}$ and $4 \mathrm{~mm}$ anodes on the GDOES.

Figure 63. GDOES measurement of an unirradiated W-0.4\%Re sample. 85

Figure 64. Core mapping of the GENTEN capsule format with F82H specimens.

Figure 65. Representative layouts of EUROfusion-KIT toughness specimen capsule (left ES35) and SSJ/MPC specimen capsule (right - ES22) to irradiate Eurofer 97 in HFIR.

Figure 66. Schematic of capsule design and specimen loading.

Figure 67. Layout of components and specimens for HFIR capsule VH01. 


\section{LIST OF TABLES}

Table 1. Composition of M4 and M5 determined by chemical analysis.

Table 2. Irradiation conditions and included SS-J3 specimens of M4 and M5

Table 3. Chemical composition in at. \% of the 106ZY powder and the ZY105 and

ZY11alloys measured by inductively coupled plasma combustion and inert gas fusion analysis

Table 4. Aberration Corrected APT Results: $R_{p}$ is the mean particle diameter and $N_{p}$ is the particle density number. Errors are reported as one standard deviation from the mean.

Table 5. Material types for HHF testing

Table 6. Summary of HFIR operation in FY2018

Table 7. Fusion materials program rabbits that completed HFIR irradiation in FY-2018

Table 8. HFIR fusion materials program rabbit capsules continuing irradiation beyond FY-2018 


\section{INTRODUCTION}

\section{Yutai Katoh(katohy@ornl.gov) and F.W.Wiffen}

Achieving fusion energy presents a formidable challenge to the field of materials science, to provide a suite of suitable materials in close integration to the plasma physics and other applied technologies. The technological challenge presented by the conceptual future fusion power systems is the inability of current materials and components to withstand the harsh fusion nuclear environment. The overarching goal of the ORNL fusion materials program is to provide the applied materials science support and materials understanding to underpin the ongoing DOE Office of Science - Fusion Energy Sciences program, in parallel with developing materials for fusion power systems. In this effort the program continues to be integrated both with the larger U.S. and international fusion materials communities and with the international fusion design and technology communities.

This long-running ORNL program continues to pursue development of low activation structural materials such as the Reduced Activation Ferritic/Martensitic Steels, higher strength/higher creep resistant/coolant compatible/radiation tolerant advanced steels, and Silicon Carbide Composites. Focused tasks within the steels portfolio are development of Castable Nanostructured Alloys, exploratory work on Bainitic steels and Oxide Dispersion Strengthened (ODS) steels, and liquid metal compatibility evaluations. Parallel to this is the increased emphasis on radiation effects, high heat flux testing and the development of refractory metals. This includes the use of an ORNL Plasma Arc Lamp facility adapted for the thermal testing of irradiated materials, the development and evaluation of new tungsten materials, and the study and understanding of the irradiation performance of tungsten. In each case the materials are being developed in a design-informed fashion where properties improvements are led by fusion-relevant design studies and directed at advancing the Technology Readiness Level of the material systems.

Work supported by an Early Career Award is looking in depth at the materials side of the Plasma Materials Interactions, characterizing the materials response to plasma impingement and determining the controlling mechanisms of the materials behavior.

A limited effort continues to examine functional and exploratory materials. Work on materials for diagnostic systems has been inactive during FY 2018, although ORNL stands ready to support basic irradiation materials science of ceramics that could be used in diagnostic systems. For high-temperature superconductors, ORNL continues a limited program to quantify the irradiation sensitivity of the most recently developed tape materials. A new fixture to evaluate effects of gamma field exposure of these materials is ready for use with the spent HFIR core radiation source. Studies of the MAX-phase ceramics continue, focused on the effects of elevated temperature neutron and ion irradiation on the properties of these unique materials that potentially possess exceptional radiation tolerance.

This program integrates fundamental modeling into the development efforts as much as practicable, directed especially at understanding experimentally observed behavior.

This fusion materials program makes heavy reliance on neutron irradiation in HFIR, the High Flux Isotope Reactor at ORNL. This is complemented by limited use of ion irradiation facilities when these are better suited to explore fundamental aspects of materials behavior under irradiation. Associated with the HFIR irradiations is the infrastructure needed to evaluate the effects of the irradiation on the material properties and microstructures. This requires both the hot cells needed for experiment disassembly and the equipment to test highly radioactive specimens, and the shielded test equipment in the Low Activation Materials Development and Analysis Laboratory (LAMDA). Maintaining, upgrading, and replacing this state-of-the-art suite of instruments and test stands is an ongoing effort, shared with other programs focused on similar needs. 
A continuing activity initiated several years ago, "Materials Engineering in Support of the FNSF Program," for the FESS studies is also reported.

This document summarizes Fiscal Year - 2018 activities supporting the Office of Science, Office of Fusion Energy Sciences Materials Research for Magnetic Fusion Energy carried out by ORNL. The organization of the report is mainly by material type, with sections on specific technical activities.

The fusion materials effort consists of a wide array of tasks and collaborations both within the US and with international partners. The major continuing international collaborating partners are the Japan Agency for Quantum and Radiological Science and Technology (QST, reorganized and transferred from Japan Atomic Energy Agency, the US DOE-JAEA collaboration, focused on structural materials), the Japanese National Institute for Fusion Sciences (the PHENIX collaboration, emphasizing plasma facing materials and tritium fuel issues) and the Karlsruhe Institute of Technology in Germany, acting for EUROfusion (examining steel materials). Discussion of a potential collaboration with China on Fusion Materials research continues but have not yet reached the point of a contract for collaborative work. 


\title{
2. ADVANCED STEELS
}

\subsection{DEVELOPMENT OF ADVANCED RAFM STEELS - CASTABLE NANOSTRUCTURED ALLOYS}

\author{
L.Tan(tanl@ornl.gov), C.M. Parish, X. Hu, T. Graening (KIT), Y. Yang
}

\section{OBJECTIVE}

Castable nanostructured alloys (CNAs) are being developed at Oak Ridge National Laboratory to fill the performance gap between current reduced-activation ferritic-martensitic (RAFM) steels and oxidedispersion-strengthened alloys. The CNAs accomplish this by developing a larger population of ultrafine stable precipitates via conventional, affordable steel making production methods.

\section{SUMMARY}

Following the progress in developing generation one (Gen.-1) CNAs implemented with ultrafine carbide precipitates, Gen.-2 CNAs development was introduced focusing on ultrafine nitride precipitates. Microstructural characterization and creep tests were conducted. In the meantime, microstructural engineering by thermomechanical treatment was explored to study the effects on some of the key properties. Two papers based on this work were published in the Journal of Nuclear Materials in FY18.

\section{PROGRESS AND STATUS}

The CNAs are nominally Fe-9Cr-1.2W with varying additions of other elements. A commercial heat of Gen.-1 CNA, designated CNA7, with a weight of $\sim 60 \mathrm{lbs}$. was procured. Microstructural characterization indicated a high-density of nanoprecipitates and dislocations (Figure 1a), implementing the microstructure design goal of CNAs. Creep tests at $650^{\circ} \mathrm{C}$ and $100 \mathrm{MPa}$ were conducted in air using type SS-3 miniature specimens for a Gen.-2 CNA, CNA7, CNA4 and a commercial reference steel T91 (Figure 1b). The results indicated comparable creep resistance of CNA7 and the Gen.-2 CNA, both slightly superior to that of CNA4. All the CNAs had noticeably greater creep resistance than T91.

Three types of microstructures, i.e., full ferrite ( $F-F C)$, full tempered-martensite (TM - R900), and dual phase (TM+F - R700) (Figure 2a), were developed in CNA5 by different thermomechanical treatments. Tensile and Charpy impact tests, together with helium thermal desorption measurement, were conducted on the samples with the three microstructures. Full ferrite tended to retain more helium (Figure 2b). Refined microstructures (peak-IV) and nanoprecipitates (peak-III) indicated strong effects on releasing and trapping helium (Figure $2 b$ ).

A thermomechanical treatment was developed for CNA7 to obtain refined grains, which yielded some ferrite grains without tempered martensite (Figure 3a). Dilatometry of CNA7 indicated an austenite finish temperature at $917^{\circ} \mathrm{C}$ (Figure 3b), which explains the presence of ferrite grains (Figure 3a) resulted from the final brief annealing at $900^{\circ} \mathrm{C}$ before tempering at $750^{\circ} \mathrm{C}$.

\section{FUTURE PLANS}

A revised thermomechanical treatment based on the dilatometry result will be developed for CNA7 to obtain refined fully TM grains. The resulting material will be subjected to a variety of mechanical tests and microstructural characterization. Atom probe tomography will be employed to better characterize the nanoprecipitates in representative CNAs. 

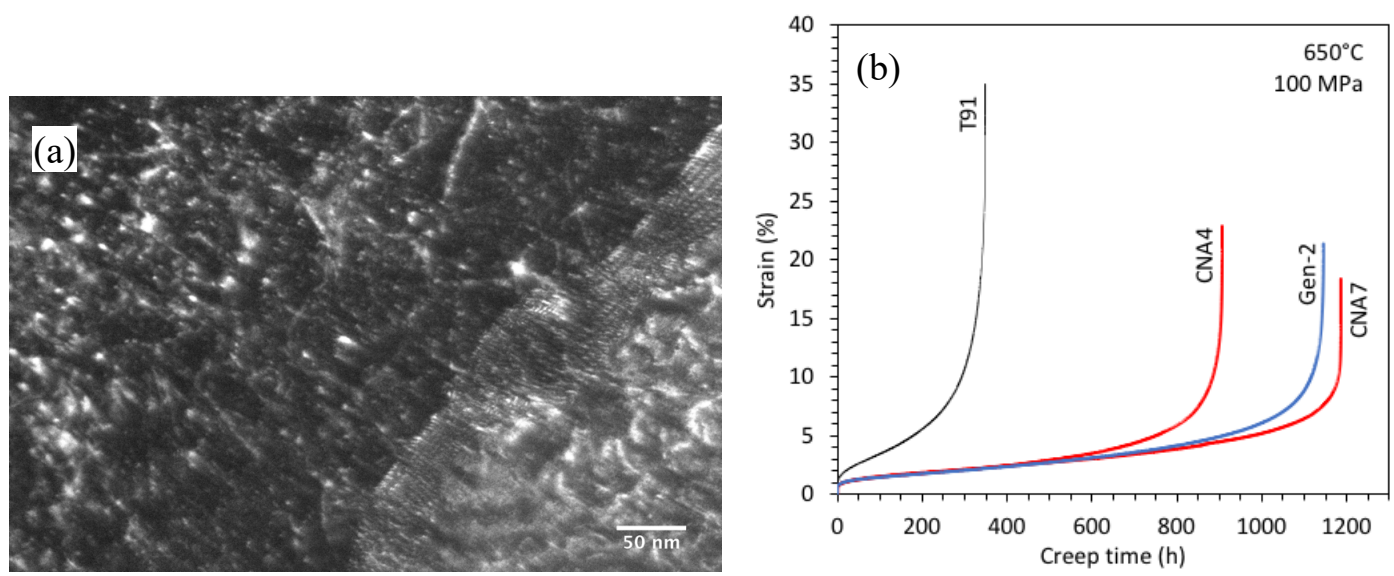

Figure 1. Representative (a) high-density nanoprecipitates and dislocations in a CNA and (b) creep curves of CNAs and reference T91.
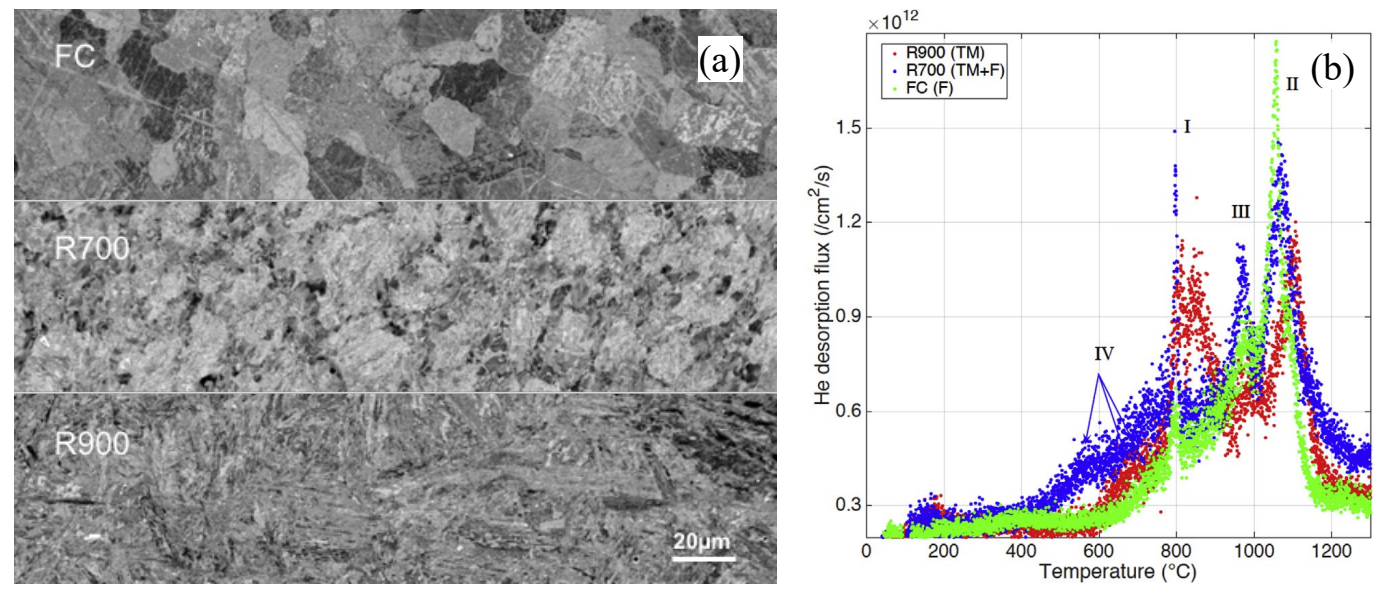

Figure 2. (a) Three types of microstructures developed in CNA5 and (b) the effect on helium thermal desorption behavior.
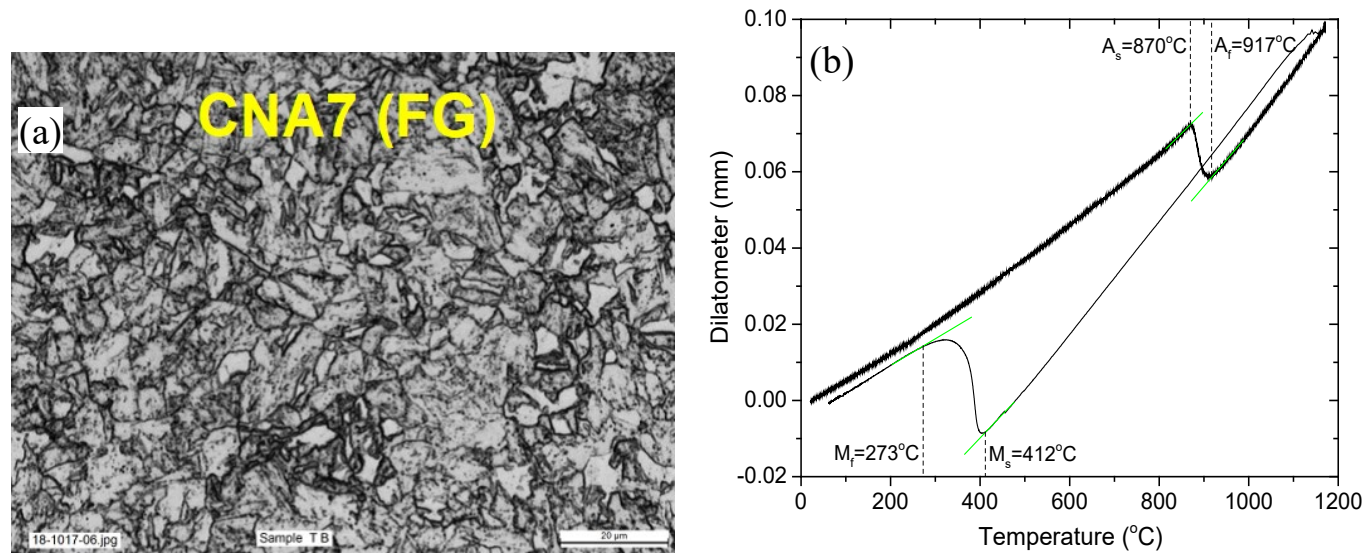

Figure 3. (a) Fine-grain CNA7 after annealing at $900^{\circ} \mathrm{C}$ and (b) dilatometry determined phase transformation temperatures of CNA7. 


\title{
2.2 PRE-IRRADIATION CHARACTERIZATION OF EUROFUSION PROJECT ALLOYS
}

\author{
A. Bhattacharya (bhattacharya@ornl.gov), X. Chen, M. Sokolov, L. Clowers, K. Linton, Y. Yamamoto, Y. \\ Katoh
}

\section{OBJECTIVE}

The objective of this task is to characterize the pre-irradiation mechanical properties and microstructure of the ten Eurofer97 steel variants for the EUROfusion project.

\section{SUMMARY}

Pre-irradiation mechanical properties and multi-length scale microstructure characterization were completed on all ten Eurofer97 steel variants (designated as H, I, P, J, K, L, M, N, O, and reference E series) for the EUROfusion project. This provides a thorough structure-property relationship for these alloys that will serve as the base for characterizing the HFIR irradiated material.

\section{PROGRESS AND STATUS}

Ten variants of Eurofer97 steels including reference Eurofer97 were irradiated in HFIR to target 2.5 dpa at $\sim 300^{\circ} \mathrm{C}$. The reference Eurofer97 is also being irradiated to $20 \mathrm{dpa}$ at temperatures within the range $220-370^{\circ} \mathrm{C}$. To understand the irradiation induced effects on these steels, it is essential to characterize them in the unirradiated form. This study evaluated Vickers micro-hardness, room temperature uniaxial tensile behavior using SS-J3 miniature specimens, and transition fracture toughness using miniature multi-notch bend bars of the ten steels per ASTM E384, ASTM E8, and ASTM E1921 standards respectively. Furthermore, detailed microstructure characterization included light optical microscopy (LOM), transmission electron microscopy (TEM) in both conventional TEM and scanning TEM (STEM) mode, energy dispersive X-ray spectroscopy (EDX) in STEM mode, a study of the fracture surfaces after room temperature tensile tests and general microstructure observations using scanning electron microscopy (SEM).

The study found that most of the EUROfusion steels had quite similar hardness (Figure 4), except for two under-tempered steels ( $\mathrm{K}$ and $\mathrm{L}$ series) which showed the highest hardness. Vickers hardness results are reflected in the tensile behavior (Figure 5) where the under-tempered $\mathrm{K}$ and $\mathrm{L}$ series steels have considerably higher yield (YS) and ultimate tensile strengths (UTS) compared to other series but appear to show significantly reduced tensile fracture toughness. YS and UTS of the reference Eurofer97 steel (E series) are lower than the values expected based on previously reported data for Eurofer97 steel. This unexpected behavior was due to the presence of significantly coarse carbides (Figure 6) revealed in this alloy in the condition provided to ORNL. Finally, most steel variants exhibited fracture toughness transition temperatures $\left(\mathrm{T}_{0}\right)$ within the upper scatter band of the standard Eurofer97 range, Figure 7. However, $\mathrm{E}, \mathrm{K}$, and $\mathrm{L}$ showed $\mathrm{T}_{0}$ above the standard Eurofer97, indicating poor fracture toughness. This study has developed a structure-property characterization of the ten steels that will be used in understanding their behavior after the neutron irradiations.

\section{FUTURE PLANS}

Once SiC-passive thermometry data are available, tensile tests on unirradiated steels at the irradiation temperature and PIE of the ten irradiated steels will commence. The PIE experiments will include uniaxial tensile tests at room temperature and the irradiation temperature, Vickers hardness indentation tests, and fracture toughness testing in the hot cell. Following the mechanical property tests, fractography 
of the irradiated tensile-tested specimens using SEM will be performed at the hot cell and then samples will be transferred to LAMDA for detailed microstructure characterization using TEM/STEM.

A journal paper summarizing the mechanical properties of these unirradiated alloys is in preparation.

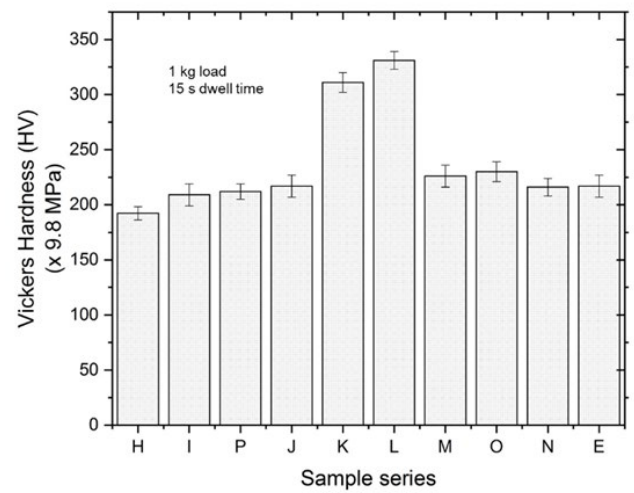

Figure 4. Vickers hardness values from tests performed on SS-J3 head/grip sections of the different Eurofer97 steels.
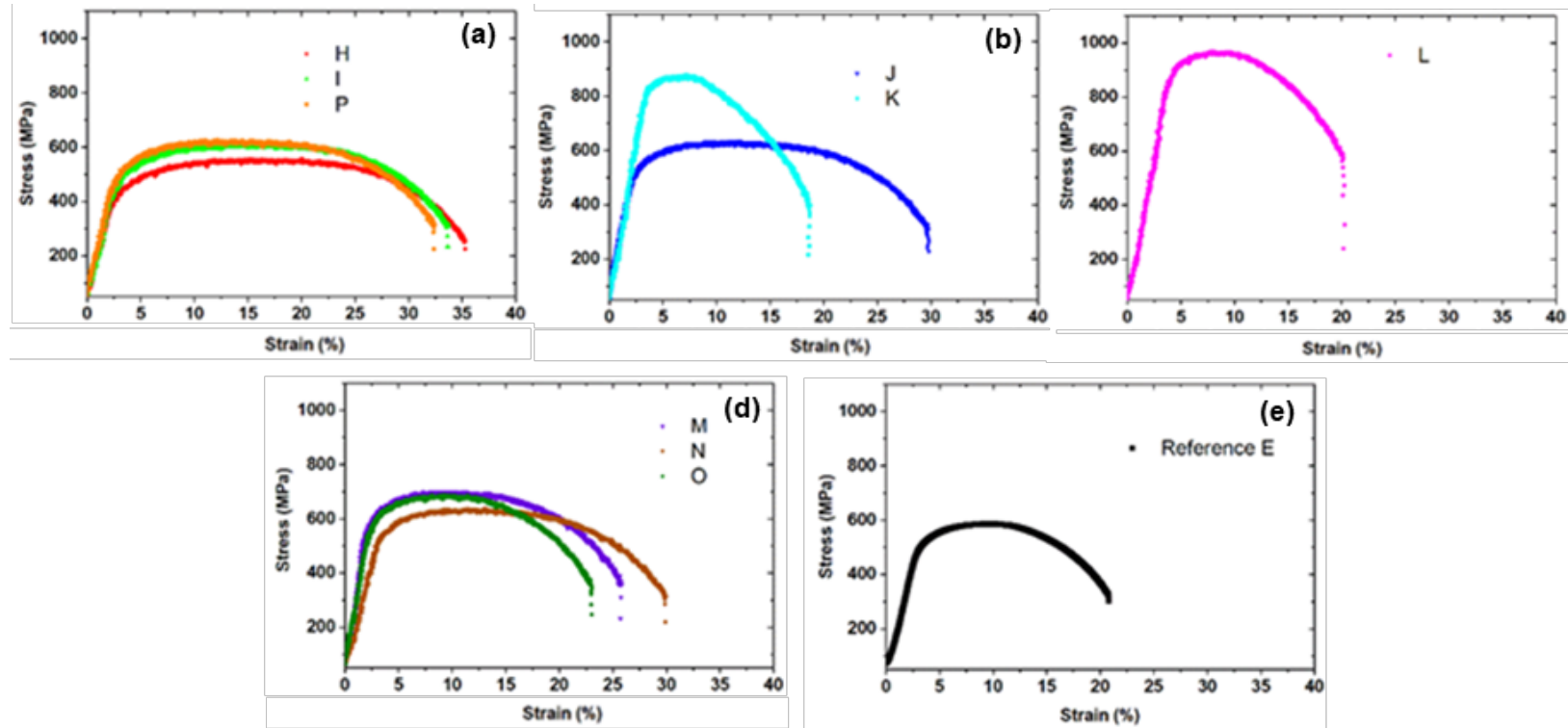

Figure 5. Engineering stress-strain curves for the Eurofer97 steel variants. SS-J3 samples, strain rate $: 10^{-3} \mathrm{~s}^{-1}$. Elongation measured from machine stroke. 

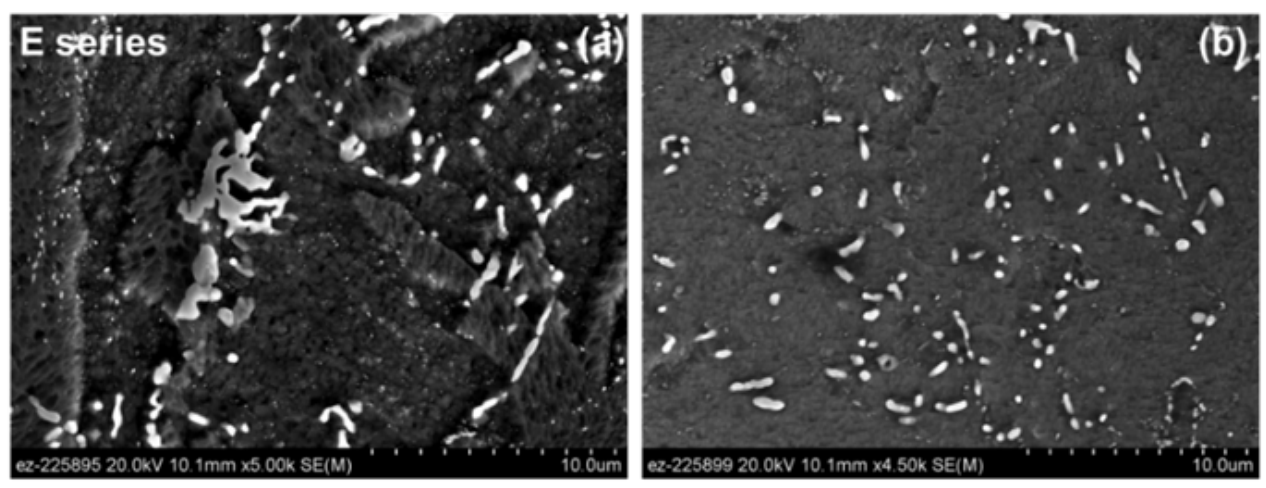

Figure 6. SEM secondary electron images of very coarse precipitates in reference $E$ series Eurofer97 steel.

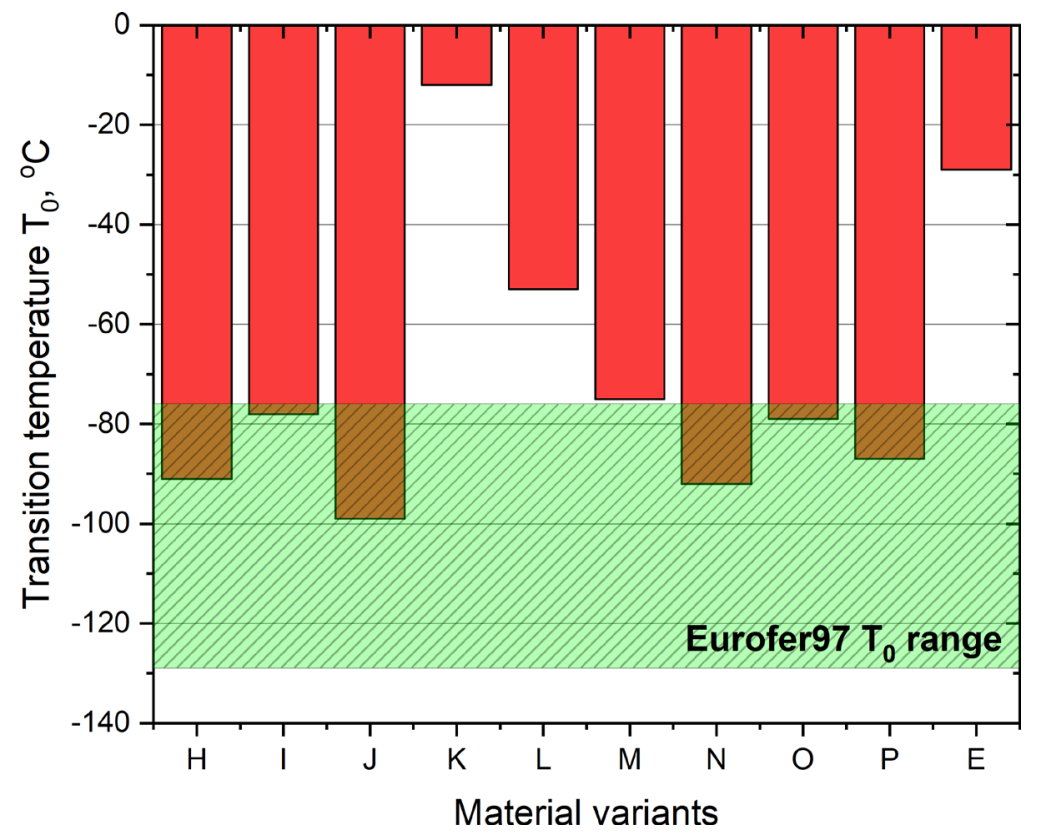

Figure 7. Transition temperature $T_{0}$ of ten Eurofer97 variants, compared to the $T_{0}$ range of standard Eurofer97. 


\subsection{DEVELOPMENT OF TRANSFORMATION ENHANCED ODS Fe-Cr ALLOYS}

\section{D.T.Hoelzer (hoelzerd@ornl.gov)}

\section{OBJECTIVE}

The objective of this task is to develop two transformation enhanced oxide dispersion strengthened (ODS) $\mathrm{Fe}-10 \mathrm{Cr}$ alloys for fusion reactor applications requiring high-temperature strength and toughness properties and microstructural stability during exposure to energetic neutrons and transmutated $\mathrm{He}$ concentrations.

\section{SUMMARY}

A large number of tensile specimens were fabricated from the two ODS Fe-10Cr alloys, designated M4 and M5, for inclusion in rabbit capsules that will be neutron irradiated in HFIR in the Fusion 2018 Irradiation campaign. The purpose of the irradiation experiments is to determine the neutron irradiation tolerance of the 2 ODS Fe-10Cr alloys and to determine if the $1 \% \mathrm{~W}$ addition to M4, versus no addition to M5, has any benefit to radiation tolerance.

\section{PROGRESS AND STATUS}

Over 30 SS-J3 tensile specimens were fabricated from the two ODS Fe-10Cr alloys (M4 and M5). The nominal composition of the two alloys are Fe-10Cr-1 W-0.3Ti-0.2V (M4) and Fe-10Cr-0.3Ti-0.2V (M5), both contain $0.3 \mathrm{Y}_{2} \mathrm{O}_{3}$ additions (weight \%). Chemical analysis of M4 and M5 was obtained from Dirats Laboratories and the results are shown in Table 1. The results confirmed that the $\mathrm{W}$ level in M5 was much lower than that in M4 and that the ball milling conditions lead to relatively low $\mathrm{C}$ and $\mathrm{N}$ levels.

Table 1. Composition of M4 and M5 determined by chemical analysis

\begin{tabular}{|c|c|c|c|c|c|c|c|c|c|}
\hline Alloy & $\mathrm{Fe}$ & $\mathrm{Cr}$ & $\mathrm{W}$ & $\mathrm{Ti}$ & $\mathrm{V}$ & & $\mathrm{Y}$ & $\mathrm{C}$ & $\mathrm{N}$ \\
\hline M4 & Bal. & 9.70 & 0.97 & 0.15 & 0.18 & & 0.23 & 0.031 & 0.018 \\
\hline M5 & Bal. & 9.57 & 0.08 & 0.18 & 0.17 & & 0.22 & 0.027 & 0.018 \\
\hline
\end{tabular}

The planned neutron irradiation conditions and number of SS-J3 specimens of M4 and M5 to be include in the rabbit capsule are shown in Table 2 . There are 3 SS-J3 specimens for each irradiation conditions except for the lower doses at $525^{\circ} \mathrm{C}$.

Table 2. Irradiation conditions and included SS-J3 specimens of M4 and M5

\begin{tabular}{|c|c|c|c|c|}
\hline \multirow{2}{*}{ Dose (dpa) } & \multicolumn{4}{|c|}{ Temperature } \\
\hline & $300^{\circ} \mathrm{C}$ & $385^{\circ} \mathrm{C}$ & $525^{\circ} \mathrm{C}$ & $650^{\circ} \mathrm{C}$ \\
\hline $5-7$ & $\begin{array}{l}3-\mathrm{M} 4 \\
3-\mathrm{M} 5\end{array}$ & $\begin{array}{l}3 \text { - M4 } \\
3 \text { - M5 }\end{array}$ & & $\begin{array}{l}3 \text { - M4 } \\
3 \text { - M5 }\end{array}$ \\
\hline 20 & $\begin{array}{l}3-\mathrm{M} 4 \\
3-\mathrm{M} 5\end{array}$ & $\begin{array}{l}3 \text { - M4 } \\
3 \text { - M5 }\end{array}$ & & $\begin{array}{l}3 \text { - M4 } \\
3 \text { - M5 }\end{array}$ \\
\hline 80 & $\begin{array}{l}3-\mathrm{M} 4 \\
3-\mathrm{M}\end{array}$ & $\begin{array}{l}3-\mathrm{M} 4 \\
3-\mathrm{M}\end{array}$ & $\begin{array}{l}3 \text { - M4 } \\
3 \text { - M5 }\end{array}$ & $\begin{array}{l}3-M 4 \\
3-M 5\end{array}$ \\
\hline
\end{tabular}




\section{FUTURE PLANS}

The creep properties of the two ODS Fe-10Cr alloys will assessed using SS-J3 specimens in strain rate jump tensile tests. In-situ high-temperature X-ray diffraction experiments will be conducted on the two ODS Fe-10Cr alloys to investigate the transformation kinetics and volume fractions between the bcc-Fe phase that is stable below $\sim 910^{\circ} \mathrm{C}$ and the fcc-Fe phase that is stable above this temperature. The results on microstructures and mechanical properties will be used to select one of the two ODS Fe-10Cr alloys for further development. 


\title{
2.4 Fe-Cr-AI ODS ALLOYS FOR FUSION REACTOR APPLICATIONS
}

\author{
Sebastien Dryepondt: dryepondtsn@ornl.gov,Caleb Massey and Phil Edmondson
}

\section{OBJECTIVE}

The goal of this project is to develop new oxide dispersion strengthened (ODS) FeCrAlZr $+\mathrm{Y}_{2} \mathrm{O}_{3}$ alloys with creep and irradiation resistance approaching the resistance of (ODS) FeCr alloys such as 14YWT but with enhanced $\mathrm{Pb}-\mathrm{Li}$ compatibility at $600-800^{\circ} \mathrm{C}$.

\section{SUMMARY}

SANS and APT measurements were conducted to characterize the evolution of (Y,Al) nano oxides during annealing/extrusion of ODS FeCrAl precipitates. These results show that precipitate nucleation and growth took place at temperature below $600^{\circ} \mathrm{C}$ and no precipitate coarsening was observed below $\sim 1000^{\circ} \mathrm{C}$.

\section{BACKGROUND}

Several ODS Fe-12Cr-5.5Al alloys were fabricated at ORNL to assess the effect of minor additions of $\mathrm{Ti}$, $\mathrm{Hf}$ and $\mathrm{Zr}$ on the tensile strength, creep resistance and $\mathrm{Pb}-17 \mathrm{Li}$ compatibility of these ODS FeCrAl alloys $[1,2]$. All these alloys showed good $\mathrm{Pb}-\mathrm{Li}$ compatibility due to the formation of $\mathrm{LiAlO}_{2}$ scales but the $\mathrm{Zr}$ containing alloys exhibited better creep resistance compared to the Hf and Ti containing alloys, which led to the selection of an ODS Fe-10Cr-6Al-0.3Zr+0.3 $\mathrm{Y}_{2} \mathrm{O}_{3}(106 \mathrm{ZY})$ alloys for further characterization and testing [1,3]. The $\mathrm{Cr}$ content was slightly reduced to avoid the formation of the brittle $\alpha$ ' phase under high-dose irradiation, and the Al content was only slightly increased to improve the alloy corrosion resistance without affecting the alloy fabricability. Several 106ZY alloys were then produced using various ball milling durations and extrusion temperatures. The tensile strength of the 106ZY alloys was found to increase with increasing the ball milling duration from 10 to $40 \mathrm{~h}$, or by decreasing the extrusion temperature from 1050 to $900^{\circ} \mathrm{C}$ [4]. The alloy ductility, on the other side, was reduced when the ball milling time was increased, or when the extrusion temperature was lowered. Alloy characterization revealed that the reduction in alloy strength was due to larger grains at higher extrusion temperatures, or bi-modal grain distributions for ball milling durations shorter than $40 \mathrm{~h} \mathrm{[4].} \mathrm{The} \mathrm{nano} \mathrm{precipitates} \mathrm{size} \mathrm{and}$ number density are also affected by the processing conditions [5], and recent work focused on key experiments to understand the formation and growth of these precipitates during the extrusion process.

\section{EXPERIMENTS}

Small batches of ball milled ODS 106ZY powder were encapsulated into evacuated quartz tubes and annealed for $15 \mathrm{~min}$ to $500 \mathrm{~h}$ in either a box furnace or a tube furnace at either 1000 or $1050^{\circ} \mathrm{C}$. The nano precipitates distribution was then characterized using small angle neutron scattering (SANS) and atom probe tomography (APT). The APT maps were also compared with similar APT maps generated for alloys fabricated by extrusion at 1050 or $1100^{\circ} \mathrm{C}$ of a similar powder. The composition of the 106ZY powder and the alloys produced at $1050^{\circ} \mathrm{C}(\mathrm{ZY} 105)$ and $1100^{\circ} \mathrm{C}(\mathrm{ZY} 11)$ are given in Table 3 . Details on the alloy fabrication procedure can be found elsewhere [6].

The APT specimens were prepared using the focused ion-beam (FIB) lift-out technique with a FEI Quanta 3D dual-beam at ORNL. Final tip sharpening was conducted on the FEI Quanta or a FEI Helios 600 FIB at the Max-Planck-Institut für Eisenforschung (MPIE) in Düsseldorf, Germany. APT was performed using either a Cameca model 4000X HR local electrode atom probe (LEAP) at ORNL or using a Cameca model 5000 XR LEAP at MPIE. A minimum of two tips per specimen were analyzed, with at 
Table 3. Chemical composition in at. \% of the 106ZY powder and the ZY105 and ZY11alloys measured by inductively coupled plasma combustion and inert gas fusion analysis

\begin{tabular}{lllllllll}
\hline Specimen & $\mathrm{Fe}$ & $\mathrm{Cr}$ & $\mathrm{Al}$ & $\mathrm{Zr}$ & $\mathrm{Y}$ & $\mathrm{O}$ & $\mathrm{C}$ & $\mathrm{N}$ \\
\hline 106ZY powder & 77.42 & 9.73 & 11.78 & 0.15 & 0.13 & 0.43 & 0.25 & 0.04 \\
ZY105 alloy & 77.80 & 9.58 & 11.33 & 0.15 & 0.12 & 0.61 & 0.01 & 0.25 \\
ZY11 alloy & 77.66 & 9.76 & 11.40 & 0.15 & 0.13 & 0.37 & 0.30 & 0.06 \\
\hline
\end{tabular}

least 10 million collected ions per specimen. Data reconstruction and analysis was carried out using Cameca's Integrated Visualization \& Analysis Software (IVAS) package.

In-situ SANS experiments were conducted at the HFIR. A vacuum furnace was used to heat ODS FeCrAl powder packed in Mo foil from room temperature to $1000^{\circ} \mathrm{C}$ with a heating rate of $20^{\circ} \mathrm{C} / \mathrm{min}$. Data was collected every minute at either 1.5 or $5 \mathrm{~m}$ detector distances to cover a scattering vector range of $0.01<$ $\mathrm{Q}<0.6 \AA$. Details on the APT and SANS measurements can be found in [6].

\section{RESULTS}

Neutron scattering intensities of the ODS 106ZY powder measured between 200 and $900^{\circ} \mathrm{C}$ are shown in Figure 8. Data at temperature lower than $200^{\circ} \mathrm{C}$ is not presented because no scattering was measured. A clear increase of the scattering intensity for vector range $>0.03 \AA^{-1}$ was observed from $200^{\circ} \mathrm{C}$ to $600^{\circ} \mathrm{C}$. At higher temperature, all the scattering curves were similar as represented in Figure 8 by the $900^{\circ} \mathrm{C}$ curve. These results indicate that nucleation and growth of the nano precipitates took place during annealing at $200-600^{\circ} \mathrm{C}$ but then the precipitate size and number density remained constant up to $1000^{\circ} \mathrm{C}$.

Figure 9 highlights the evolution of the (Y,Al)-rich oxide precipitates after annealing at $1000-1100^{\circ} \mathrm{C}$ for $15 \mathrm{~min}$ to $500 \mathrm{~h}$. The average size and number density of the nano precipitates calculated from these APT reconstruction maps are shown in Table 4 . These results clearly demonstrate that a very fine dispersion of nano precipitates can be achieved as long as the annealing or extrusion temperature is kept below $1000^{\circ} \mathrm{C}$. At higher temperature, significant coarsening took place leading to an increase of the average particle size from $\sim 1.6 \mathrm{~nm}$ after $1 \mathrm{~h}$ at $1000^{\circ} \mathrm{C}$ to $4 \mathrm{~nm}$ after $500 \mathrm{~h}$ at $1050^{\circ} \mathrm{C}$. This size increase was associated with a decrease of the particle density number by more than one order of magnitude.

These results suggest that a two-step extrusion process might be recommended to fabricate an alloy with high sink strength and acceptable ductility. Annealing at temperature below $800^{\circ} \mathrm{C}$ will ensure the formation of a fine dispersion of nano precipitates while conducting powder extrusion at $\sim 900-1000^{\circ} \mathrm{C}$ will improve the alloy ductility by increasing the alloy grain size. 


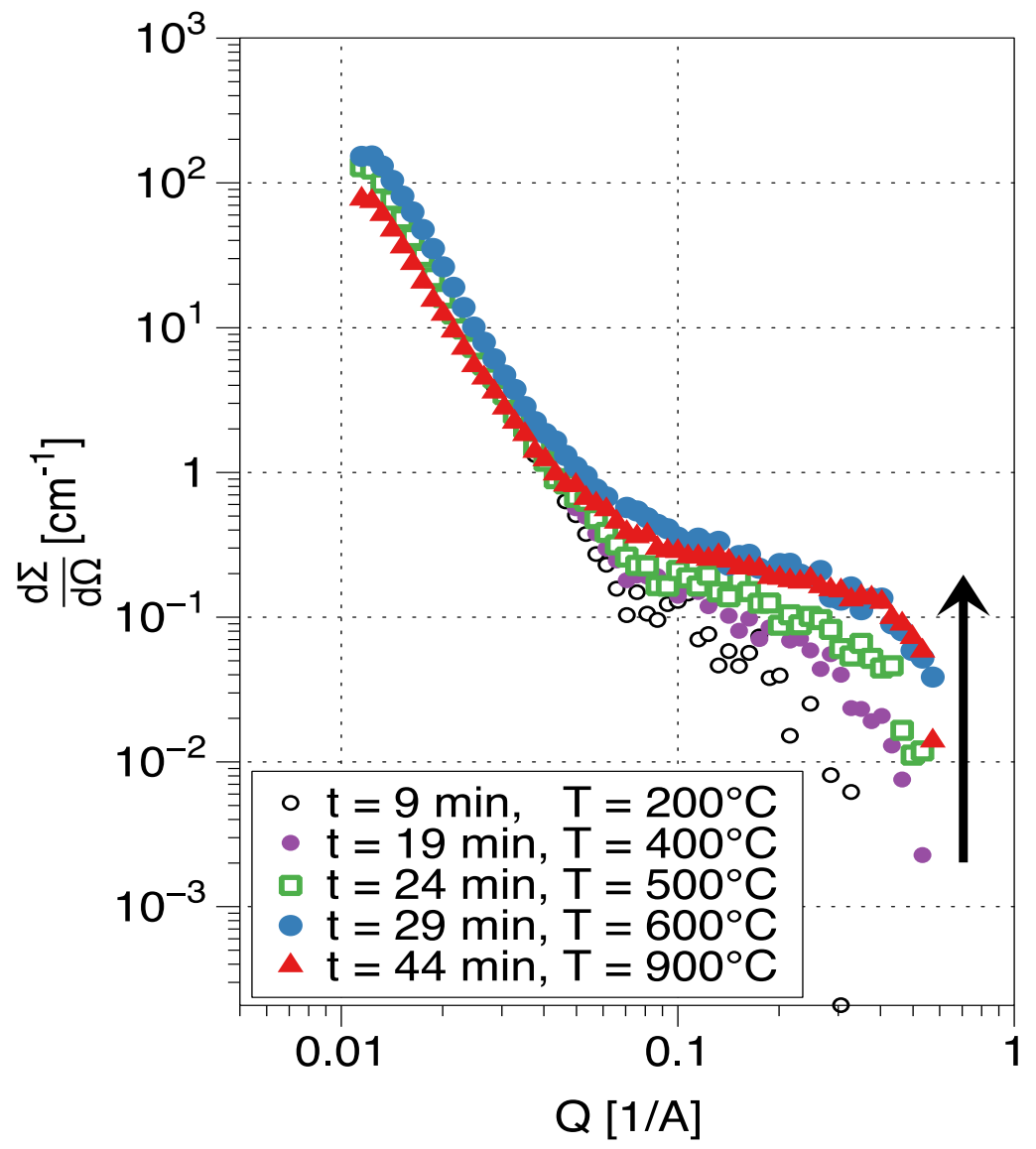

Figure 8. Neutron scattering intensities measured between 200 and $900^{\circ} \mathrm{C}$ during the in-situ SANS experiments.

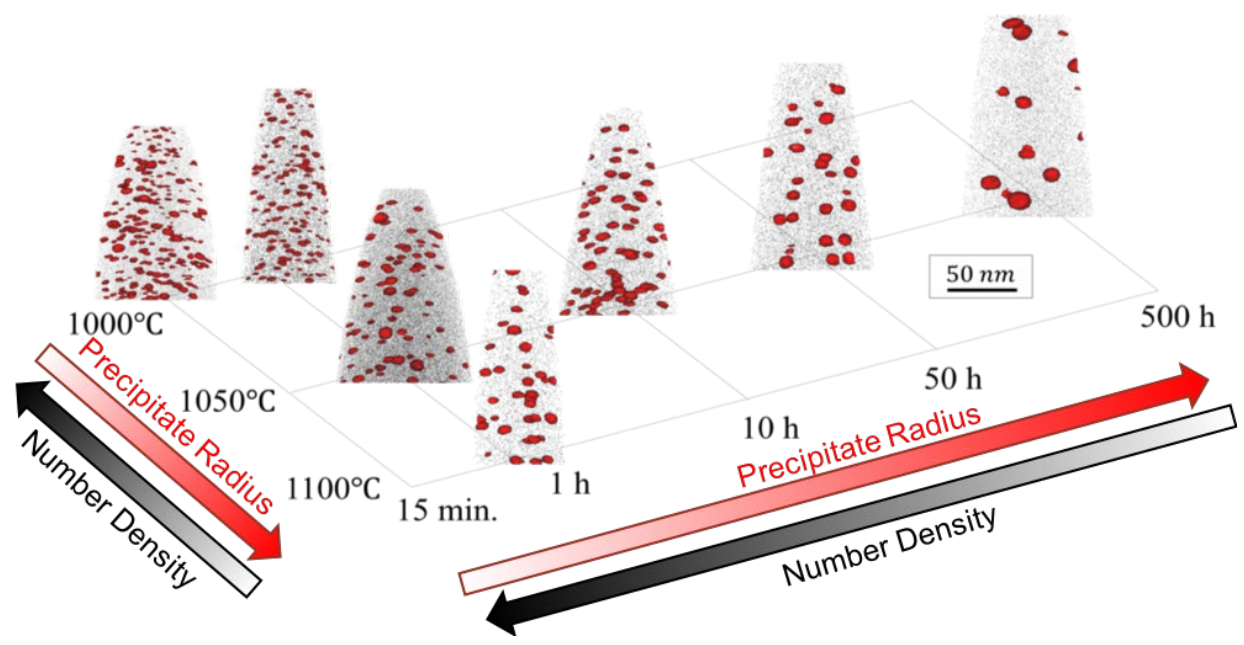

Figure 9. APT maps illustrating the evolution of the nano precipitate size during annealing/extrusion at $1000-1100^{\circ} \mathrm{C}$ for durations ranging from $15 \mathrm{~min}$ to $500 \mathrm{~h}$. 
Table 4. Aberration Corrected APT Results: $R_{p}$ is the mean particle diameter and $\mathbf{N}_{p}$ is the particle density number. Errors are reported as one standard deviation from the mean.

\begin{tabular}{llll}
\hline Temperature & Duration & $\mathrm{R}_{\mathrm{p}}[\mathrm{nm}]$ & $\mathrm{N}_{\mathrm{p}} \times 10^{23}\left[\mathrm{~m}^{-3}\right]$ \\
\hline $1000^{\circ} \mathrm{C}$ & $15 \mathrm{~min}$ & $1.56 \pm 0.64$ & $4.77 \pm 1.47$ \\
$1000^{\circ} \mathrm{C}$ & $1 \mathrm{~h}$ & $1.58 \pm 0.61$ & $4.19 \pm 1.21$ \\
$1050^{\circ} \mathrm{C}$ & $1 \mathrm{~h}$ & $2.08 \pm 0.75$ & $1.11 \pm 0.18$ \\
$1050^{\circ} \mathrm{C}$ & $10 \mathrm{~h}$ & $2.16 \pm 0.65$ & $1.79 \pm 0.01$ \\
$1050^{\circ} \mathrm{C}$ & $50 \mathrm{~h}$ & $2.82 \pm 1.16$ & $0.58 \pm 0.01$ \\
$1050^{\circ} \mathrm{C}$ & $500 \mathrm{~h}$ & $4.07 \pm 1.21$ & $0.12 \pm 0.03$ \\
$1100^{\circ} \mathrm{C}$ & $1 \mathrm{~h}$ & $2.58 \pm 0.85$ & $0.79 \pm 0.05$ \\
\hline
\end{tabular}

\section{FUTURE WORK}

Development and characterization will continue on this oxide dispersion strengthened $\mathrm{FeCrAlZr}+\mathrm{Y}_{2} \mathrm{O}_{3}$ alloy. The results of this work may be used to help design new fabrication strategies to enhance ODS FeCrAl properties.

\section{REFERENCES}

[1.] B.A. Pint, S. Dryepondt, K.A. Unocic, D.T. Hoelzer, Development of ODS FeCrAl for Compatibility in Fusion and Fission Energy Applications, JOM 66 (2014) 2458-2466.

[2.] K. A. Unocic, B. A. Pint, and D. T. Hoelzer, Journal of Materials Science, 51 (2016) 9190-9206.

[3.] K. A. Unocic, and D. T. Hoelzer, Journal of Nuclear Materials, 479 (2016) 357-364.

[4.] C.P. Massey, S.N. Dryepondt, P.D. Edmondson, K.A. Terrani and S.J. Zinkle, Journal of Nuclear Materials, 15 (2018) 227-238.

[5.] P. Dou, A. Kimura, T. Okuda, M. Inoue, S. Ukai, S. Ohnuki, T. Fujisawa, F. Abe, Journal of Nuclear Materials, 417 (2011) 166-170.

[6.] C.P. Massey, S. N. Dryepondt, P.D. Edmondson, M.G. Frith, K C. Littrell, A. Kini, B. Gault, K.A. Terrani, and S.J. Zinkle, submitted to Acta Materialia. 


\subsection{BAINITIC STEEL DEVELOPMENT FOR FUSION APPLICATIONS}

\section{Y.Yamamoto(yamamotoy@ornl.gov)}

\section{OBJECTIVE}

This work aims to develop new bainitic steels, based on $3 \mathrm{Cr}-3 \mathrm{WV}(\mathrm{Ta})$ steels originally developed at ORNL [1]. The target applications are high temperature structural components in fusion reactors such as the vacuum vessel, structural ring which supports the blanket modules, and magnet shields. The goal is to achieve improved mechanical properties of both base metal and weldments superior to those of existing commercial bainitic steels or ferritic-martensitic (F-M) steels, at or above the $400-500^{\circ} \mathrm{C}$ range, together with no requirement for post-weld heat treatment (PWHT).

\section{SUMMARY}

Evaluation of creep-rupture properties of the modified 3Cr-3WVTa steel (high $\mathrm{Mn}+\mathrm{Si}$ and low C) was completed. The cross-weld creep performance of the modified steel at $550^{\circ} \mathrm{C}$ was improved slightly compared to the original steel. However, the room-temperature toughness in the heat affected zone was significantly lower, which was attributed to the temper-embrittlement of the modified steel. Three new lab-scale heats based on 3Cr-3WV steel (Ta-free) with modified alloy compositions were prepared. Preliminary Charpy impact test results indicated that the new heats successfully eliminated temperembrittlement. Preparation of the weld joint for the cross-weld property evaluation was completed.

\section{PROGRESS AND STATUS}

A series of creep-rupture tests at $550^{\circ} \mathrm{C}$ of the original $3 \mathrm{Cr}-3 \mathrm{WVTa}$ steel and previously proposed modified steel (MSLC2, with high $\mathrm{Mn}+\mathrm{Si}$ and low $\mathrm{C}$ additions) was completed. As shown in Figure 10, the creep-rupture performances of the base metals were almost identical. The cross-weld creep properties of MSLC2 in the as-welded condition were slightly better than that of the original 3Cr-3WVTa steel, indicating that the alloy design strategy to improve creep performance had worked. However, temperembrittlement was also observed in MSLC2 Charpy impact tests. This caused significantly lower absorbed energy in the heat affected zone of MSLC2 in the as-welded condition, which could be an issue for using MSLC2 as a PWHT-free material.

Further alloy modification was pursued based on the 3Cr-3WV steel (Ta-free) composition combined with high $\mathrm{Mn}$, low $\mathrm{C}$, and additional $\mathrm{B}$. This modification is expected to provide improvement in creep performance and elimination of temper embrittlement. Three lab-scale heats of new steels were prepared at ORNL. Micro-Vickers hardness tests of normalized and tempered materials were conducted as the first screening, which indicated no temper-embrittlement in the new heats, as summarized in Figure 11. This was potentially due to the lower Si addition compared to MSLC2 (0.16 wt.\% vs. 0.5 wt.\%). The gas tungsten arc weld of the new heats with a $3 \mathrm{Cr}-3 \mathrm{WVTa}$ steel weld filler metal has been completed (shown in Figure 11) for further evaluation of the cross-weld properties. The cross-sectional microstructure characterization is currently in progress.

\section{FUTURE PLANS}

The cross-weld mechanical properties (creep and toughness) of the three new heats are to be evaluated and compared with the original $3 \mathrm{Cr}-3 \mathrm{WV}$ steel. The effect of alloying additions ( $\mathrm{Mn}, \mathrm{C}$, and $\mathrm{B}$ ) on microstructure, cross-weld creep properties, and the room temperature toughness will be determined to understand the mechanism of the property improvement and used as the basis for further optimization of the alloy composition to achieve the PWHT-free alloy design. 


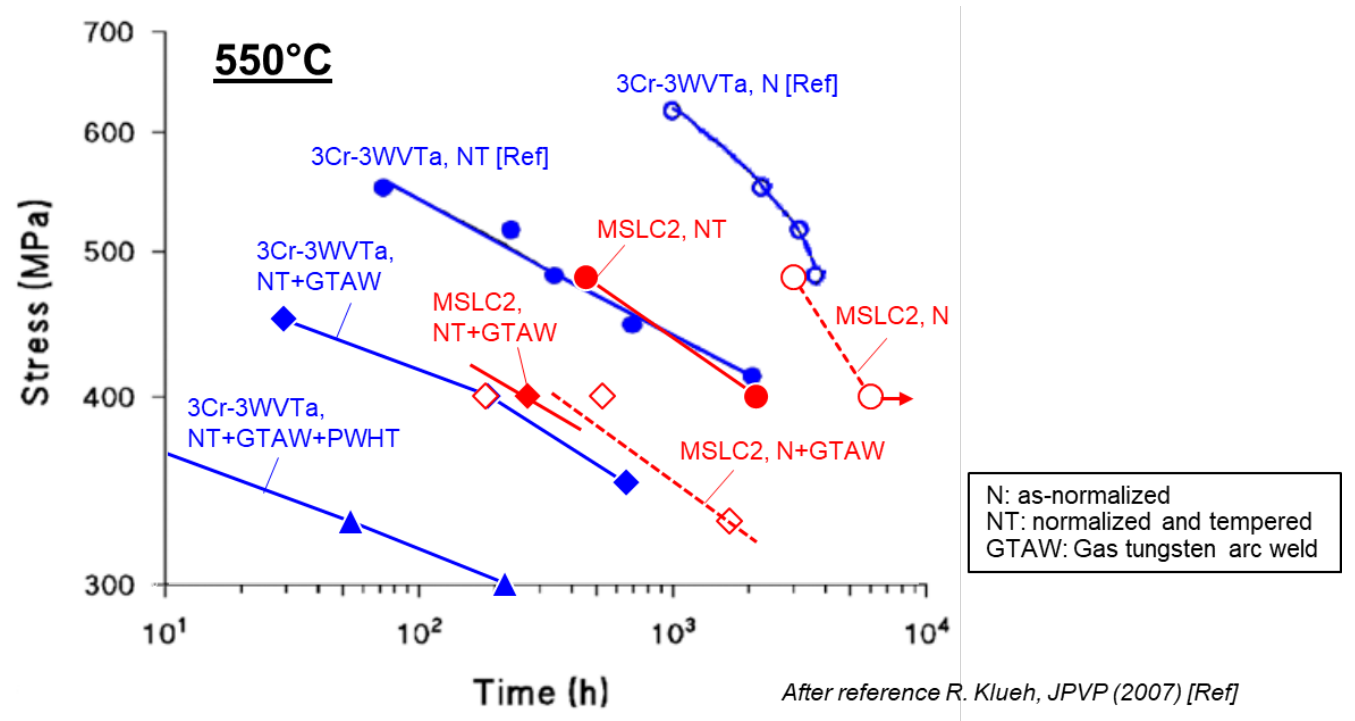

Figure 10. Creep-rupture test results at $550^{\circ} \mathrm{C}$ of the original $3 \mathrm{Cr}-3 \mathrm{WVTa}$ steel (black symbols: base metal [1]; blue symbols: cross-weld) and the MSLC2 (open red symbols: as-normalized, base metal and cross-weld; filled red symbols: normalized-and-tempered, base metal and cross-weld).

(a)

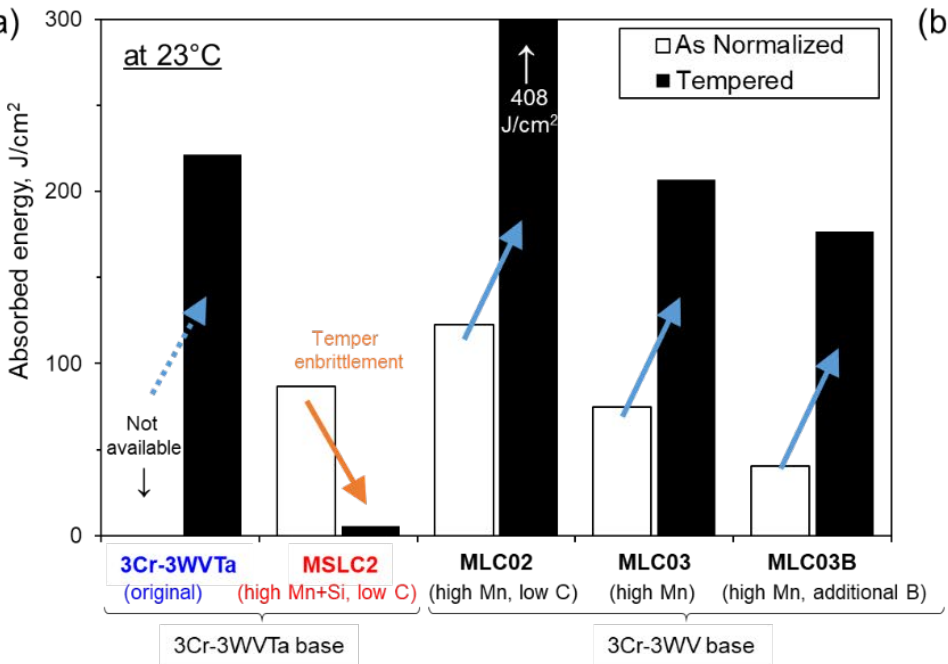

(b)

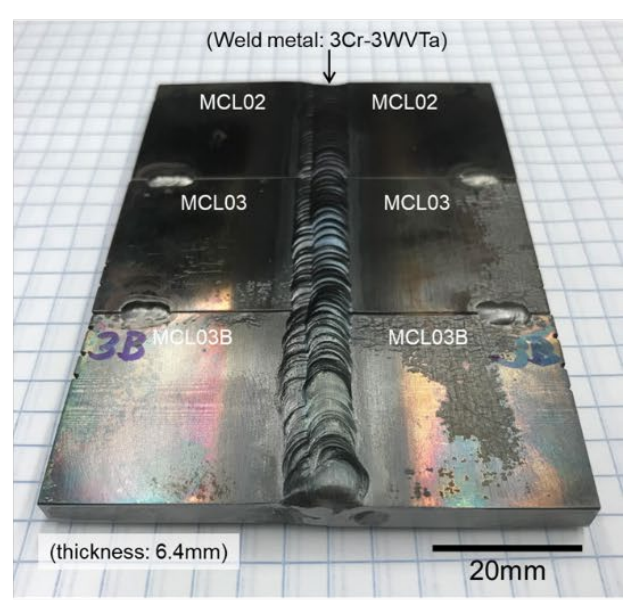

Figure 11. (a) Charpy impact test results of as-normalized and tempered materials (3Cr-3WVTa base and newly proposed $3 \mathrm{Cr}-3 \mathrm{WV}$ base steels), and (b) as-GTAW $3 \mathrm{Cr}-3 \mathrm{WV}$ base steel plates with original 3Cr-3WVTa steel weld filler metal.

\section{REFERENCES}

[1] R.L. Klueh, N.D. Evans, P.J. Maziasz, V.K. Sikka, Creep-rupture behavior of 3Cr-3W-V bainitic steels, International Journal of Pressure Vessels and Piping 84 (2007) 29-36. 


\title{
2.6 MICROSTRUCTURAL CHARACTERIZATION OF RAFM STEELS IN HFIR JP28 AND JP29 IRRADIATION CAPSULES
}

\author{
K.G. Field (fieldkg@ornl.gov), K. Wang, D. Zhang, K. Smith, J.W. Geringer, D.T. Hoelzer
}

\section{OBJECTIVE}

Reduced activation ferritic-martensitic (RAFM) steels can undergo drastic changes in the microstructure and local microchemistry due to significant damage from energetic neutron irradiation. These microstructural evolutions can result in changes in mechanical performance including in the strength and ductility of an alloy. Previous work has focused on the mechanical performance of neutron irradiated steels within the JP28 and JP29 HFIR irradiation experiments. The objective of this work was to begin investigating the microstructural and microchemical variations in these specimens using advanced electron microscopy techniques to develop structure-property correlations for RAFM steels within the high-dose (>50 dpa) regime.

\section{SUMMARY}

Post-irradiation examination (PIE) via advanced electron microscopy has been completed on a RAFM steel irradiated near $300^{\circ} \mathrm{C}$ to a dose of approximately 72 dpa. Advanced electron microscopy was enabled using a novel material sampling device in a shielded hot-cell facility. Current results indicate that the RAFM steel undergoes microstructural changes at high dose include small $(<5-10 \mathrm{~nm})$ cavity formation, radiation-induced segregation, and radiation-induced/enhanced precipitation. This framework established for PIE is now being extended to other alloy systems.

\section{PROGRESS AND STATUS}

The high radioactivity of the RAFM steels within the JP28 and JP29 HFIR irradiation capsules necessitated the design and manufacturing of a fixture to cut ultra-miniature specimens from the bulk samples. Significantly reducing the specimen volume reduces the radiological threat allowing access to state-of-the-art electron microscopy equipment. Figure 12 shows a schematic of the fixture used. The fixture design incorporates a quick connect system for attachment to a slow speed saw and a sample alignment and closure mechanism that allows a corner of a SS-J type specimen to be cut without losing the daughter or parent sample under remote shielded handling operations. The fixture proved to be effective in producing reduced radiological threat specimens and streamlined the process compared to historical approaches. Both RAFM steels and oxide dispersion strengthened steels were cut resulting in seven daughter samples being prepared and shipped to the LAMDA facility for characterization. 

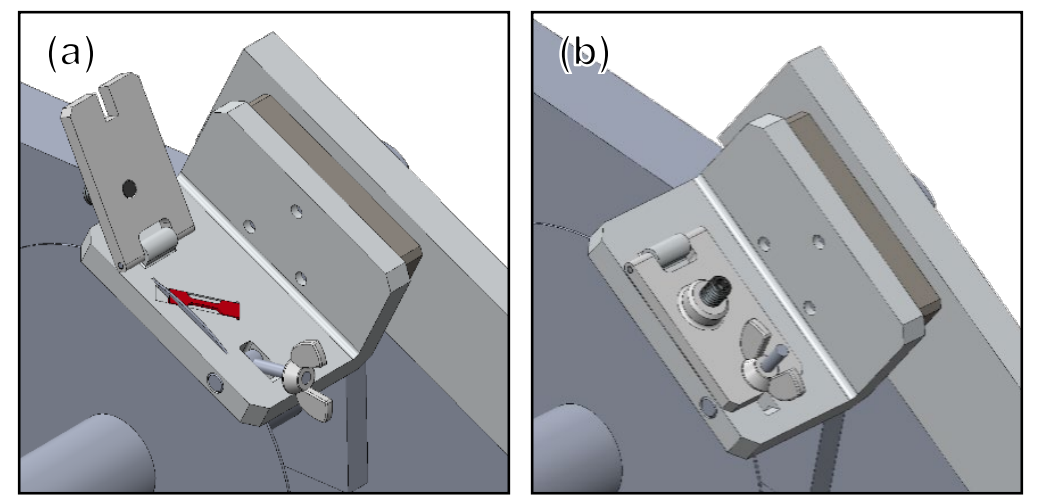

Figure 12. Schematic of a cutting fixture for highly radioactive SS-J type specimens (red in image): (a) mounted in the open position and (b) mounted in the closed position both shown above the cutoff blade.

The RAFM steels were selected as the highest priority specimens for characterization, with the Eurofer97 specimen irradiated at $300^{\circ} \mathrm{C}$ up to 72 dpa taking precedence over other specimens. Characterization of the Eurofer97 specimen aligns the tasks with on-going collaborations across the research program. The Eurofer97 daughter specimen was prepared for transmission electron microscopy (TEM) investigations using a FEI Quanta 3D DualBeam ${ }^{\mathrm{TM}}$ FIB-SEM. FIB specimen preparation was completed with a final low-energy $(>10 \mathrm{kV})$ ion polish to reduce FIB-induced artifacts within the specimens. TEM observation used JEOL JEM2100F TEM or FEI Talos F200X instruments, both operating at $200 \mathrm{keV}$. Diffractioncontrast TEM images and STEM-EDS elemental mapping was performed in FEI Talos F200X TEM equipped with four X-ray detectors. High resolution TEM imaging and energy filtered TEM for thickness mapping were conducted in JEOL JEM2100F TEM.

Electron microscopy characterization revealed segregation behavior, phase instability, and small cavity formation in the Eurofer97 specimen. For example, Figure 13 shows the formation of $\mathrm{Cr}$-rich clusters in the matrix. The average size and volume are estimated at $3.1 \pm 0.8 \mathrm{~nm}$ and $1.7 \times 10^{23} \mathrm{~m}^{-3}$, respectively. High-Cr alloys are known to exhibit a miscibility gap at the irradiation temperature investigated leading to the precipitation of the Cr-rich $\alpha^{\prime}$ phase. The results in Figure 13 suggest the possibility of Cr-rich $\alpha^{\prime}$ precipitation in Eurofer97 even with the relatively low Cr-content of the alloy at $8.87 \mathrm{wt} . \%$. Additional STEM-EDS studies on lath boundaries in the specimen also show Cr-clustering at or near lath boundaries which is accompanied by depletion of Fe and V and the enrichment of Ni. (This heat of Eurofer97 has a small amount of Ni in the alloy.) Diffraction-based TEM imaging showed the formation of tiny $(<5 \mathrm{~nm})$ cavities populating both the matrix and at higher concentrations on the lath boundaries. The relative size and number density observed for the cavities is in agreement with irradiations conducted below $400^{\circ} \mathrm{C}$ in RAFM steels in other investigations. 


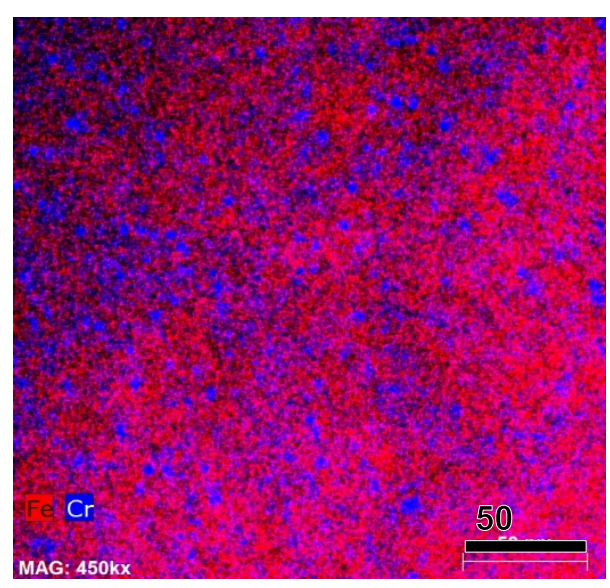

Figure 13. STEM-EDS map showing Cr-rich clusters (blue images) in the Eurofer97 matrix irradiated near $300^{\circ} \mathrm{C}$. A 3 by 3 pixel smoothing filter was used.

\section{FUTURE PLANS}

Future work will complete characterization of the RAFM steels and then expanded to include oxide dispersion strengthened steels. The results will be complied and used to develop structure-property relationships on the alloy variants using various available models. 


\subsection{IRRADIATION CREEP OF F82H PRESSURIZED TUBES}

\section{A.A. Campbell (campbellaa@ornl.gov), Y. Katoh, J.W. Geringer, M. Ando (QST), D. Hamaguchi (QST)}

\section{OBJECTIVE}

The objective of this task the measurement of neutron irradiation-induced creep of reduced activation ferritic martensitic (RAFM) steel alloy $\mathrm{F} 82 \mathrm{H}$ at $300^{\circ} \mathrm{C}$. The stress necessary to drive irradiation creep was provided using thin-walled pressurized tubes. The internal inert gas pressure induces a hoop stress in the sealed tubes. The hoop stress drives irradiation-induced creep in the tube, which is measured as changes in the tube diameter.

\section{SUMMARY}

Four creep capsules designed for a target irradiation temperature of $300^{\circ} \mathrm{C}$ and hoop stresses of 0 to 380 MPa, were irradiated in the HFIR during cycles 475 and 476. The capsules were shipped from HFIR to the Irradiated Materials Examination and Testing (IMET) hot cells facility for disassembly and evaluation.

\section{PROGRESS AND STATUS}

The neutron irradiation creep of reduced activation ferritic martensitic (RAFM) steels, such as F82H, will be important for the design of fusion reactor blanket systems. This work is redeveloping the capability at ORNL to perform pressurized creep tube (PCT) experiments in HFIR and the capability to measure the creep deformation.

The four) capsules completed the two-cycle irradiation in HFIR in December 2017, to a nominal 3.7 dpa. The capsules were shipped from the HFIR to the Irradiated Materials Examination and Testing (IMET) hot cells facility. The capsule disassembly and post-irradiation exanimation (PIE) work will all be performed in the hot cells in the IMET facility.

\section{FUTURE PLANS}

The preliminary PIE plan has been developed. This includes visual inspection of tubes after capsule opening, installation of a laser profilometer, diameter measurements of the tubes with the laser profilometer, depressurization of the tubes, remeasurement of diameter, and the recovery and analysis of thermometry. Microstructural characterization and other evaluation may follow if warranted by results of the creep measurements. 


\title{
3. CERAMIC AND COMPOSITE MATERIALS
}

\subsection{HIGH DOSE NEUTRON IRRADIATION EFFECTS ON MECHANICAL PROPERTIES OF SiC COMPOSITES}

\author{
T. Koyanagi (koyangit@ornl.gov), T. Nozawa (QST), and Y. Katoh
}

\section{OBJECTIVE}

The objective of this task is to obtain a better understanding of the effects of high neutron fluence irradiation on the mechanical properties and microstructures of silicon carbide $(\mathrm{SiC})$ and $\mathrm{SiC}$ fiber reinforced $\mathrm{SiC}$ matrix $(\mathrm{SiC} / \mathrm{SiC}$ ) composites to be used in fusion structural applications.

\section{SUMMARY}

Post-irradiation examination of $\mathrm{SiC} / \mathrm{SiC}$ composites with different fiber/matrix interface systems irradiated to $\sim 44 \mathrm{dpa}$ has been conducted. Electron microscopy analysis found that Tyranno SA3 $\mathrm{SiC}$ fiber is more suitable than Hi Nicalon Type $\mathrm{S} \mathrm{SiC}$ fiber in terms of dimensional stability under irradiation.

\section{PROGRESS AND STATUS}

For development of $\mathrm{SiC}$ materials for next generation nuclear structural applications, degradation of material properties due to intense neutron irradiation at relatively low irradiation temperatures is currently recognized as a critical feasibility issue. In this study, the neutron irradiation effects on mechanical properties to high doses (11-44 dpa) at intermediate irradiation temperatures $\left(\sim 600^{\circ} \mathrm{C}\right)$ were evaluated for Hi-Nicalon Type S (HNS) or Tyranno SA3 (SA3) fiber reinforced chemical-vapor-infiltration (CVI) $\mathrm{SiC}$ matrix composites. The influence of various fiber/matrix $(\mathrm{F} / \mathrm{M})$ interfaces such as $50-120 \mathrm{~nm}$ thick pyrolytic carbon (PyC) monolayer interphase or 70-130 nm thick PyC with subsequent PyC ( 20 $\mathrm{nm}) / \mathrm{SiC}(\sim 100 \mathrm{~nm})$ multilayer were evaluated and compared with the previous results of the thin-layered PyC $(\sim 20 \mathrm{~nm}) / \mathrm{SiC}(\sim 100 \mathrm{~nm})$ multilayer interphase. Four-point flexural tests were conducted to evaluate post-irradiation strength and SEM was used to investigate the microstructure. Regardless of the fiber type, composites with monolayer interphase showed considerable reduction of flexural properties for irradiation to $11-12 \mathrm{dpa}$ at $450-500{ }^{\circ} \mathrm{C}$. Further irradiation to $44 \mathrm{dpa}$ at $590-640{ }^{\circ} \mathrm{C}$ enhanced the degradation (Figure 14) compared to the previously studied multilayer composites with PyC thickness of $\sim 20 \mathrm{~nm}$. The multilayer composites have shown comparably good strength retention for irradiation to $\sim 40$ dpa, with moderate mechanical property degradation beginning at 70-100 dpa. It was found that irradiation-induced debonding of the $\mathrm{F} / \mathrm{M}$ interface was the major cause of deterioration of various composites. Another important finding was the better dimensional stability of the SA3 fiber compared with the HNS fiber based on SEM observation (Figure 15), indicating that the SA3 fiber is more suitable for composite reinforcement, although further improvement of radiation resistance of the composite interface is essential.

A paper on the results of this study was submitted for journal publication.

\section{FUTURE PLANS}

Understanding fiber/matrix debonding mechanism is essential to improve radiation resistance of $\mathrm{SiC}$ composites. Further microstructural evaluations will be conducted to identify the debonding mechanism, with the results used to optimize the composite interfaces. 

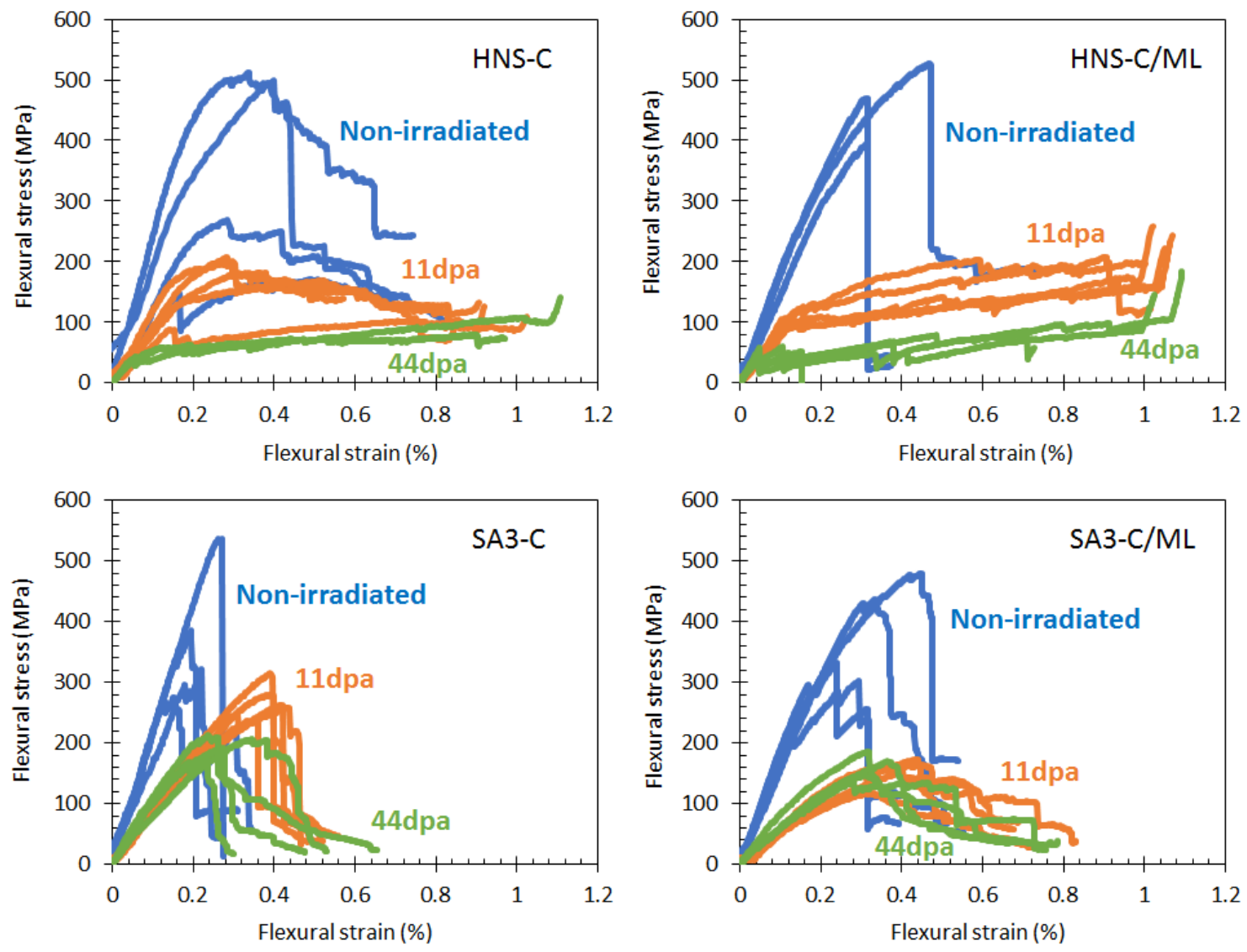

Figure 14. Typical flexural behavior of non-irradiated and neutron irradiated $\left(11 \mathrm{dpa}\right.$ at $500{ }^{\circ} \mathrm{C}$ and 44 dpa at $590-640{ }^{\circ} \mathrm{C}$ ) $\mathrm{SiC}$ composites with various fiber matrix interfaces. HNS fiber reinforced CVI-SiC matrix composites with $\mathrm{PyC}$ monolayer and $\mathrm{PyC} / \mathrm{SiC}$ multilayer are referred to as HNS-C and HNS-C/ML, respectively. In a similar manner, SA3 fiber reinforced CVI-SiC matrix composites with monolayer and multilayer were denoted as SA3-C and SA3-C/ML, respectively. 

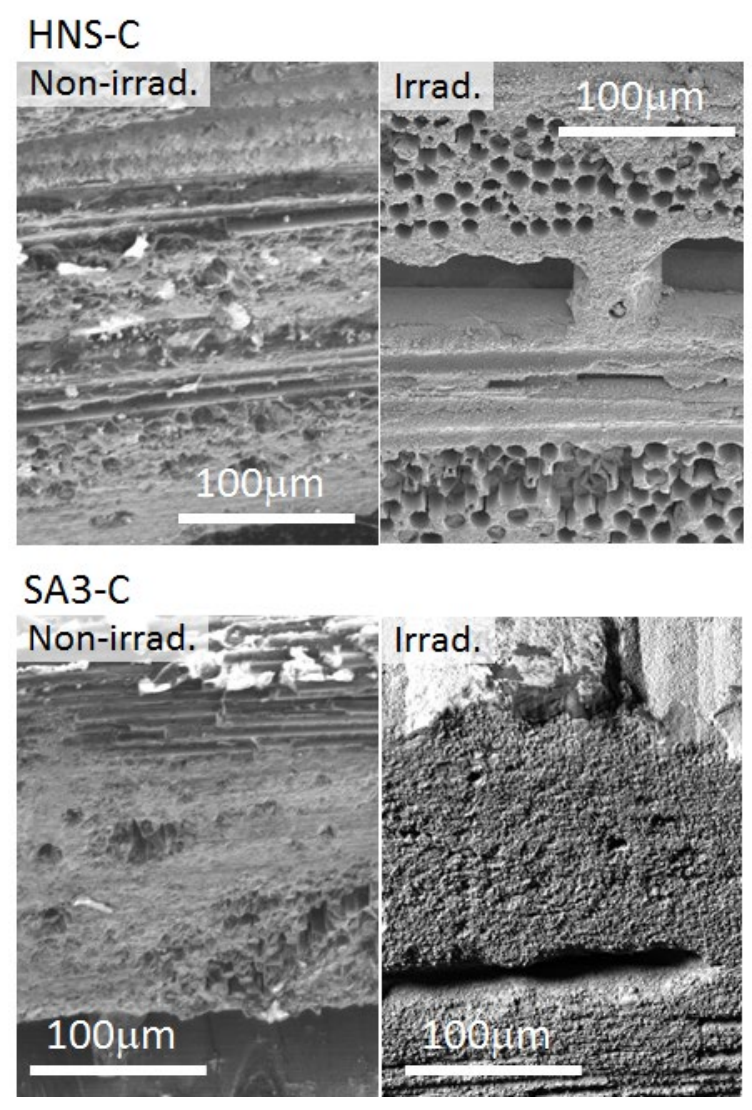

Figure 15. Typical specimen surface images of $\mathrm{SiC}$ composites before and after neutron irradiation at 590-640 ${ }^{\circ} \mathrm{C}$ to 44 dpa. HNS-C and SA3-C indicate single layer PyC interfaces with HNS and SA3 $\mathrm{SiC}$ fiber reinforcement, respectively. The images show significant differential swelling between HNS fiber and matrix, but limited differential swelling between SA3 fiber and matrix. 


\title{
3.2 ADVANCED CHARACTERIZATION OF IRRADIATION DEFECTS IN SILICON CARBIDE: RAMAN SPECTROSCOPY
}

\author{
T.Koyanagi (koyangit@,ornl.gov), Y. Katoh, and M. Lance
}

\section{OBJECTIVE}

This project is developing advanced techniques for characterizing defects in irradiated $\mathrm{SiC}$. One of these, Raman spectroscopy, will be useful to nondestructively assess irradiated $\mathrm{SiC}$ materials.

\section{SUMMARY}

We found empirical correlations among Raman phonon line positions, swelling, and irradiation temperature for high-purity $\beta-\mathrm{SiC}$ ceramics exposed to reactor neutron irradiation to $0.01-11.8 \mathrm{dpa}$ at $235-750^{\circ} \mathrm{C}$. In addition, the thermal conductivity of the irradiated $\mathrm{SiC}$ was indirectly correlated to the phonon peak positions, based on the known correlation between swelling and thermal conductivity. These findings are useful for nondestructively probing and assessing neutron irradiation effects in $\mathrm{SiC}$ for nuclear fusion applications.

This work has been published in the Journal of Raman Spectroscopy. A figure from this article has been selected as a cover of the Journal, Figure 16, and is available online.

\section{PROGRESS AND STATUS}

The effects of neutron irradiation on microstructural evolution and the resultant changes in physical and mechanical properties are of critical importance for the development of $\mathrm{SiC}$ materials for nuclear fusion applications. This study neutron-irradiated $\beta$-SiC under a wide range of conditions at temperatures between 235 and $750^{\circ} \mathrm{C}$ and neutron doses of $0.01-11.8$ displacements per atom, then evaluated the effects on the $\mathrm{SiC}$ structure using Raman spectroscopy. The SiC optical phonon lines were shifted to lower wavenumbers by irradiation. Correlations were found among the wavenumber of the longitudinal optical phonon line, irradiation-induced swelling, and irradiation temperature (Figure 16). The peak shift also correlated indirectly with decreasing thermal conductivity of irradiated SiC. The irradiation-induced peak shift is explained by combinations of lattice strain, reduction of the elastic modulus, and other factors including decreasing coherent domain size. These findings bridge irradiation-induced microstructural changes and property changes and illustrate how Raman spectroscopy is a useful tool for nondestructively assessing irradiated $\mathrm{SiC}$ materials for nuclear applications.

\section{FUTURE PLANS}

Further advancement of evaluation of $\mathrm{SiC}$ using Raman spectroscopy will be explored; chemical disordering due to irradiation will be evaluated. In addition, high-energy x-ray diffraction will be utilized to evaluate atomic structure of neutron-irradiated $\mathrm{SiC}$. 


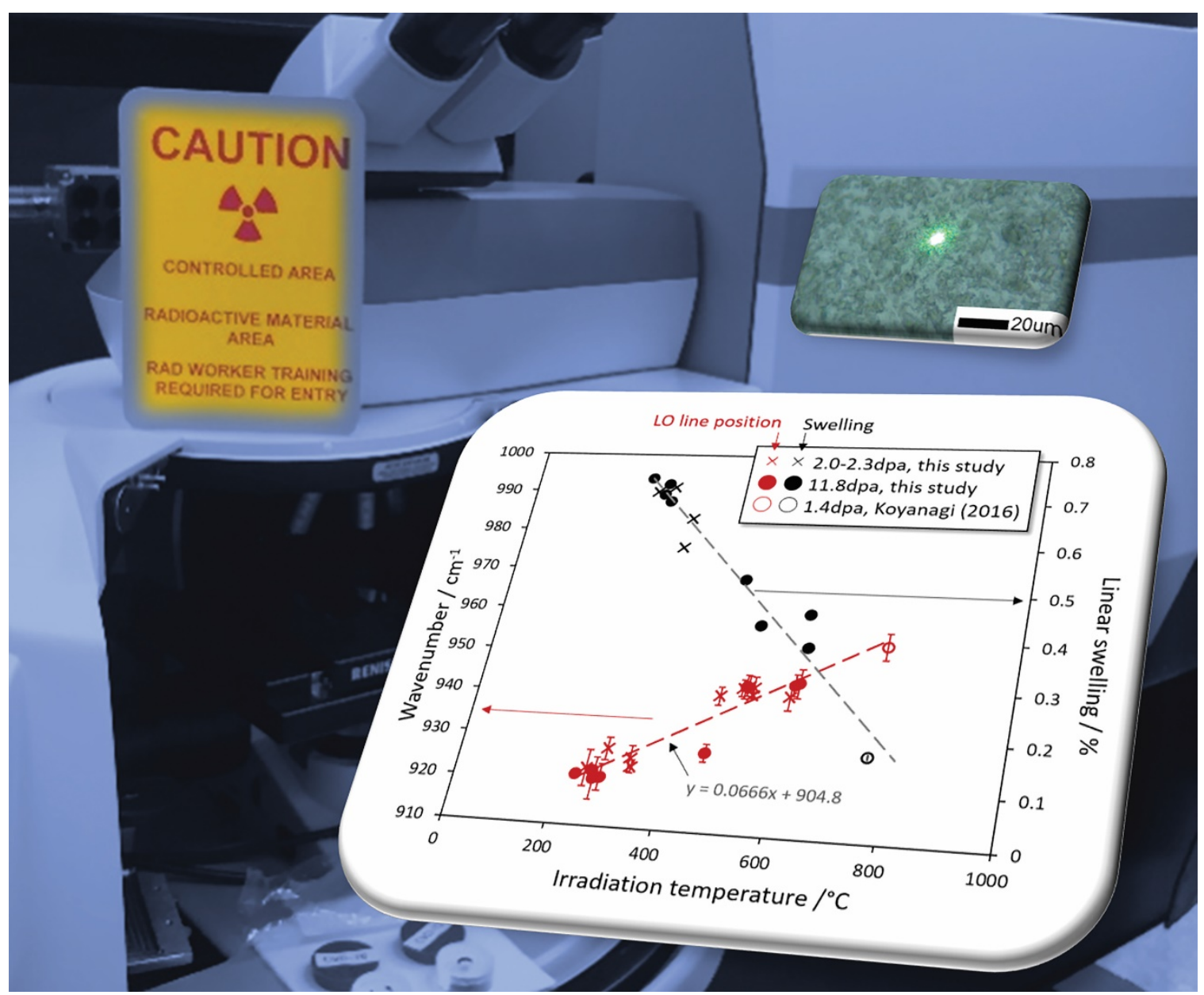

Figure 16. Irradiation temperature dependence of longitudinal optical peak position and swelling of B-SiC neutron irradiated to 1.4-11.8 dpa. This image will be shown in a cover of the Journal of Raman Spectroscopy. 


\subsection{EXPLORING ALTERNATIVE STRUCTURAL CERAMICS}

T. Koyanagi (koyangit@ornl.gov), Y. Katoh, C. Ang, D. King (Missouri University of Science and Technology [MUST]), G. Hilmas (MUST), and W. Fahrenholtz (MUST)

\section{OBJECTIVE}

The objective of this task is to explore alternative high-temperature ceramics materials for potential fusion applications. $\mathrm{TiB}_{2}$ was selected for evaluation because of its high melting point, above $3000^{\circ} \mathrm{C}$, and the high thermal conductivity.

\section{SUMMARY}

The response of polycrystalline $\mathrm{TiB}_{2}$ to neutron irradiation was investigated. The material was fabricated using isotopically enriched ${ }^{11} \mathrm{~B}$ powders to minimize helium production via the ${ }^{10} \mathrm{~B}(\mathrm{n}, \alpha)^{7} \mathrm{Li}$ reaction. Neutron irradiation was conducted in HFIR at temperatures of $\sim 200^{\circ} \mathrm{C}$ and $\sim 600^{\circ} \mathrm{C}$ to a fast fluence of 2.4 $\times 10^{25} \mathrm{n} / \mathrm{m}^{2}(>0.1 \mathrm{MeV})$. The material exhibited some swelling, but less swelling at the higher irradiation temperature. No macroscopic damage was observed in the irradiated material, although moderate irradiation-induced microcracking was found in the irradiated $\mathrm{TiB}_{2}$. This study demonstrated improved radiation resistance of isotopically tailored $\mathrm{TiB}_{2}$ compared with natural boron $\mathrm{TiB}_{2}$, which exhibited macroscopic fracture during irradiation. A paper on this work has been accepted by Journal of the American Ceramic Society.

\section{PROGRESS AND STATUS}

$\mathrm{TiB}_{2}$ is an ultra-high temperature ceramic with melting point above $3000^{\circ} \mathrm{C}$. Diborides are currently not considered structural materials for nuclear applications because of accumulation of helium from the transmutation reaction. Demonstration of radiation tolerance of the material could result in reconsideration of diborides for use in nuclear structures. For example, diborides could be used as plasma-facing components of a fusion reactor.

Isotopically tailored $\mathrm{Ti}^{11} \mathrm{~B}_{2}$ material was neutron-irradiated in HFIR at temperatures of $\sim 200^{\circ} \mathrm{C}$ and $\sim 600^{\circ} \mathrm{C}$ to $2.4 \times 10^{25} \mathrm{n} / \mathrm{m}^{2}(>0.1 \mathrm{MeV})$. The material did not undergo macroscopic fracturing during neutron irradiation, contrasting to previous observations for $\mathrm{TiB}_{2}$ made with natural boron. The experiment demonstrated that isotope modification improved the irradiation resistance of diborides, likely due to minimization of helium production in the transmutation reaction. The $\mathrm{Ti}^{11} \mathrm{~B}_{2}$ material did experience irradiation-induced swelling. In terms of dimensional stability, it exhibited better irradiation resistance at $\sim 600^{\circ} \mathrm{C}$ than at $\sim 200^{\circ} \mathrm{C}$; with length change of $1.40 \%$ at $200^{\circ} \mathrm{C}$ and $0.81 \%$ at $600^{\circ} \mathrm{C}$. The irradiated $\mathrm{Ti}^{11} \mathrm{~B}_{2}$ materials showed moderate micro-cracking, seen in Figure 17, which is explained by anisotropic lattice expansion. An X-ray diffraction experiment found a-axis swelling to be significantly larger than c-axis swelling at both irradiation temperatures.

The findings of this study encourage further investigation and development of $\mathrm{TiB}_{2}$ for nuclear applications. The evaluation of thermomechanical properties of materials irradiated at higher temperatures will also be important and will be investigated in future studies. Minimization of irradiation-induced microcracking is another aspect that will be considered in future material development. It is expected that a reduction in grain size would minimize such cracking, in analogy with an irradiation study of $\mathrm{BeO}$. 


\section{FUTURE PLANS}

The effect of neutron irradiation on thermal properties (i.e. thermal diffusivity) of $\mathrm{Ti}^{11} \mathrm{~B}_{2}$ material will be evaluated. In addition to this, the response of another ultra-high temperature ceramic $\left(\mathrm{Zr}^{11} \mathrm{~B}_{2}\right)$ to neutron irradiation will be investigated.
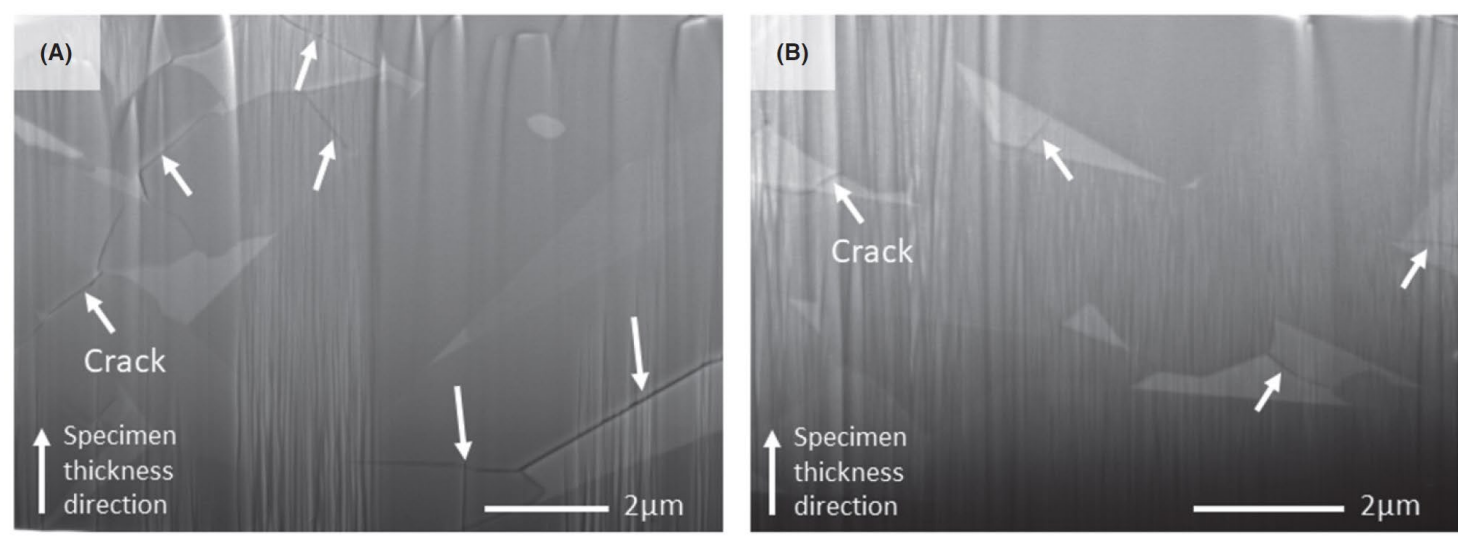

Figure 17. Micro-cracks in $\mathrm{Ti}^{11} \mathrm{~B}_{2}$ irradiated in HFIR at $(\mathrm{A}) \sim 200^{\circ} \mathrm{C}$ and $(\mathrm{B}) \sim 600^{\circ} \mathrm{C}$. 


\title{
4. HIGH HEAT FLUX AND PLASMA FACING MATERIALS
}

\subsection{NEUTRON IRRADIATION EFFECTS IN TUNGSTEN}

\author{
L.M. Garrison (garrisonlm@ornl.gov), Y. Katoh, N. A. P. Kiran Kumar
}

\section{OBJECTIVE}

The objective of this work is to evaluate the effects of neutron irradiation on the mechanical properties and microstructure of tungsten-based materials.

\section{SUMMARY}

Single crystal tungsten irradiated as part of the TITAN collaboration have been tensile tested. The tungsten showed an initial increase in strength followed by a decrease in strength with increasing irradiation dose. The critical transition doses from ductile to brittle tensile behavior for tungsten irradiated in HFIR were identified as between 0.1 and $0.55 \mathrm{dpa}$ for tests at $300^{\circ} \mathrm{C}$, and between 0.1 and $0.43 \mathrm{dpa}$ for tests at $500^{\circ} \mathrm{C}$.

\section{PROGRESS AND STATUS}

Elevated temperature tensile tests were completed on irradiated single crystal tungsten samples (Figure 18). The $<110>$ orientation tungsten irradiated between 360 and $460^{\circ} \mathrm{C}$ and tested at $300^{\circ} \mathrm{C}$ had a transition to brittle behavior for dose between 0.1 and $0.55 \mathrm{dpa}$. Similarly, the same material irradiated between 690 and $800^{\circ} \mathrm{C}$ and tested at $500^{\circ} \mathrm{C}$ had a transition to brittle behavior between 0.1 and $0.43 \mathrm{dpa}$. These tensile transition doses are in agreement with the observed dose of $\sim 0.4 \mathrm{dpa}$ where Re- and Os-rich clusters or precipitates become the main contributor to indentation hardness [1-4], indicating that the precipitates are probably the driving microstructural feature leading to brittle tensile failures. For material tested at $650^{\circ} \mathrm{C}$, samples were irradiated to a maximum dose of $0.09 \mathrm{dpa}$, which is below the critical transition for this temperature.

Figure 19 compares the observed microstructures with the tensile behavior. At low temperatures, loops are the dominant observed microstructure feature. Between 400 and $500^{\circ} \mathrm{C}$, there is a transition and more voids are visible in TEM observation. As dose increases at elevated temperatures, voids and precipitates are the main features. The tensile transitions from ductile to brittle behavior with increasing dose both occurred at doses $(\sim 0.4$ dpa) lower than the dose where precipitates are clearly visible by TEM ( 1 dpa).

\section{FUTURE PLANS}

Selected additional higher dose samples have been selected for mechanical property and microstructure investigation. The results of the TITAN irradiations (unshielded rabbits) will be compared with the PHENIX irradiation (thermal neutron shielded capsule) to better understand the effect of transmutation on the properties of irradiated tungsten. 
(a)

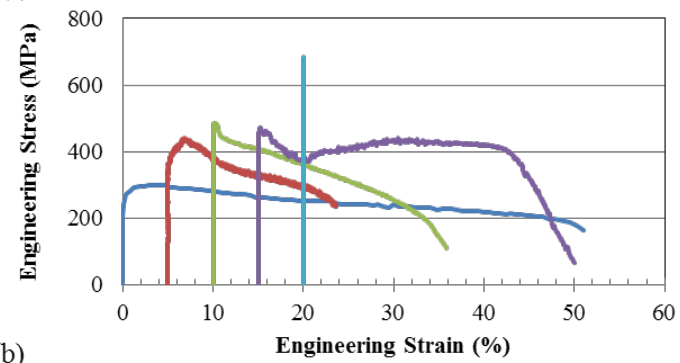

- $1 \mathrm{~W} 57-300$

-1W02-0.004-370-300

-1W48-0.02-460-300

-1W49-0.1-360-300

-1W08-0.55-430-300

(b)

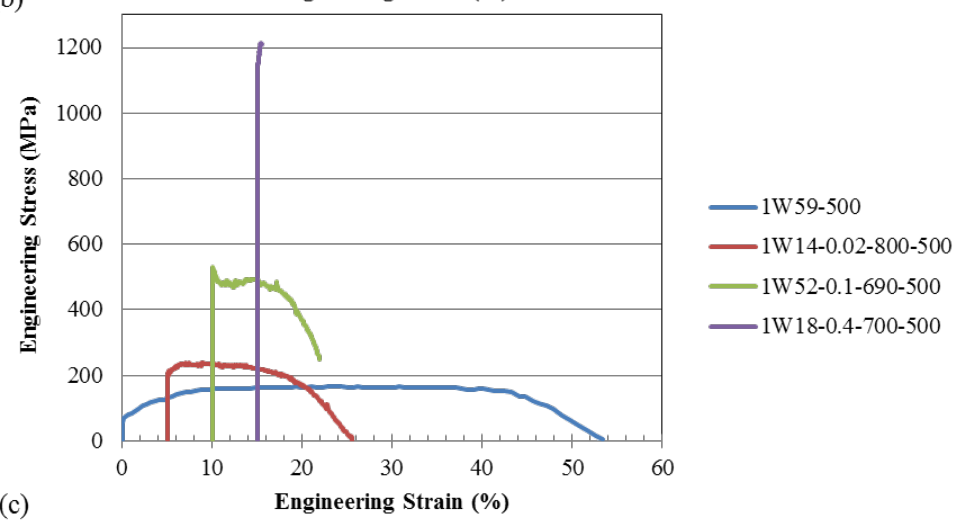

(c)

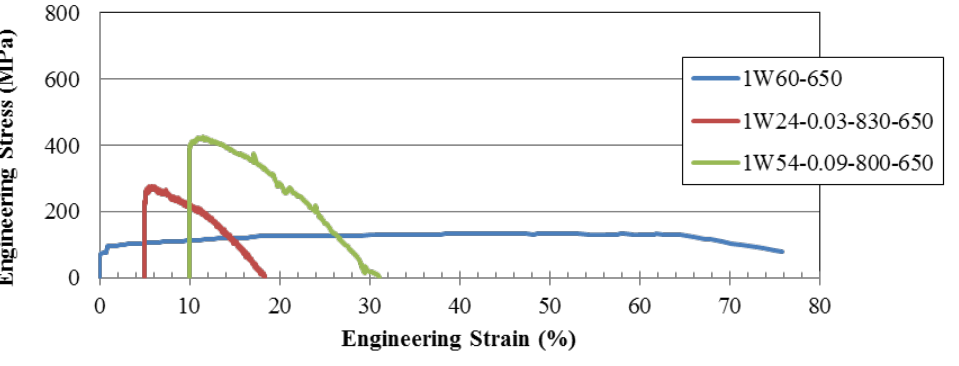

Figure 18. Tensile properties of single-crystal tungsten with $<110>$ crystal direction along the tensile axis (a) irradiated at $360-460^{\circ} \mathrm{C}$ and tested at $300^{\circ} \mathrm{C}$, (b) irradiated at $690-800^{\circ} \mathrm{C}$ and tested at $500^{\circ} \mathrm{C}$, and (c) irradiated at $800-830^{\circ} \mathrm{C}$ and tested at $650^{\circ} \mathrm{C}$. Curves are offset by $5 \%$ strain with the same scale used for all curves. 


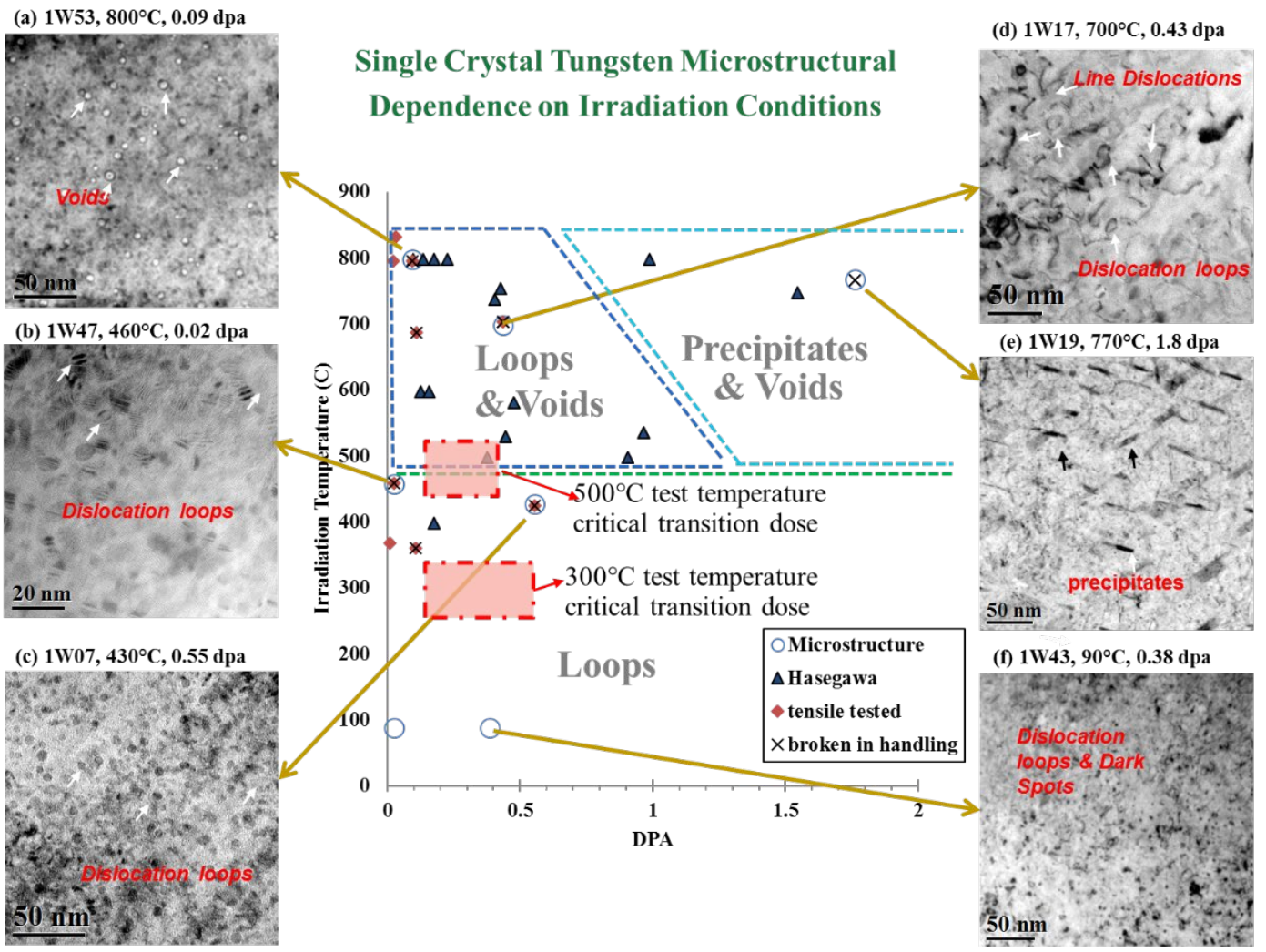

Figure 19. Summary of microstructures from tungsten irradiated in the TITAN/PHENIX programs compared with previous data from JMTR, JOYO, and HFIR irradiations reported by Hasegawa et al. [2]. Selected microstructures have been evaluated in more detail in recent articles: (a) from Hu et al. [3], (b)-(c)-(d) this work, (e) Fukuda et al. [4], and (f) Hu et al. [3].

\section{REFERENCES}

[1] R.G. Rau, J. Moteff, R.L. Ladd, Comparison of microstructure with mechanical properties of irradiated tungsten, J. Nucl. Mater. 24 (1967) 164-173.

[2] A. Hasegawa, M. Fukuda, S. Nogami, K. Yabuuchi, Neutron irradiation effects on tungsten materials, Fusion Eng. Des. 89(7-8) (2014) 1568-1572.

[3] X. Hu, T. Koyanagi, M. Fukuda, N.A.P.K. Kumar, L.L. Snead, B.D. Wirth, Y. Katoh, Irradiation hardening of pure tungsten exposed to neutron irradiation, J. Nucl. Mater. 480 (2016) 235-243.

[4] M. Fukuda, N.A.P. Kiran Kumar, T. Koyanagi, L.M. Garrison, L.L. Snead, Y. Katoh, A. Hasegawa, Neutron energy spectrum influence on irradiation hardening and microstructural development of tungsten, J. Nucl. Mater. 479 (2016) 249-254. 


\title{
4.2 TRANSMUTATION-INDUCED PRECIPITATION IN TUNGSTEN IRRADIATED IN A MIXED ENERGY NEUTRON SPECTRUM
}

\author{
X.Hu (hux1@ornl.gov), K. Wang, T.Koyanagi, C.M. Parish, T.Y. Katoh
}

\section{OBJECTIVE}

The objective of this work is to understand the transmutation-induced precipitation in neutron-irradiated tungsten through detailed microstructural characterization of irradiated tungsten.

\section{SUMMARY}

Segregation and precipitation of transmutant elements in single crystal and polycrystal tungsten irradiated at $460 \sim 1100^{\circ} \mathrm{C}$ to $0.02 \sim 2.4$ displacements per atom (dpa) in HFIR were investigated by transmission electron microscopy. A tentative roadmap of the kinetics process of the transmutation-induced precipitation is presented characterizing the defect features (i.e., W-Re-Os clusters and precipitates) at various doses.

\section{PROGRESS AND STATUS}

Defect features consisting of transmutant elements in tungsten irradiated at $460 \sim 1100^{\circ} \mathrm{C}$ to $0.02 \sim 2.4 \mathrm{dpa}$ in HFIR were characterized using TEM. The general process of transmutation-induced precipitation was revealed by capturing the microstructures of tungsten irradiated to various conditions. The configuration and size distribution of defect features consisting of Re and Os are strongly dependent on the irradiation dose and temperature. Nanoscale clusters enriched in Re and Os were observed in the low dose regime from 0.02 to 0.44 dpa while acicular-shaped precipitates appeared for irradiation doses higher than 1.8 dpa in single crystal tungsten irradiated in the temperature regime $460^{\circ} \mathrm{C}$ to $770^{\circ} \mathrm{C}$. A roadmap of the kinetics process of the transmutation-induced precipitation in neutron-irradiated tungsten is represented by the images and element maps for several irradiation conditions, shown in Figure 20. The segregation and precipitation are controlled by the highly mobile W-Re and W-Os dumbbells. Thermal stability of the nanoclusters consisting of transmutant elements was tentatively investigated by performing a $2-\mathrm{h} 1200^{\circ} \mathrm{C}$ anneal of the sample irradiated to $0.44 \mathrm{dpa}$ at $705^{\circ} \mathrm{C}$. 3D TEM analysis confirmed the association of voids and precipitates, shown in Figure 21.

\section{FUTURE PLANS}

Work will continue to investigate the thermal stability of W-Re-Os nanoclusters and acicular precipitates. The transition from W-Re-Os clusters to acicular precipitates needs to be better understood so will be addressed by combining modeling and experiments. 
(a)
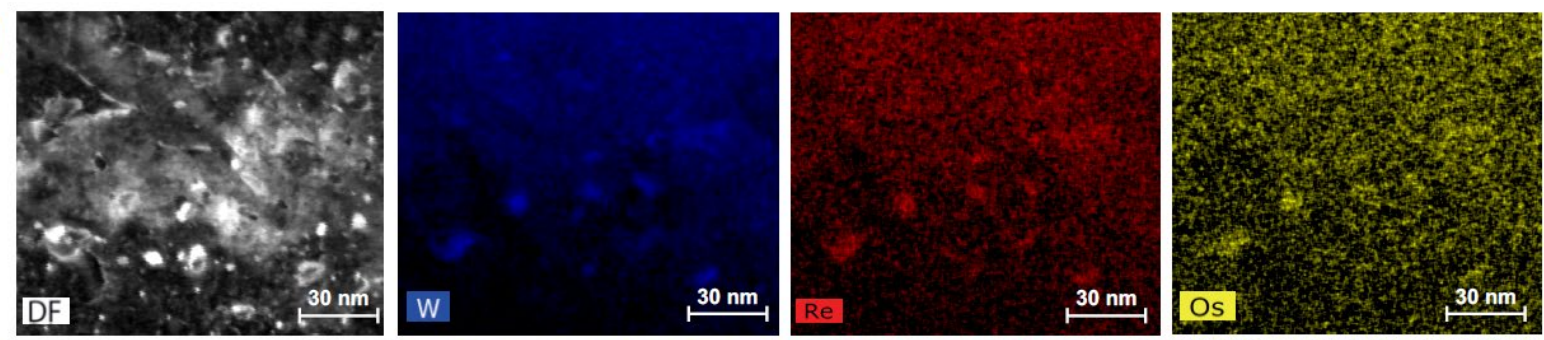

(b)
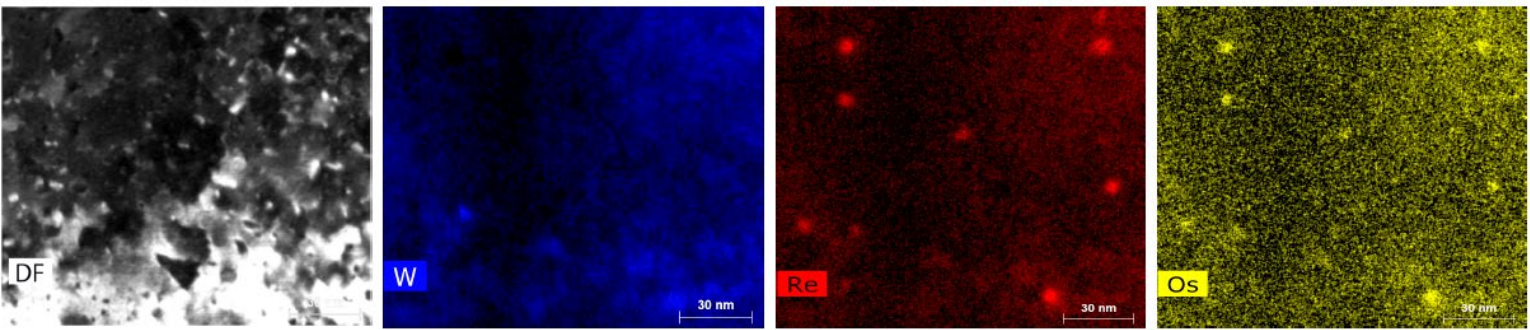

(c)
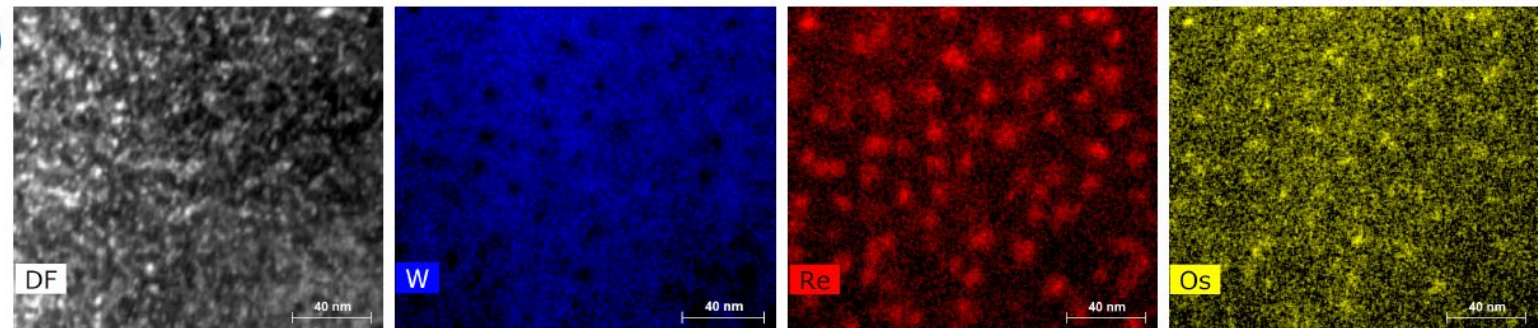

(d)
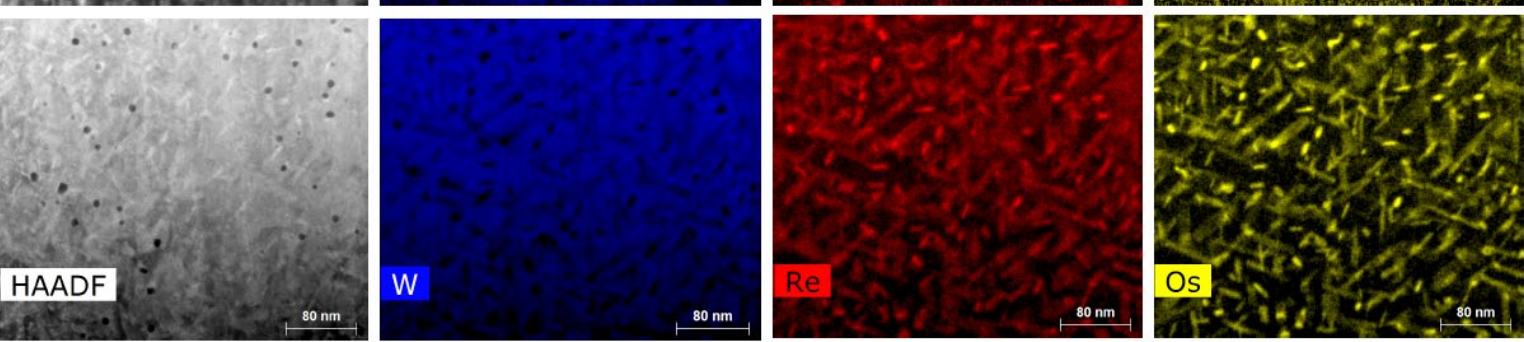

Figure 20. STEM dark field images and $X$-ray maps of neutron-irradiated single crystal tungsten (110): (a) $0.02 \mathrm{dpa}, 4_{60}^{\circ} \mathrm{C}$; (b) $0.09 \mathrm{dpa}, 7^{\circ} \mathrm{C}$; (c) $0.44 \mathrm{dpa}, 7^{\circ} \mathrm{C}$; (d) $1.80 \mathrm{dpa}, 7^{\circ}{ }^{\circ} \mathrm{C}$. 

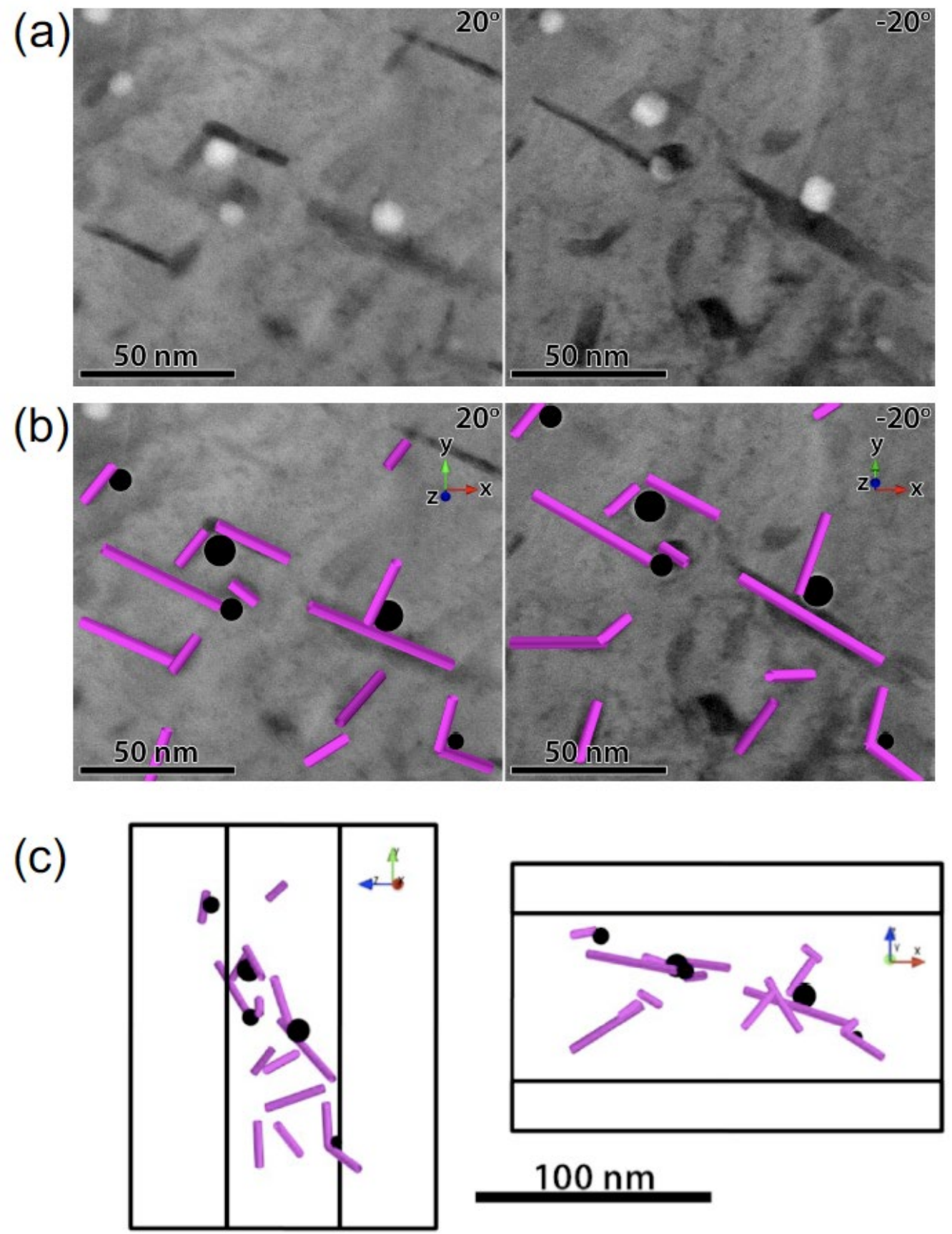

Figure 21. (a) STEM bright-field images taken at the same location in sample OW158 (1.5dpa, $800^{\circ} \mathrm{C}$ ) using different sample tilts; (b) computer generated model of acicular precipitates (purple straight lines) and voids (black circles); (c) snapshots of movie showing the correlation of precipitates and voids. 


\subsection{MECHANICAL PROPERTIES OF TUNGSTEN IRRADIATED IN THE PHENIX COLLABORATION}

L. M. Garrison (garrisonlm@ornl.gov), T. Miyazawa, N. Reid, E. Lang, B. Gregory, T. Ray, E. Proehl, C. Lin, Y. Katoh

\section{OBJECTIVE}

The PHENIX collaboration tungsten irradiation is expanding the database on neutron irradiation effects in tungsten materials.

\section{SUMMARY}

The HFIR RB*19J irradiation capsule included over 20 varieties of tungsten as part of the PHENIX collaboration. It had three temperature zones, nominally 500,800 , and $1200^{\circ} \mathrm{C}$. Hardness tests on the unirradiated materials and on selected irradiated samples from the 500 and $800^{\circ} \mathrm{C}$ sub-capsules were completed and will continue on the other materials. Equibiaxial flexure tests were completed on selected unirradiated samples, and a majority of the elevated temperature tensile tests on materials from the 500 and $800^{\circ} \mathrm{C}$ sub-capsules have been completed. Other mechanical tests will follow, including fracture toughness tests.

\section{PROGRESS AND STATUS}

An example of data for one of the unalloyed thick plate tungsten materials from the PHENIX irradiation is presented here. The SEM analysis before irradiation shows relatively even distributions of grain size in the directions parallel and perpendicular to the tensile axis (Figure 22). The Vickers microhardness of the material increased from the unirradiated value of $460 \mathrm{Hv}$ to $634 \mathrm{Hv}$ after irradiation in the "500C-zone" and to $667 \mathrm{Hv}$ after irradiation in the "800C-zone" of the HFIR RB*19J capsule (Figure 23). Tensile testing has focused on elevated temperature tests near the irradiation temperatures of the different zones. When the thick plate tungsten was irradiated and tested at $500^{\circ} \mathrm{C}$, it retained approximately $2 \%$ elongation (Figure 24). However, when irradiated and tested at $700^{\circ} \mathrm{C}$, the material failed in a brittle fracture. 

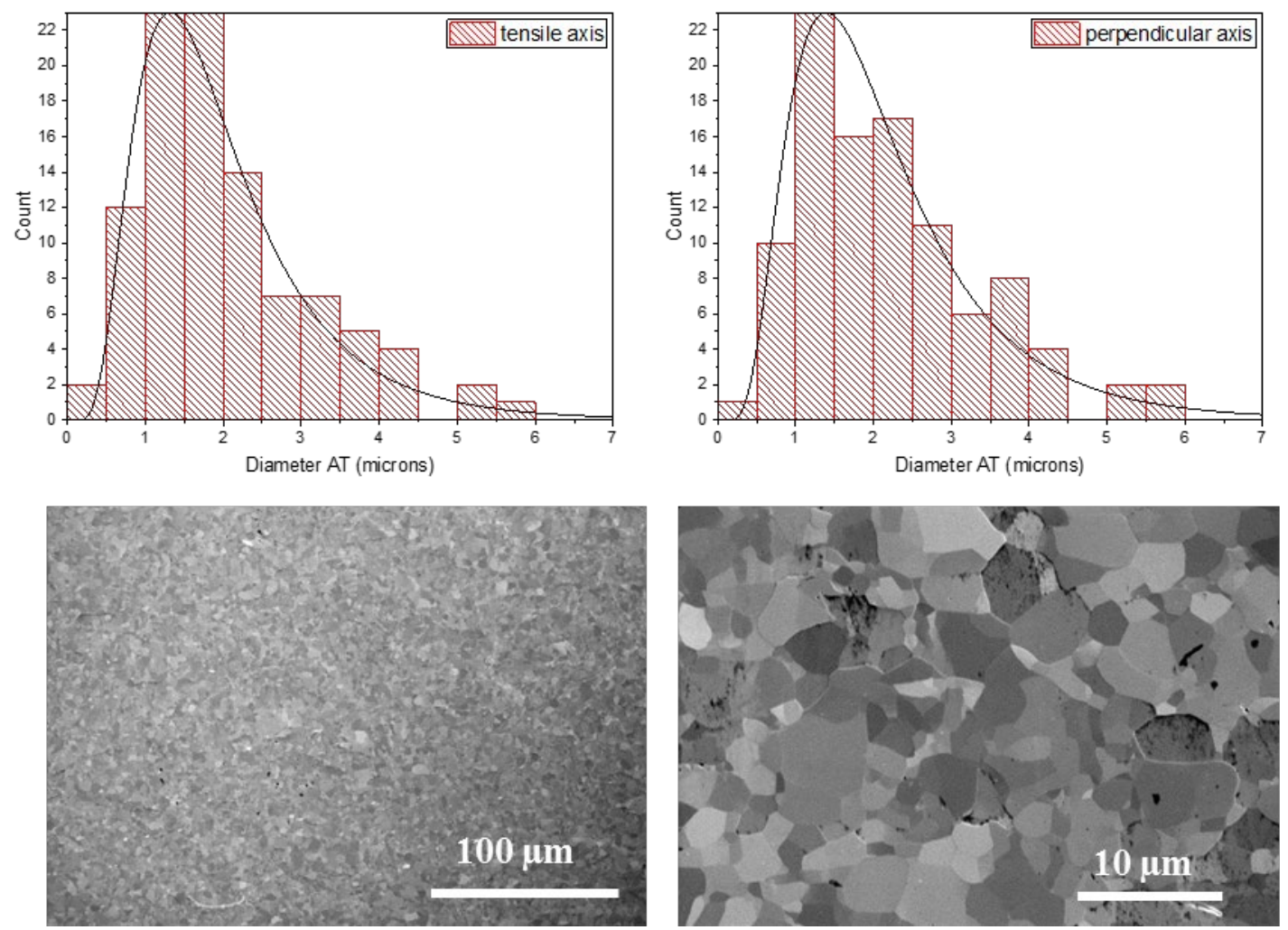

Figure 22. Unirradiated microstructure of thick plate unalloyed tungsten, orientation "A."

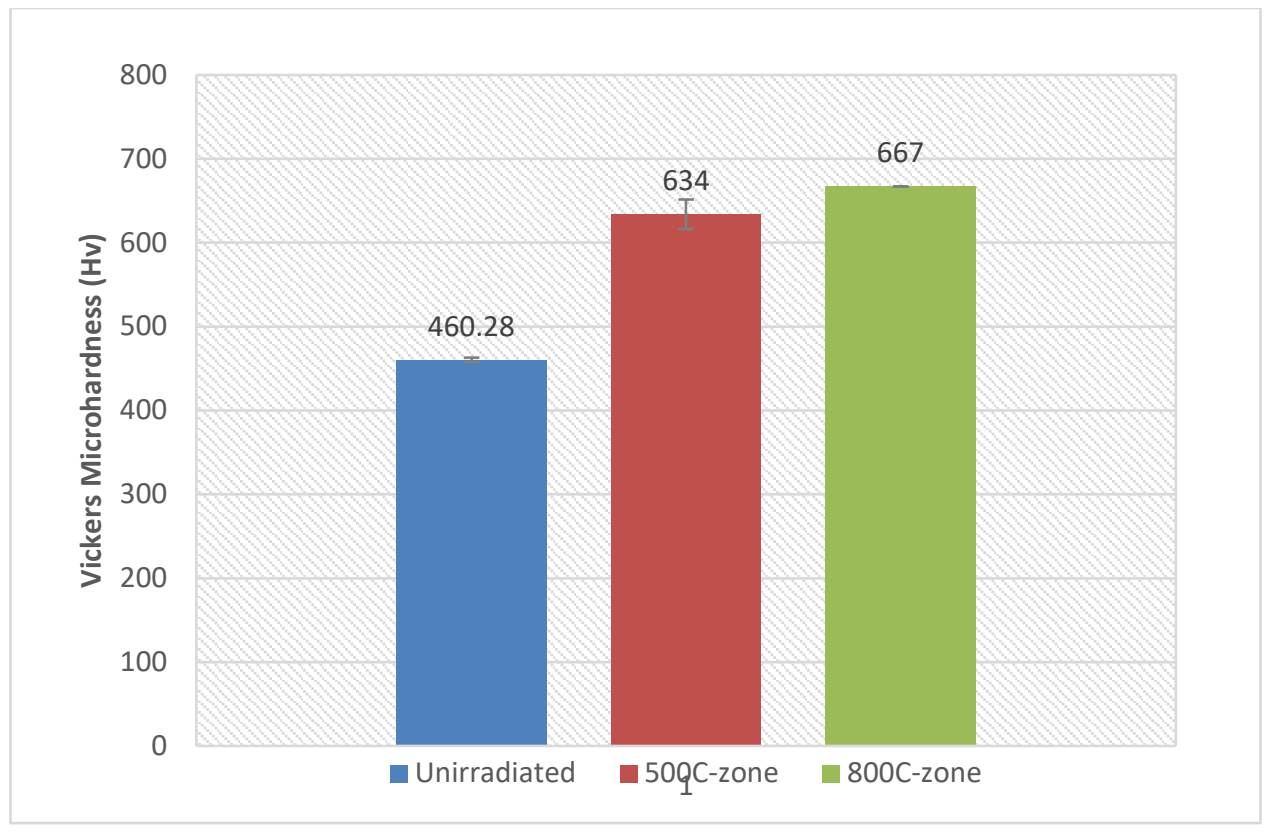

Figure 23. Vickers microhardness of thick plate unalloyed tungsten, orientation " $A$ ", before and after irradiation at the nominal temperatures indicated. 


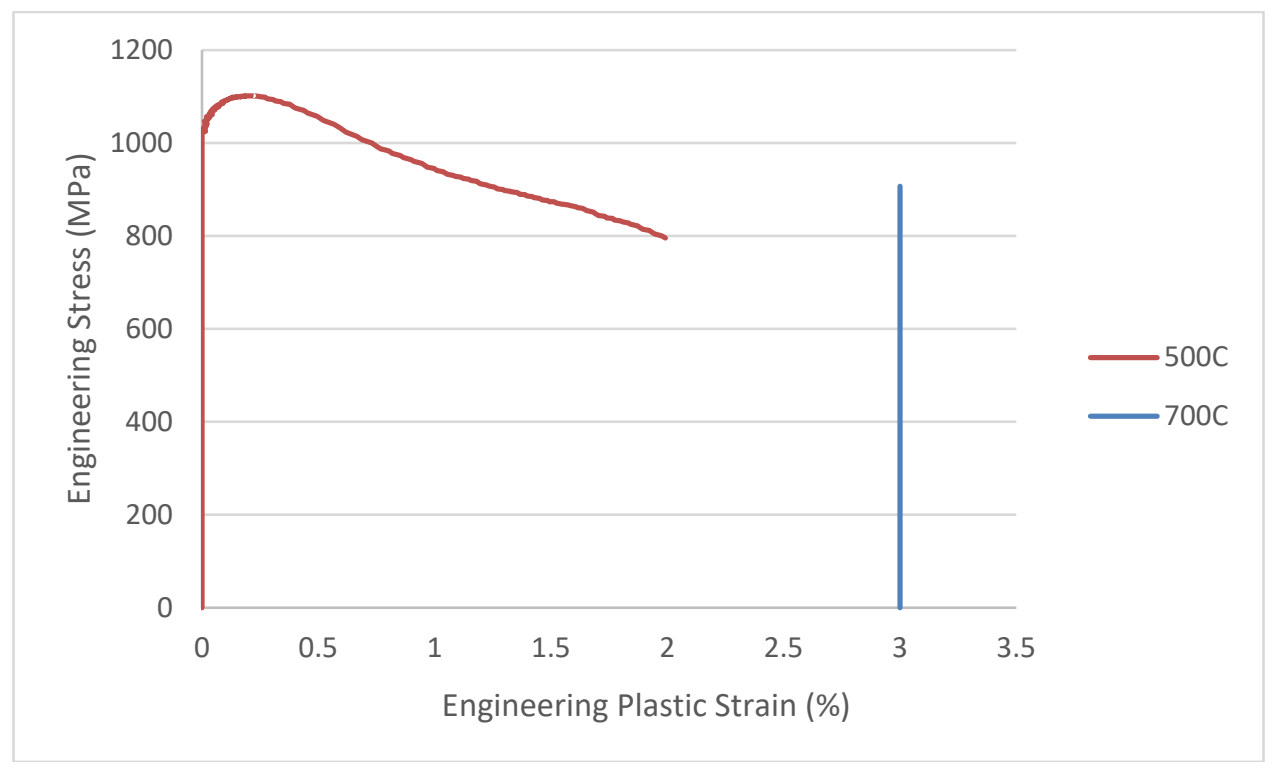

Figure 24. Tensile tests at the approximate irradiation temperature of the thick plate tungsten, orientation " $A$ ". Curves are offset on the $x$-axis for clarity.

\section{FUTURE PLANS}

The mechanical testing will continue with the "1200C-zone" samples from the RB*19J capsule and the results of this thermal neutron shielded irradiation experiment will be compared with previous unshielded irradiation data. 


\subsection{THERMAL PROPERTIES OF PHENIX COLLABORATION NEUTRON IRRADIATED TUNGSTEN}

L. M. Garrison (garrisonlm@ornl.gov), H. Wang, M. Akiyoshi (Osaka University, Japan), T. Ray (Purdue University)

\section{OBJECTIVE}

This project is measuring the thermal properties of tungsten-based materials.

\section{SUMMARY}

The newly acquired LFA467 thermal diffusivity instrument is being prepared for testing through several benchmark tests. The first tests of irradiated materials using the LFA467 were completed. Oxidation and software issues are being addressed before continuing with measuring the PHENIX collaboration materials.

\section{PROGRESS AND STATUS}

Two instruments are available for testing thermal diffusivity: the LFA 457 and the LFA 467 . The LFA 457 uses a roughing pump and Ar flow gas during measurements. It was determined that for tungsten, the level of vacuum and gas purity in the LFA 457 is not sufficient to prevent oxidation at temperatures of $\sim 400^{\circ} \mathrm{C}$ and above. The oxide formation during thermal diffusivity testing has at least three negative consequences. It can alter the thermal diffusivity measurement so that unreliable data is collected. Some of the oxide products are volatile and can re-deposit in colder areas of the instrument, which harms the instrument, for example by clouding the window between the laser and sample. Additionally, for irradiated samples which are planned for multiple measurements, having an oxide on the surface can interfere with or prevent further testing. Some initial results on the LFA 467 also resulted in an oxide layer on the tungsten samples, and this issue is currently being addressed.

An additional challenge is the measurement of small samples in the LFA 467. The software from the instrument manufacturer is only set up to measure $10 \mathrm{~mm}$ diameter and larger samples, even though the equipment has the capability to measure smaller ones. Using the manufacturer software for analysis, the various sized samples in Figure 25 all have different thermal diffusivity values even though the samples were cut from the same tungsten host material produced by Alfa Aesar. To calculate the thermal diffusivity accurately from the pulse measured by the LFA 467 currently requires the user to calculate this outside of the instrument. Netzsch, the manufacturer of the LFA 467 is working to provide an update to their instrument software to allow proper calculation for samples smaller than $10 \mathrm{~mm}$.

Using the separate software analysis and the LFA 467, data was collected from selected 6 mm diameter, 2 $\mathrm{mm}$ thick tungsten samples (Figure 26 and Figure 27). The materials selected for these first measurements will be used for high heat flux testing in the Plasma Arc Lamp, and then their thermal diffusivity measured after high heat flux testing. All the materials show some reduction in thermal diffusivity after irradiation. The W-Re alloys had lower thermal diffusivity than the unalloyed tungsten, but there was little difference in the two orientations of the materials. Certain of these samples did show thin oxide layers after the thermal diffusivity measurement, but it was not believed to interfere with the measurement. 


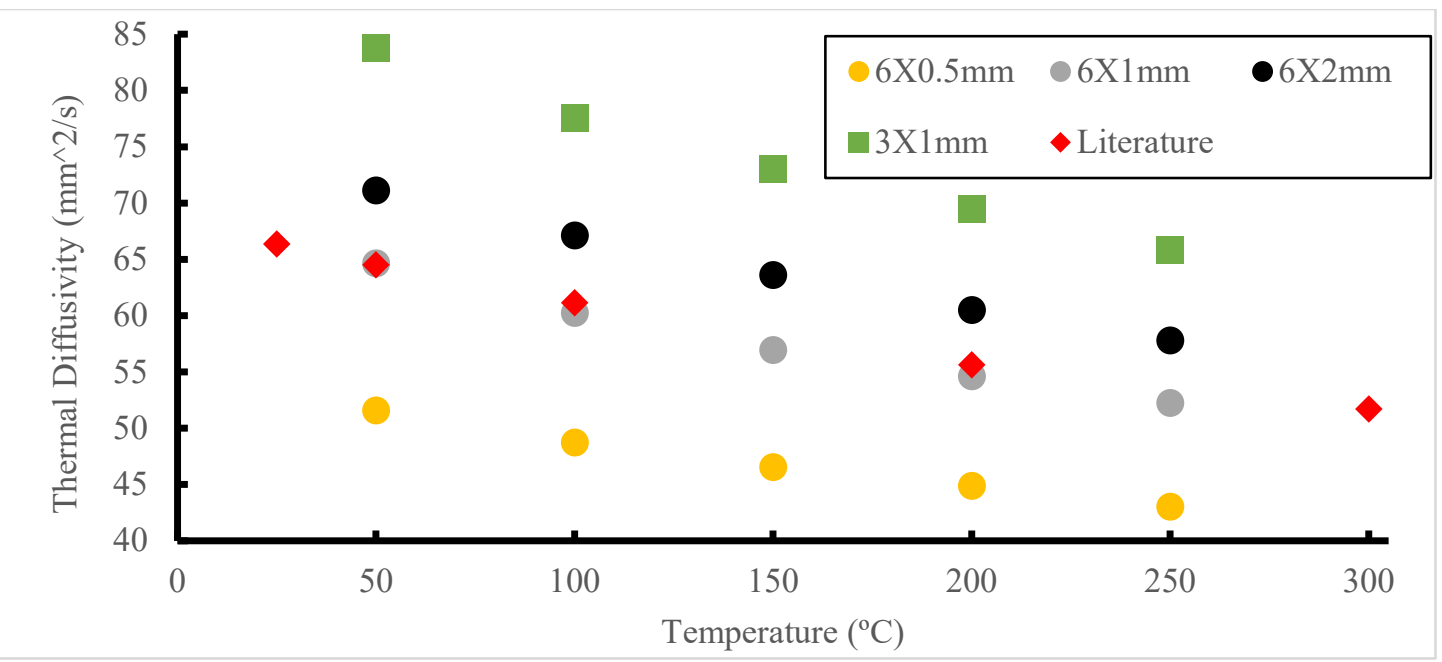

Figure 25. Sample size comparison measured with the LFA 467 and analyzed with the instrument software. Literature values are from Ref. [1].

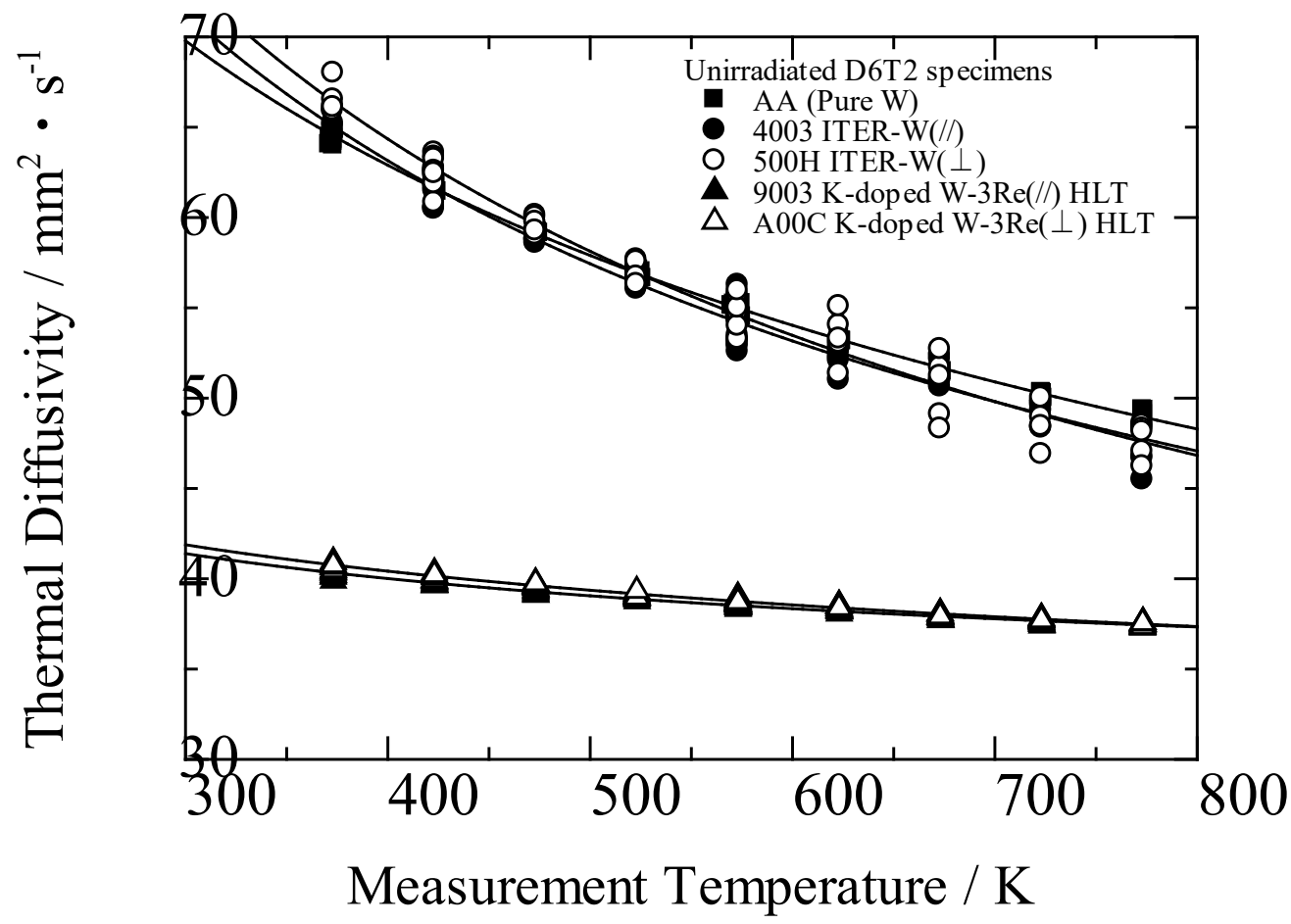

Figure 26. Thermal diffusivity of unirradiated tungsten materials intended for high heat flux testing. 


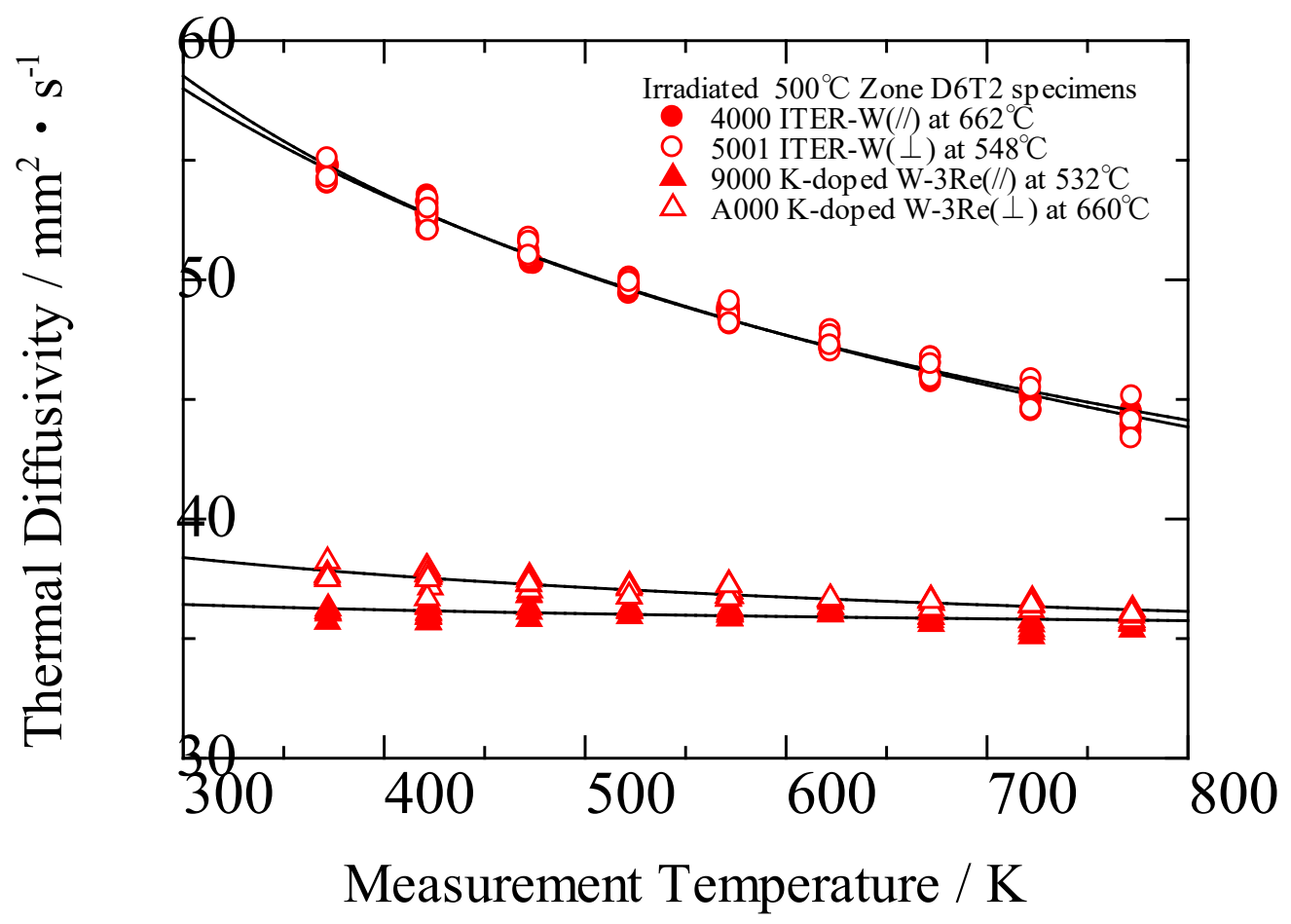

Figure 27. Thermal diffusivity of irradiated tungsten the materials intended for high heat flux testing.

\section{FUTURE PLANS}

The vacuum and gas flow system on the LFA 467 is being tested to reduce the rate of oxide formation on tungsten materials during measurements. The instrument software is being updated by the manufacturer to allow direct calculation of the thermal diffusivity of a wide range of sample sizes. The measurements of the other tungsten materials in the PHENIX collaboration will continue in the LFA 467.

\section{REFERENCES}

[1.] Y. S. Touloukian, T.W. Powell, C.Y. Ho \& M.C. Nicolaou, Thermophysical Electronic Properties Information Analysis Center Lafayette In. (1974), "Thermophysical Properties of Matter - the TPRC Data Series," Volume 10. Thermal Diffusivity. 


\subsection{NEUTRON IRRADIATION EFFECTS IN TUNGSTEN-COPPER COMPOSITES}

\section{L.M. Garrison (garrisonlm@ornl.gov), Y.Katoh}

\section{OBJECTIVE}

The aim of this work is to evaluate tungsten-copper composites for potential use in plasma-facing component of fusion reactors.

\section{SUMMARY}

As part of the TITAN program, two types of tungsten-copper composites were irradiated in HFIR at temperatures from 300 to $900^{\circ} \mathrm{C}$ to fast neutron fluences of 0.01 to $20 \times 10^{25} \mathrm{n} / \mathrm{m}^{2}$ at $\mathrm{E}>0.1 \mathrm{MeV}$. One material was a tungsten-copper laminate composite composed of $0.1 \mathrm{~mm}$ alternating layers of tungsten and copper; the other was a tungsten-copper powder sintered composite, with $75 \% \mathrm{~W}$ and $25 \% \mathrm{Cu}$. Tensile tests at $22^{\circ} \mathrm{C}$ and elevated temperatures of unirradiated and irradiated tungsten-copper sintered composite have been completed.

\section{PROGRESS AND STATUS}

A powder sintered tungsten copper composite with $75 \mathrm{wt} . \% \mathrm{~W}$ and $25 \mathrm{wt} . \% \mathrm{Cu}$ (abbreviated material code $\mathrm{KW}$ ) was investigated. Vickers hardness tests and tensile tests at room and elevated temperatures were completed on selected unirradiated and irradiated KW samples.

After irradiation at the higher temperature range, $630-780^{\circ} \mathrm{C}$, and tensile tests at room temperature, the KW tensile data are clustered for doses up to $0.11 \mathrm{dpa}$ (Figure 28a). However, at the highest dose material tested, $1.8 \mathrm{dpa}$, there is a sharp increase in ultimate tensile strength (UTS) and drop in total elongation (TE). It is postulated that between 0.11 and $1.8 \mathrm{dpa}$ the defect structure changes or accumulates to a critical level that in turn causes the changes in the mechanical behavior. For the material irradiated to the same conditions but tensile tested at the irradiation temperatures, the same pattern is seen with a change in behavior by $1.8 \mathrm{dpa}$, but all the UTS values are reduced (Figure 28b).

In comparison, the unirradiated and irradiated unalloyed tungsten had no ductility at room temperature. For the irradiated tungsten, a critical transition from ductile to brittle behavior at elevated test temperatures was identified to be between 0.1 and $0.5 \mathrm{dpa}$. The tungsten-copper laminate composite had unirradiated room temperature ductility but had a transition to brittle behavior after very low dose irradiation. Thus, the KW composite material has advantageous tensile properties compared to tungsten and the tungsten-copper laminate composite.

\section{FUTURE PLANS}

Nanoindentation measurements will be conducted on the composite to separately measure the hardness changes in the copper and tungsten phases. Microstructure analysis is planned to characterize the irradiated material. 
(a)

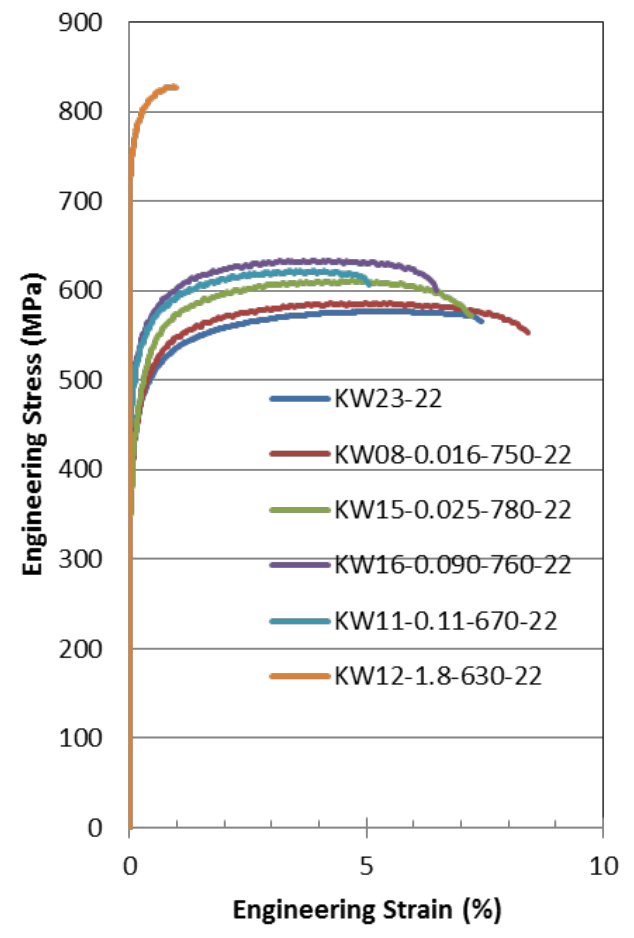

(b)

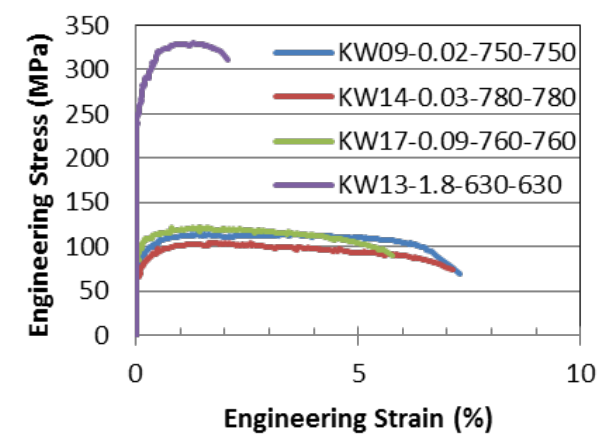

Figure 28. Tungsten-copper sintered composite irradiated at $630-780^{\circ} \mathrm{C}$ and tested at (a) room temperature and (b) the irradiation temperature. Only the plastic strain is shown and approximately the same scale is used for all tensile curves. 


\subsection{W-Re-Os ALLOYS FOR THE FUSION PROGRAM}

\section{X.Hu(hux1@ornl.gov), Y. Katoh, K. Hanson}

\section{OBJECTIVE}

This task is directed at producing tungsten-rhenium-osmium alloys needed for the fusion materials program.

\section{SUMMARY}

W-Re-Os alloys have been fabricated for irradiation effects and plasma materials interaction studies. It is anticipated that the material may also be used as a calibration standard for measurement of composition in transmutation effects studies.

\section{PROGRESS AND STATUS}

When exposed to fusion neutron spectrum, tungsten will be transmuted to Re and then Os. The starting pure tungsten will become W-Re-Os as the irradiation dose increases. However, there is no available study on the plasma response of W-Re-Os alloys due to the unavailability of this ternary alloy in the market.

We have successfully fabricated $\mathrm{W}-5 \mathrm{wt} \% \mathrm{Re}-3 \mathrm{wt} \% \mathrm{Os}$ alloys by mixing $\mathrm{W}, \mathrm{W}-\mathrm{Re}$, and $\mathrm{W}-\mathrm{Os}$ alloys using arc melting method. Figure 29(a) shows the as fabricated W-5Re-3Os ingot and specimens cut from the button ingot using EDM. Chemical analysis showed the final product is $5.03 \mathrm{wt} \% \mathrm{Re}$ and $2.77 \mathrm{wt} \%$ Os. Glow discharge-optical emission spectroscopy (GD-OES) measurements indicates the Re and Os distributions are homogeneous, as shown in Figure 29(b).

It is anticipated that the material will be useful as a calibration standard for measurement of composition in transmutation effects studies.
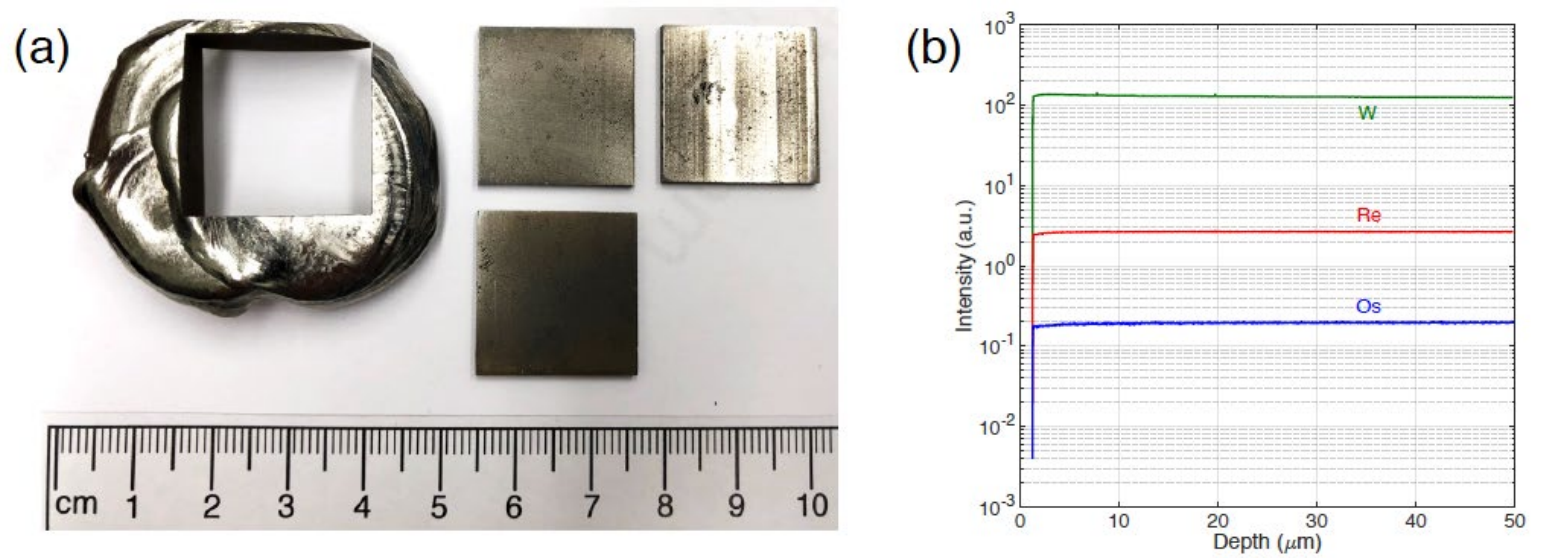

Figure 29. (a) As fabricated W-5Re-Os ingot and specimens cut using EDM; (b) GD-OES elemental distribution profile. 


\section{FUTURE PLANS}

Other W-Re-Os ternary alloys with different compositions will be fabricated and shared with the fusion materials community for irradiation effects and PMI studies. 


\title{
5. PLASMA MATERIALS INTERACTIONS
}

\subsection{DAMAGE-MECHANISM INTERACTIONS AT THE PLASMA-MATERIALS INTERFACE}

\author{
C.M.Parish (parishcm@ornl.gov), K.Wang (Now at Alfred University)
}

\section{OBJECTIVE}

The overarching objective of this work is to bridge the gap between the atomistic knowledge and models and the phenomenological materials science underlying the design, fabrication, and service of divertors and other plasma-facing materials for magnetic confinement fusion. Specifically, the influence of intrinsic defects (dislocations, grain boundaries) and extrinsic defects (ion- and neutron-irradiation damage, impurities) interactions with $\mathrm{He}$ and bubbles, in terms of nucleation sites, growth, trapping, and surface degradation, will be measured.

\section{SUMMARY}

This year we have explored both radiation damage and plasma implantation effects. Radiation effects studies included continued analysis of neutron-irradiated tungsten, and ion-irradiation on tungsten blanks in preparation for adding plasma-exposure on top of the radiation damage. Plasma effects included analysis of the flux and fluence effects on the near-surface region of tungsten, and exploration of helium effects on the near-surface mechanical properties.

\section{PROGRESS AND STATUS}

Tungsten ion irradiation of tungsten specimens was performed at the University of Kyoto, and preliminary TEM results indicate a dense damage structure, Figure 30. Currently we are determining how to mount these specimens for helium plasma exposure in order to evaluate the effects of helium / irradiation damage synergy.

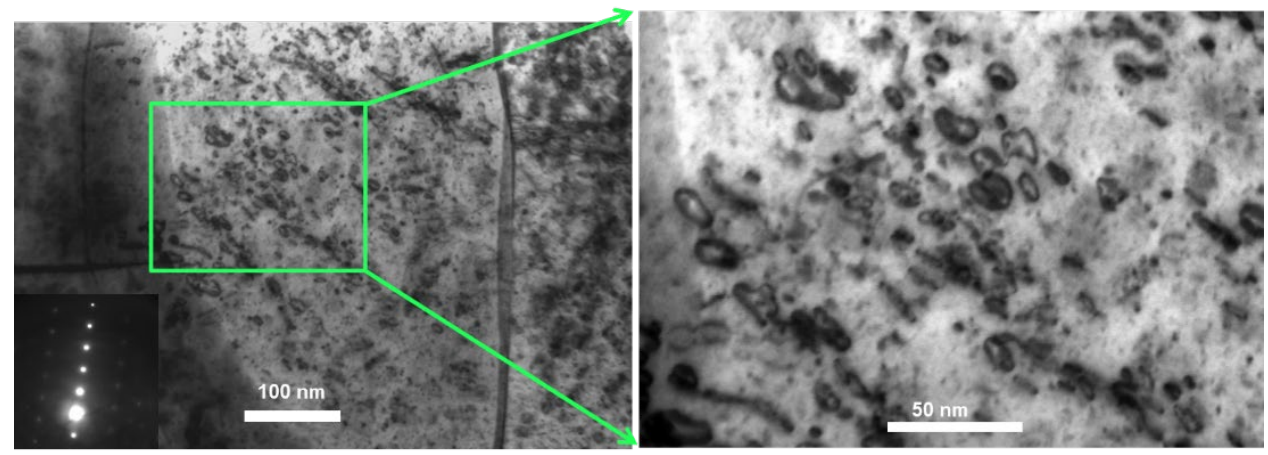

Figure 30. Tungsten-ion-irradiated tungsten, imaged by transmission electron microscopy.

We also published results on technique development for measuring the grain boundary character at the nanotendril / substrate interface in "fuzzy" tungsten, Figure 31. This method allowed us to probe the tendril / substrate interface with good statistics and draw conclusions about the tendril growth mechanisms. 

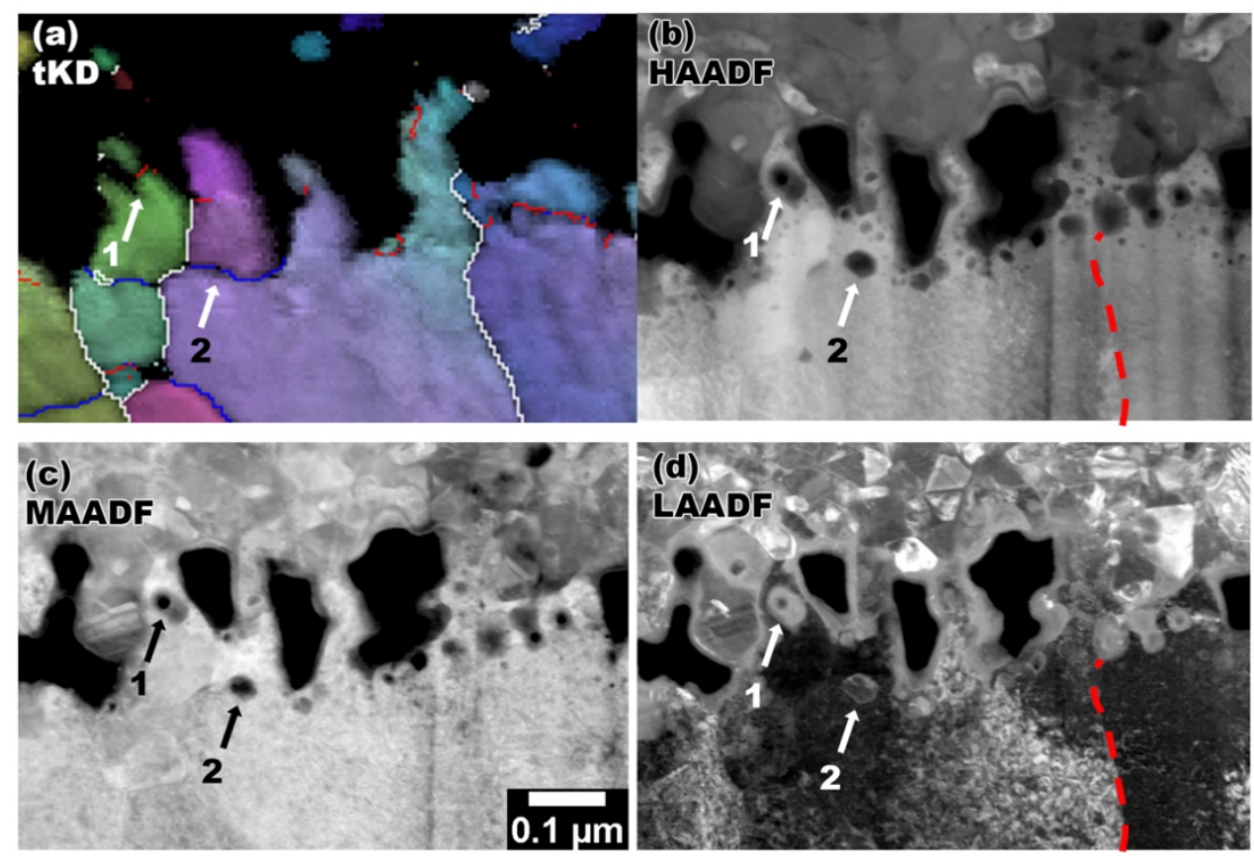

Figure 31. Example of analysis of the tendril / substrate interface, using a specially-developed experimental method.

We are also exploring the use of "high resolution electron backscatter diffraction" as a method, combined with nanoindentation, to probe the mechanical properties at the surface and measure the changes caused by helium implantation. $600^{\circ} \mathrm{C}$ helium loading was performed at UC-San Diego PISCES lab in order to introduce dense helium bubble mats without growing fuzz, and these samples are being tested. Figure 32 shows a control (with no helium plasma exposure) sample subjected to nanoindentation, and with its local strain tensor and geometrically necessary dislocation density measured using high-resolution Electron Back Scattered Diffraction (EBSD).

\section{FUTURE PLANS}

We are continuing these experiments, and plan to push onward with quantification of the strain around the indents, to expose the ion irradiated specimens to helium plasma, and to continue the examination of the radiation effects in neutron irradiated tungsten. Our collaborations with UC-San Diego, University of Tennessee, and University of Illinois will continue. 

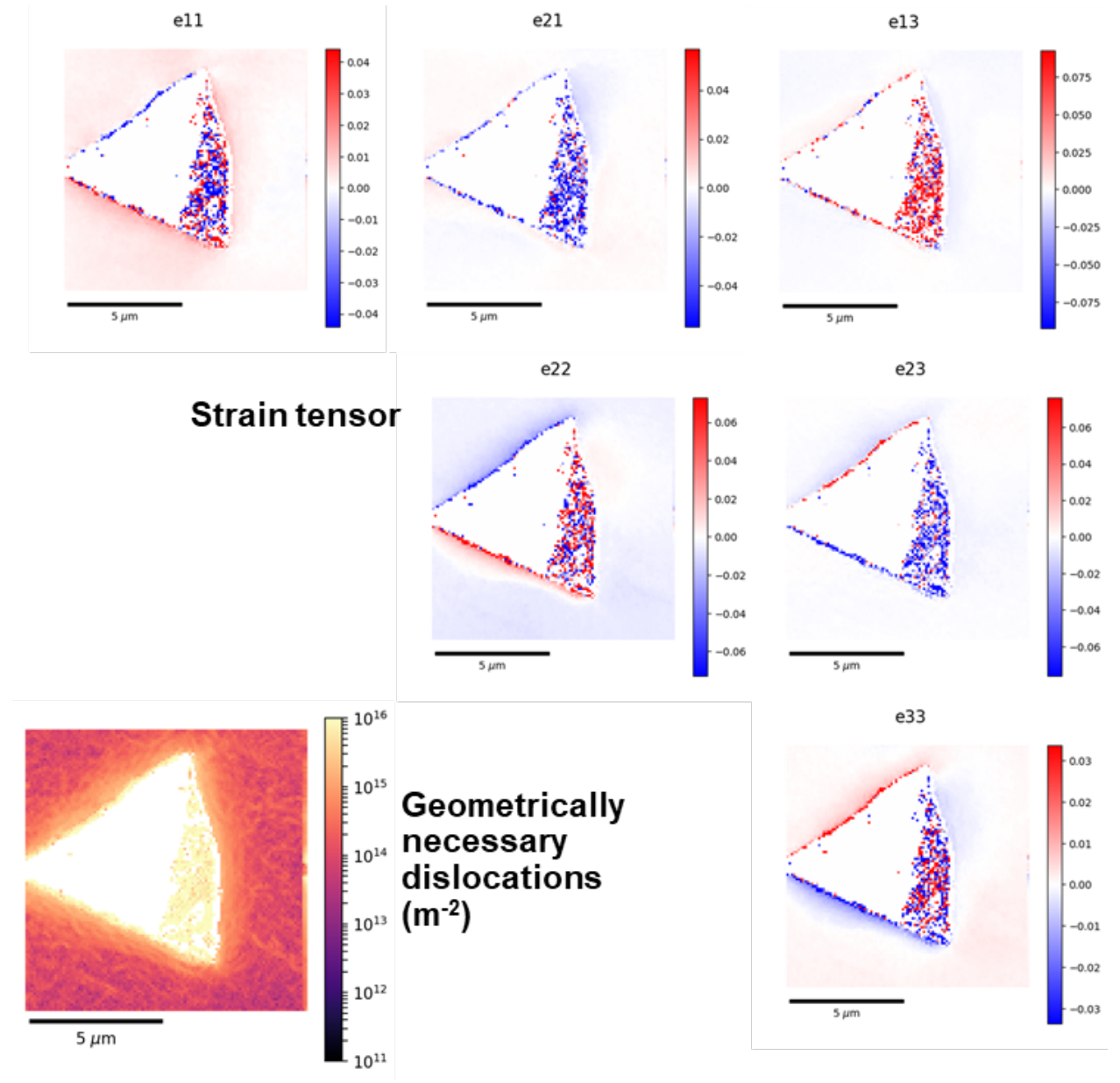

Figure 32. The local strain tensor measured around a nanoindent in (001) single crystal tungsten, as determined by high-resolution EBSD. Inset is the measured density of geometrically necessary dislocations. 


\subsection{GAS-DEFECT INTERACTIONS IN FUSION MATERIALS}

X.Hu (hux1@ornl.gov), L. Tan, K. Wang, C. P. Massey (University of Tennessee), D. T. Hoelzer, Y. Katoh

\section{OBJECTIVE}

This primary goal of this project is to investigate the gas-defect interactions in iron, tungsten, and $\mathrm{SiC}$, three important fusion materials, through a coordination of experiments and modeling.

\section{SUMMARY}

We have studied the deuterium retention in advanced steels for fusion reactor structural application by capturing the trapping capability of present microstructural features.

\section{PROGRESS AND STATUS}

Deuterium retention in advanced steels for fusion reactor structural application

Reduced activation ferritic-martensitic (RAFM) steels, castable nanostructured alloys (CNA), and oxidedispersion-strengthened (ODS) steels have been developed for fusion reactor structural application with improved mechanical properties and radiation resistance. However, hydrogen isotope retention in these steels is not well understood. In this study, $10 \mathrm{keV} \mathrm{D}_{2}$ was implanted at room temperature in six steels, along with pure iron and alloy T91 as references. Subsequent thermal desorption spectroscopy (TDS) measurements were used to investigate the deuterium retention. Possible deuterium trapping sites in the materials were evaluated in coordination with available microstructural information. The results indicated that ODS-steels have the largest deuterium retention, almost one order of magnitude higher than that of pure iron, $\sim 6$ times that of RAFM, and 2 4 times that of CNA steels. The difference in nanoparticle and grain/lath boundary concentrations are primarily responsible for the different deuterium retention, while other trapping sites (e.g., vacancy clusters, dislocations, etc.) are present. Deuterium retention increases with increasing sink strength in these materials, although they are not linear correlated, as shown in Figure 33.

\section{FUTURE PLANS}

Future effort will concentrate on evaluating the gas trapping capability of nanoparticles in advanced steels. 


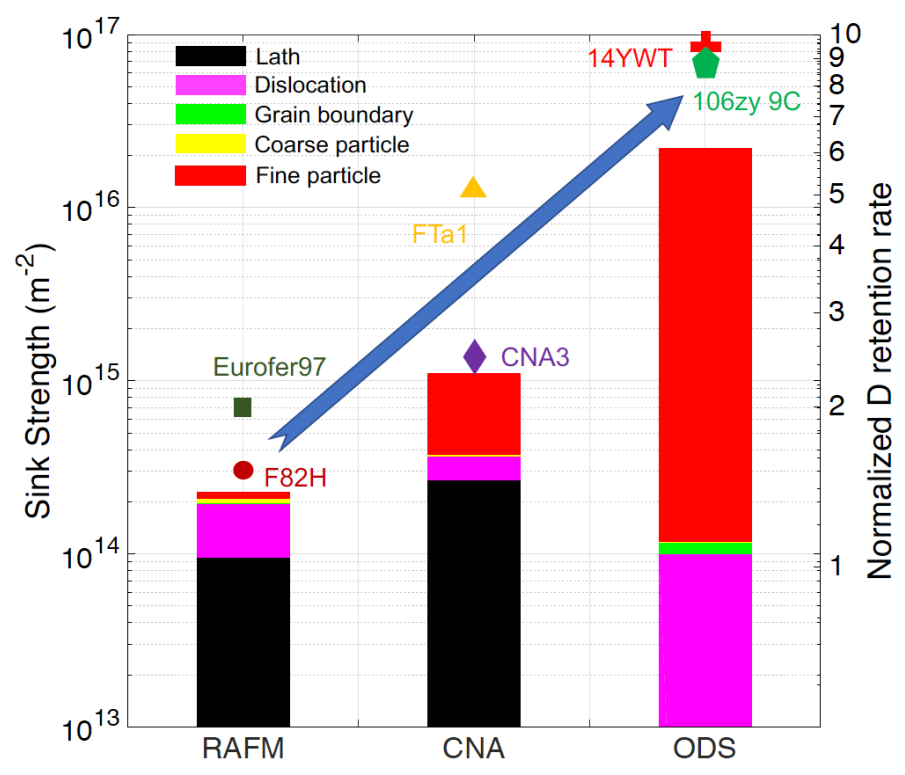

Figure 33. Sink strength of RAFM, CNA, ODS steels (bar plot) and normalized deuterium retention rate (normalized to that of pure iron) of the six steels (scattered data points with right $y$-axis). The individual sink strength of various microstructural features is also shown (left axis). The arrow shown in the figure is included as a guide to the eyes. 


\subsection{HIGH-HEAT FLUX TESTING OF FUSION MATERIALS}

\section{A.S.Sabau (sabaua@ornl.gov), R.B.Dinwiddie, K. Tokunaga (U. Kyushu, Japan), Y. Katoh}

\section{OBJECTIVE}

The objective of this work is high-heat flux testing (HHFT) of irradiated materials for plasma facing components and of mock-up divertor components using Plasma Arc Lamps (PAL). This will provide basic materials property information and constitutive equations for materials behavior in the harsh fusion environment.

\section{SUMMARY}

Effort in FY 2018 was mainly focused on three areas: (a) installation of a new reflector to increase the heat flux to its maximum achievable for the maximum arc temperature of the Plasma Arc Lamp, (b) HHFT of W specimens to obtain optimum testing cycle parameters to reach target temperatures at 5 $\mathrm{MW} / \mathrm{m}^{2}$ heat flux, and (c) demonstration of the facility readiness for testing irradiated materials.

\section{PROGRESS AND STATUS}

\section{Installation of the new reflector}

Following the successful installation of the new reflector, several positions of the specimen with respect to the top surface of the quartz dome and reflector surface shapes were investigated by Mattson Technologies Inc. to maximize the heat flux for our high-heat flux testing. The calculated incident heat flux from the new line-focus reflector is shown in Figure 34, together with the measured data for incident heat flux provided by the uniform heat flux reflector. It was found that the best configuration for the current HHFT project is the case in which the test section is contained in a quartz dome. The maximum heat flux for that optimum configuration was estimated to $12 \mathrm{MW} / \mathrm{m}^{2}$.

The measured incident heat flux at various operating currents is shown in Figure 35 for the old reflector and the new reflector (with the extension). The absorbed heat flux into $\mathrm{W}$ from the new PAL line-focus reflector and old uniform heat-flux reflector was estimated by assuming an emissivity of the W surface of 0.47 .

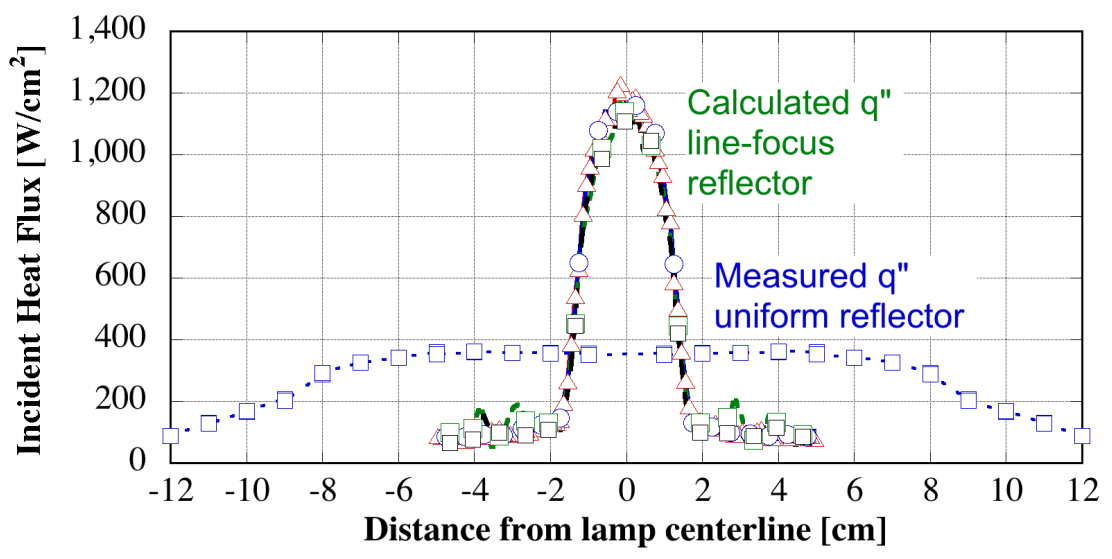

Figure 34. Incident heat flux from the plasma-arc lamp: numerical simulation results for new, linefocus reflector, and measured data for old uniform heat-flux reflector. 


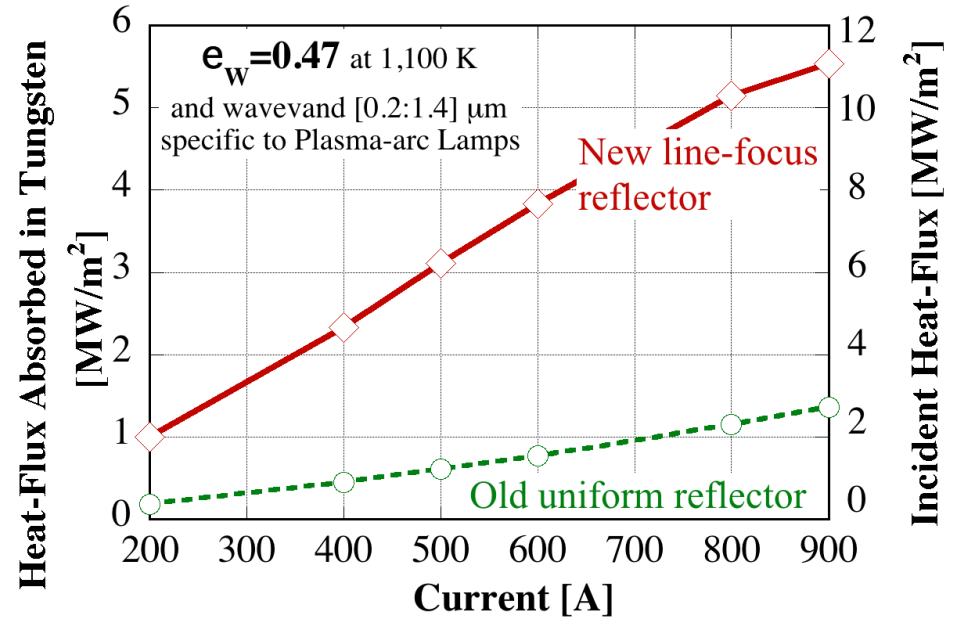

Figure 35. Measured incident heat flux and estimated absorbed heat flux into $W$ from the new PAL line-focus reflector and old uniform heat-flux reflector.

\section{HHFT of $W$ specimens to obtain optimum testing cycle parameters}

The first major roadblock in conducting HHFT at the very high heat fluxes was overheating of the specimen holding and clamping mechanism. A grafoil sheet was placed between the clamp and $\mathrm{Cu}$ cooling rod (actually the $\mathrm{Cu}$ washer), in order to eliminate the gap between the clamp and $\mathrm{Cu}$ changing the heat transfer mode on the back side of the clamp from radiation to conduction, dramatically reducing the clamp temperatures. The temperatures measured by the thermocouples will be used to obtain surface temperature of the specimen.

The second roadblock in the HHFT with PAL is difficulty in measuring the surface temperature due to limited line of sight from the area surrounding the reflector to the specimen surface. To solve this problem, the new reflector was designed with holes in its side walls to allow the external mounting of a pyrometer with direct line of sight to the specimen, enabling the direct measurement the specimen temperature.

The first step in using the pyrometer was to estimate the emissivity at which the pyrometer has to be set. Data on optical properties of $\mathrm{W}$ and spectral response of the pyrometer was used to obtain the emissivity at the working wavelength of the pyrometer. The calculated emissivity of $\mathrm{W}$ was estimated to be between 0.24 and 0.26 , consistent with PAL experiments.

Temperature measurements during HHFT have shown that the pyrometer signal is affected by the PAL IR emission (Figure 36b), even though the pyrometer operating wavelength is outside of the operating PAL spectrum. Apparently, the PAL emits insignificant IR energy at wavelengths larger than 1.4 microns, while the pyrometer operates at a waveband from $1.45 \mathrm{um}$ to $1.7 \mathrm{um}$. Thus, in order to eliminate the IR reflection to the pyrometer, PAL was turned off only for a brief period of time, e.g., 20-30 s, while maintaining the same idle period between HHF cycles of $70 \mathrm{~s}$ (Figure 36a). It was not possible to turn off PAL right at the very moment when HHF ended, thus the pyrometer data would still be affected for the first 1 to 3 seconds after PAL shut-down by the IR artifact light from PAL. However, for the entire duration of the shut-down, the pyrometer temperature is not affected by the IR artifact and its accuracy is determined only by emissivity value. Based on experience from laser-flash measurements with a similar setup (i.e., high-heat flux exposure and temperature measurement with thermocouples from below), one criterion for proofing the pyrometer temperature measurement is the agreement between the slopes of the 
temperature curves obtained with the pyrometer and thermocouples after the initial drop in the surface temperature. In Figure 36b, the pyrometer temperature is shown with solid blue circles. The temperatures measured with thermocouples inserted below the specimen (T_s_cuL, T_s_cuR) and below the $\mathrm{Cu}$ washer (T_cu_washer) are also shown in Figure 36b. Over this temperature range between $94 \mathrm{sec}$ to $100 \mathrm{sec}$ (Figure 36b), the slopes of the temperature curves obtained with the pyrometer and thermocouples are almost identical, demonstrating that a pyrometer emissivity of 0.25 is appropriate. The fact that this result for a pyrometer emissivity of 0.25 , which is between theoretical estimated value between 0.24 and 0.26 , is another strong validation of the direct temperature measurement using the pyrometer.

Once the temperature measurement was demonstrated, HHFT experiments were conducted using PAL operating at incident heat fluxes of $10.95 \mathrm{MW} / \mathrm{m}^{2}$ and $11.86 \mathrm{MW} / \mathrm{m}^{2}$. The corresponding heat fluxes absorbed in $\mathrm{W}$ were estimated to be 5.15 and $5.57 \mathrm{MW} / \mathrm{m}^{2}$, respectively. The duration of the HHF was either 1, 2, or $3 \mathrm{sec}$, with the off-time between cycles $70 \mathrm{sec}$. At incident heat fluxes of $10.95 \mathrm{MW} / \mathrm{m}^{2}$, the maximum surface temperature was approximately 800 and $1,050^{\circ} \mathrm{C}$ for $\mathrm{HHF}$ duration of 2 and $3 \mathrm{sec}$, respectively, as shown in Figure 36b. Increasing the incident heat flux to $11.86 \mathrm{MW} / \mathrm{m}^{2}$ for $2 \mathrm{~s}$ resulted in lower temperatures than for $3 \mathrm{~s}$ exposure at lower heat flux of $10.95 \mathrm{MW} / \mathrm{m}^{2}$. For the current specimen mounting, $11.86 \mathrm{MW} / \mathrm{m}^{2}$ for $3 \mathrm{~s}$ would not be sustainable, limited by the heat transfer in the entire test section. Thus, the following HHFT cycle parameters were found to be appropriate to attain the target temperatures of 900 to $1,200^{\circ} \mathrm{C}$ for the PHENIX project: cycle duration 2-3 sec and off-time between cycles $60-80 \mathrm{sec}$.
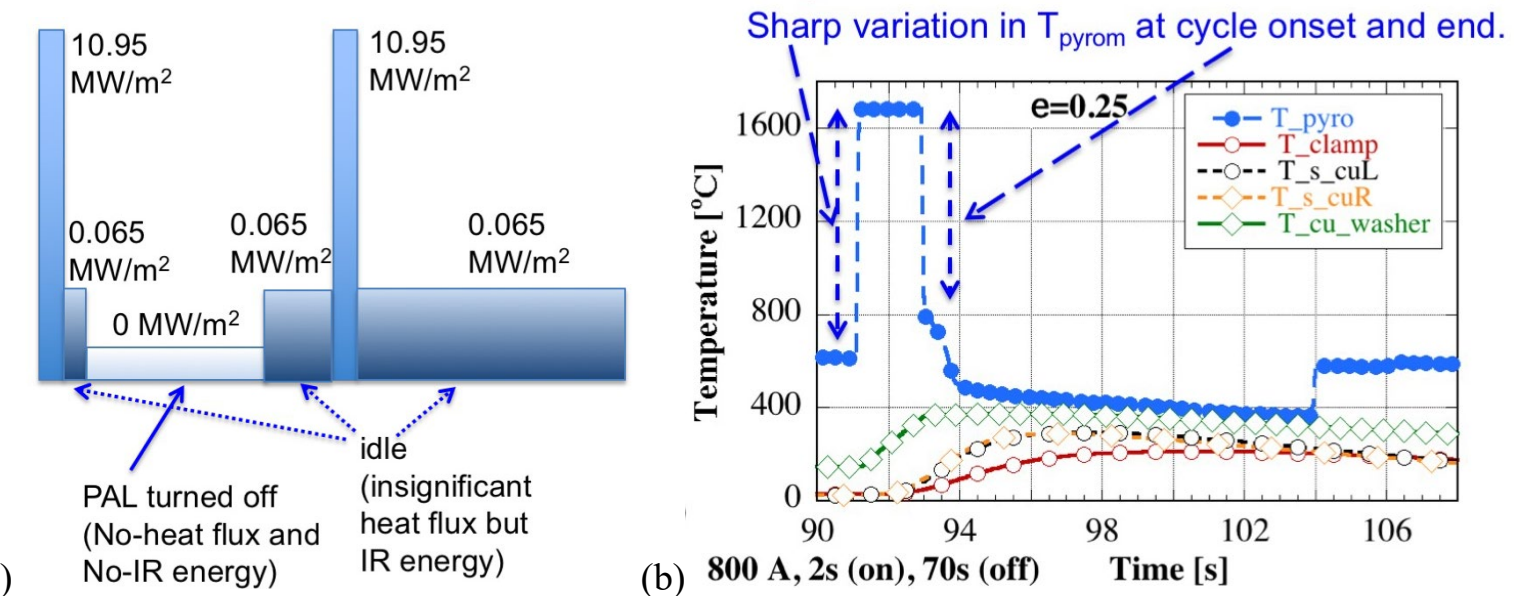

(a)

(b)

$800 \mathrm{~A}, 2 \mathrm{~s}(\mathrm{on}), 70 \mathrm{~s}$ (off) $\quad$ Time [s]

Figure 36. Heat flux evolution during HHFT and measured temperature: (a) control PAL shutdown with regular HHFT cycle and (b) temperature data (PAL shut-down after HHF ended).

\section{Demonstration of the facility readiness for irradiated materials}

The facility readiness was demonstrating by testing three specimens to more than 900 HHFT cycles for each specimen. The tests were run with incident heat flux of 9.7 to $11.8 \mathrm{MW} / \mathrm{m}^{2}$, Absorbed flux of 4.5 to $5.5 \mathrm{MW} / \mathrm{m}^{2}$.

\section{FUTURE PLANS}

Efforts are now focused on high-heat flux testing for the joint US/Japan PHENIX program: (1) finishing the HHFT of baseline, non-irradiated specimens, (2) HHFT of irradiated specimens, and (3) understanding deformation during HHFT using thermo-mechanical simulation of the tests. 


\subsection{HIGH HEAT FLUX TESTING OF NEUTRON IRRADIATED TUNGSTEN}

L.M. Garrison (garrisonlm@ornl.gov),B. Gregory, A. Sabau, M. Akiyoshi (Osaka Prefecture University)

\section{OBJECTIVE}

The aim of this work is to understand how neutron irradiation and high heat flux loading change the morphology and properties of tungsten.

\section{SUMMARY}

Task 1 of the PHENIX US-Japan collaboration is to investigate high heat flux (HHF) effects on neutron irradiated tungsten. Tungsten materials with two different orientations were irradiated for Task 1 as part of the HFIR RB*19J irradiation capsule. The goal of the experiment is to measure how the surface morphology and thermal diffusivity of the unirradiated and irradiated materials change after HHF exposure in the Plasma Arc Lamp (PAL) facility. This procedure has been completed on three unirradiated samples. The SEM and thermal diffusivity measurements have been completed on the asirradiated materials; these samples are now being prepared for PAL exposure.

\section{PROGRESS AND STATUS}

Four tungsten materials selected for HHF testing are listed in Table 5. Samples A000, 9000, 5001, and 4000 from the nominally $500^{\circ} \mathrm{C}$ zone of the RB*19J (PHENIX) irradiation capsule were used in the first PAL tests. They were examined in the SEM and thermal diffusivity measured.

Table 5. Material types for HHF testing

\begin{tabular}{|c|c|c|}
\hline Material code & Material & Processing \\
\hline $40 \# \#$ & ITER-grade W & Rolled // \\
$50 \# \#$ & ITER-grade W & Rolled $\perp$ \\
$90 \# \#$ & K-doped W-3Re & Rolled // \\
A0\#\# & K-doped W-3Re & Rolled $\perp$ \\
\hline
\end{tabular}

Figure 37 shows the surface of unirradiated K-doped W-3Re sample A00C in the as-polished state before HHF. Scratches left from polishing cover the surface and there are additional pits and raised regions. The grain boundaries cannot be seen. The same type of material, K-doped W-3Re, was imaged after neutron irradiation (Figure 38). The sample A000 was irradiated in the nominally $500^{\circ} \mathrm{C}$ capsule of the PHENIX capsule, so experienced temperatures in the range $\sim 400-600^{\circ} \mathrm{C}$. Samples in the capsule, were separated by graphite spacers. Once the capsule was disassembled, the samples were ultrasonically cleaned in LAMDA, but did not have any additional polishing before the images in Figure 38 were acquired. The contrast of the images in Figure 38 are less than in Figure 37, but the condition of the surface is similar. The striations left from the before-irradiation polishing are still visible. 

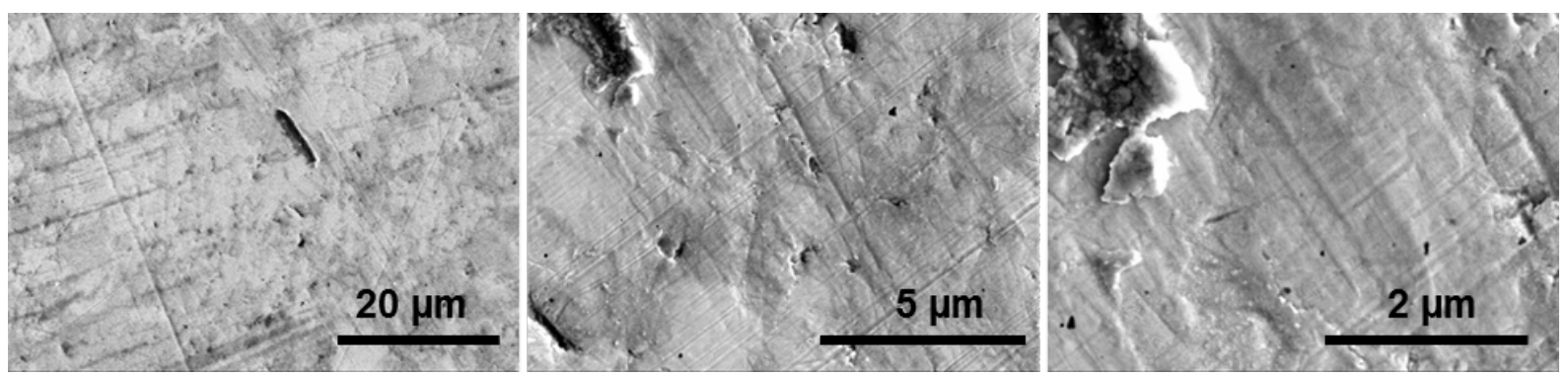

Figure 37. Images of as-polished, unirradiated K-doped W-3Re sample A00C.
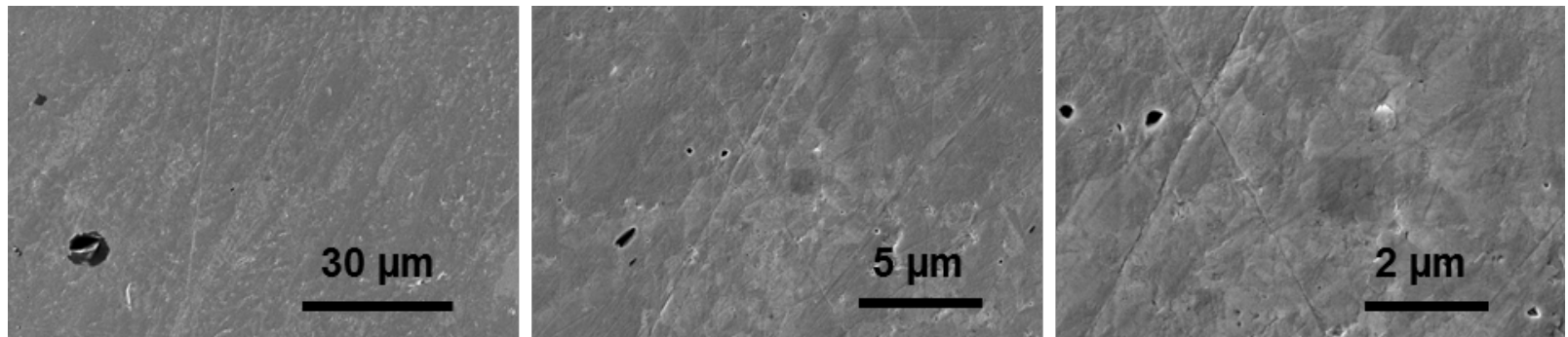

Figure 38. K-doped W-3Re sample A000 after neutron irradiation and before HHF exposure.

\section{FUTURE PLANS}

The unirradiated sample PAL exposures are now complete and SEM examination is ongoing. The irradiated samples are being prepared for PAL testing and will HHF tested after all the unirradiated tests are complete. 


\title{
6. LIQUID METAL COMPATIBILITY
}

\subsection{LIQUID METAL COMPATIBILITY IN FLOWING SYSTEMS}

\author{
B.A.Pint (pintba@ornl.gov) and J.Jun
}

\section{OBJECTIVE}

This task is investigating the possibility of increasing the Pb-Li temperature in the dual coolant leadlithium (DCLL) blanket concept in order to improve the overall system efficiency. Alloys based on $\mathrm{FeCrAl}$ are potential candidates and monometallic thermal convection loops of a commercial FeCrAl alloy are being built and operated to establish a maximum operating temperature for operation in flowing eutectic $\mathrm{Pb}$-Li.

\section{SUMMARY}

A series of monometallic thermal convection loops (TCLs) fabricated using dispersion strengthened $\mathrm{FeCrAl}$ (Kanthal APMT, Fe-21Cr-5Al-3Mo) tubing are being operated for $1000 \mathrm{~h}$ with increasing peak temperatures. The third TCL with a peak temperature of $650^{\circ} \pm 1.5^{\circ} \mathrm{C}$ was completed in FY17 and the $\mathrm{Pb}-\mathrm{Li}$ exposed specimens were characterized using a range of techniques including analytical transmission electron microscopy (TEM), x-ray diffraction and glow discharge optical emission spectroscopy (GDOES). Interestingly, bare APMT specimens formed $\alpha-\mathrm{LiAlO}_{2}$ while the $\alpha-\mathrm{Al}_{2} \mathrm{O}_{3}$ formed on pre-oxidized APMT partially transformed to $\gamma-\mathrm{LiAlO}_{2}$. Only minor changes in the tensile properties occurred for specimens exposed to the third loop at $550-650^{\circ} \mathrm{C}$.

\section{PROGRESS AND STATUS}

To assess $\mathrm{Pb}$-Li compatibility, a series of monometallic thermal convection loops (TCLs) are being operated using APMT, which is commercially available in tubing form. The first loop operated in 2014 for $1000 \mathrm{~h}$ with a maximum temperature of $550^{\circ} \mathrm{C}$ and the second loop operated for $1000 \mathrm{~h}$ in 2016 with a maximum temperature of $600^{\circ} \mathrm{C}$. The third loop completed $1000 \mathrm{~h}$ in October 2017. In each case, the hot and cold legs of the TCL each contained a chain of 20 APMT coupon and tensile ( $25 \mathrm{~mm}$ long SS-3 type) specimens that were characterized for mass change, reaction products and room temperature tensile properties. No significant degradation in ductility or yield strength was observed after exposure in the $650^{\circ} \mathrm{C}$ TCL. From the mass change data in Figure 39 it is clear that most of the specimens in both the hot and cold legs in each TCL lost mass but the specimens that were not pre-oxidized lost more mass. Presumably, the pre-formed alumina layer prevented rapid dissolution that occurred on the bare APMT specimens. Characterization of the reaction products found that bare APMT specimens eventually formed $\alpha-\mathrm{LiAlO}_{2}$ and some pitting occurred which explained the mass losses. The $\alpha-\mathrm{LiAlO}_{2}$ layer tended to show good adhesion after $\mathrm{Pb}-\mathrm{Li}$ removal and cleaning. However, the $\alpha-\mathrm{Al}_{2} \mathrm{O}_{3}$ formed on pre-oxidized APMT was not as adherent. Furthermore, x-ray diffraction results indicated the formation of $\gamma-\mathrm{LiAlO}_{2}$. To further study this evolution, TEM was used to study the microstructure of thin reaction products. Figure 40 shows images of the pre-oxidized scale and after exposure to $\mathrm{Pb}-\mathrm{Li}$ for $1,000 \mathrm{~h}$ at $650^{\circ} \mathrm{C}$. The partial transformation to $\gamma-\mathrm{LiAlO}_{2}$ resulted in a volume increase (thicker scale) that may make the scale more prone to spallation. The GDOES results indicated that Li penetrated into the substrate up to $50 \mu \mathrm{m}$ with or without pre-oxidation. 


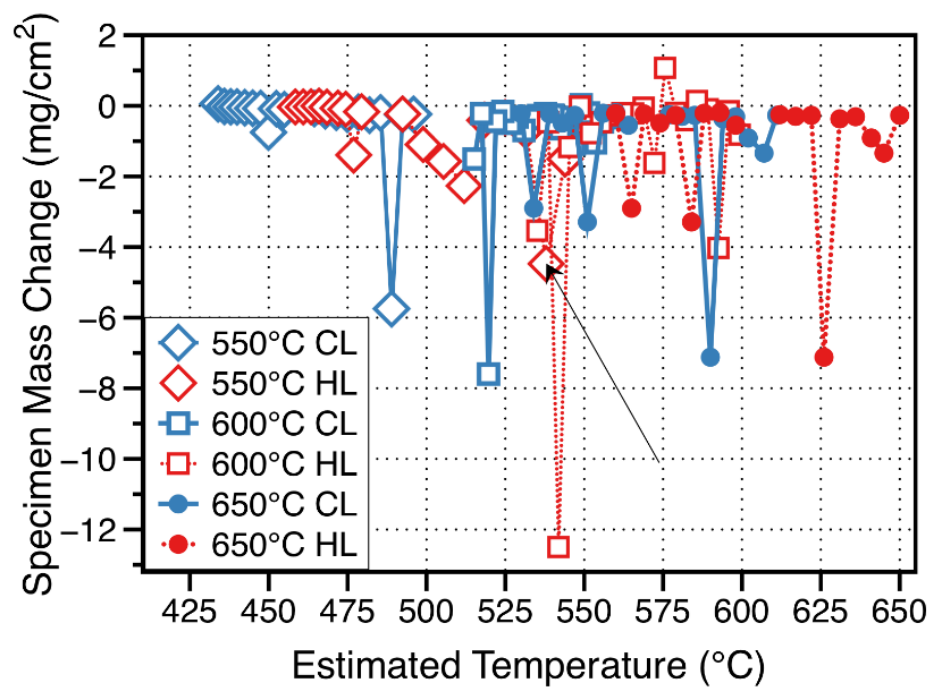

Figure 39. Specimen mass change of APMT specimens in three TCL experiments as a function of estimated temperature in the flowing $\mathrm{Pb}-\mathrm{Li}$ after $1,000 \mathrm{~h}$ exposures. Higher mass losses were typically observed for specimens that were not pre-oxidized prior to exposure.

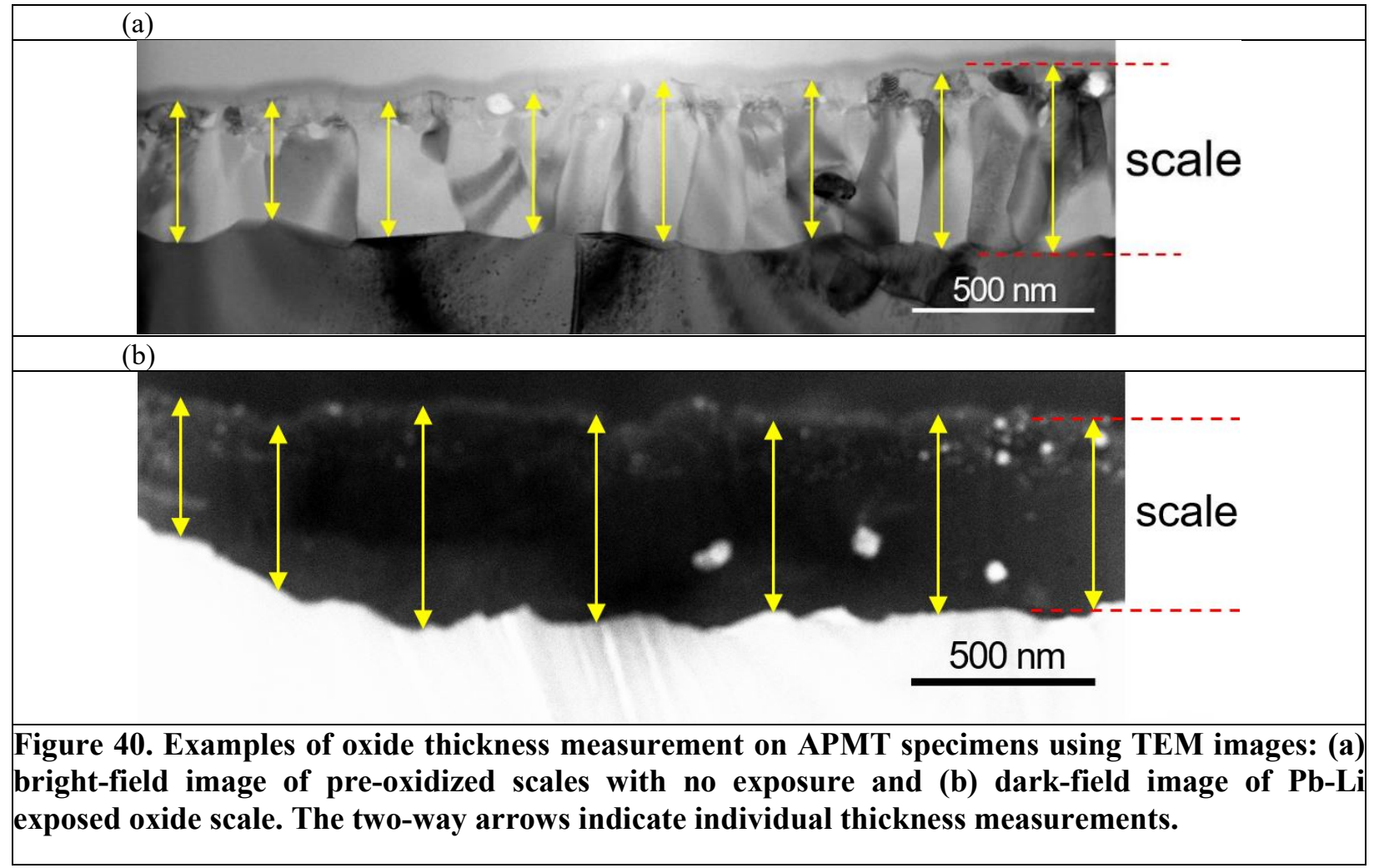

\section{FUTURE PLANS}

A fourth APMT thermal convection loop is being fabricated to operate with a peak temperature of $700^{\circ} \mathrm{C}$ and planned operation will begin in early 2019. 


\subsection{LIQUID METAL COMPATIBILITY IN STATIC Li, Sn AND Sn-Li}

\section{B.A.Pint (pintba@ornl.gov) and J.Jun}

\section{OBJECTIVE}

This task is providing an initial evaluation of the maximum use temperature for structural steel compatibility with liquid $\mathrm{Li}, \mathrm{Sn}$ and $\mathrm{Sn}-20 \mathrm{Li}$ and will determine if a thermally grown surface oxide can significantly improve compatibility. For plasma wall applications, Sn and Sn-Li offer much lower vapor pressures than $\mathrm{Li}$ but $\mathrm{Li}$ is known to be compatible at higher temperatures.

\section{SUMMARY}

A set of $1,000 \mathrm{~h}$ isothermal capsule experiments were completed at $400^{\circ} \mathrm{C}$ with $\mathrm{Sn}$ and $\mathrm{Sn}-20 \% \mathrm{Li}$ as well as at $600^{\circ} \mathrm{C}$ in $\mathrm{Li}$ for $\mathrm{F} 82 \mathrm{H}(\mathrm{Fe}-8 \mathrm{Cr}-2 \mathrm{~W})$ and Kanthal APMT (Fe-20Cr-5Al-3Mo) with and without preoxidation to form an external alumina layer. As expected, all of the mass changes in Li were relatively low at $600^{\circ} \mathrm{C}$ and the Li dissolved the alumina layer on APMT. At $400^{\circ} \mathrm{C}$, the $\mathrm{F} 82 \mathrm{H}$ was massively attacked in Sn and Sn-Li while the mass changes were less but still of concern for APMT. The exception was pre-oxidized APMT, which did not show a mass loss in Sn. Pre-oxidation of APMT was not as effective in Sn-Li where the Li attacked the oxide layer. Post-exposure characterization of the specimens was performed.

\section{PROGRESS AND STATUS}

This project is revisiting the concept of a flowing liquid metal barrier to protect the structural materials from the plasma in a fusion reactor. Based on a literature review, $\mathrm{Sn}, \mathrm{Li}$ and $\mathrm{Sn}-20 \mathrm{Li}$ were chosen for an isothermal compatibility assessment of a typical ferritic-martensitic alloy, F82H, and a FeCrAlMo alloy, APMT. The latter alloy was selected as it has been studied extensively in $\mathrm{Pb}-\mathrm{Li}$ and is able to form a very stable, adherent alumina layer, allowing the study of the potential for pre-oxidation to improve compatibility, particularly in $\mathrm{Sn}$. The main differences between $\mathrm{Sn}$ and $\mathrm{Li}$ is that the vapor pressure of $\mathrm{Li}$ is much higher but the compatibility of $\mathrm{Li}$ with steels is reasonable up to $\sim 600^{\circ} \mathrm{C}$. In contrast, $\mathrm{Sn}$ is favored because of its low vapor pressure but it is known to be extremely reactive with Fe-based alloys. Thus, Sn and $\mathrm{Sn}-20 \% \mathrm{Li}$ were evaluated at $400^{\circ} \mathrm{C}$, while the Li capsule experiments were conducted at $600^{\circ} \mathrm{C}$. Figure 41 shows the mass change results of the $1000 \mathrm{~h}$ exposures, all conducted in Mo capsules. Both coupons and $25 \mathrm{~mm}$ long tensile specimens (type SS-3) of APMT were exposed. All of the mass changes were small in Li. Small mass losses were noted for the pre-oxidized APMT specimens as the Li dissolved the alumina layer. In $\mathrm{Sn}$ and $\mathrm{Sn}-\mathrm{Li}$, the $\mathrm{F} 82 \mathrm{H}$ coupons were heavily attacked at $400^{\circ} \mathrm{C}$. The mass loss was less for APMT, which was somewhat surprising. In Sn-Li, pre-oxidation showed some reduction in mass loss, but the oxide was selectively removed leading to attack. The most promising result was for pre-oxidized APMT in Sn where small mass changes were observed, and the Sn did not appear to wet the specimens.

As part of this effort, a liquid metal compatibility literature review is being prepared. One of the best indicators of compatibility is low solubility. However, this data is not always available. Figure 42 shows an example of data available for $\mathrm{Pb}, \mathrm{Li}$ and $\mathrm{Pb}-\mathrm{Li}$. The very high $\mathrm{Ni}$ solubility in $\mathrm{Pb}$ and $\mathrm{Pb}-\mathrm{Li}$ reflects the selective removal of $\mathrm{Ni}$ in those environments. The lower solubility for $\mathrm{Ni}$ and $\mathrm{Cr}$ in $\mathrm{Li}$ results in lower dissolution rates. Similar information is being sought for other systems. 


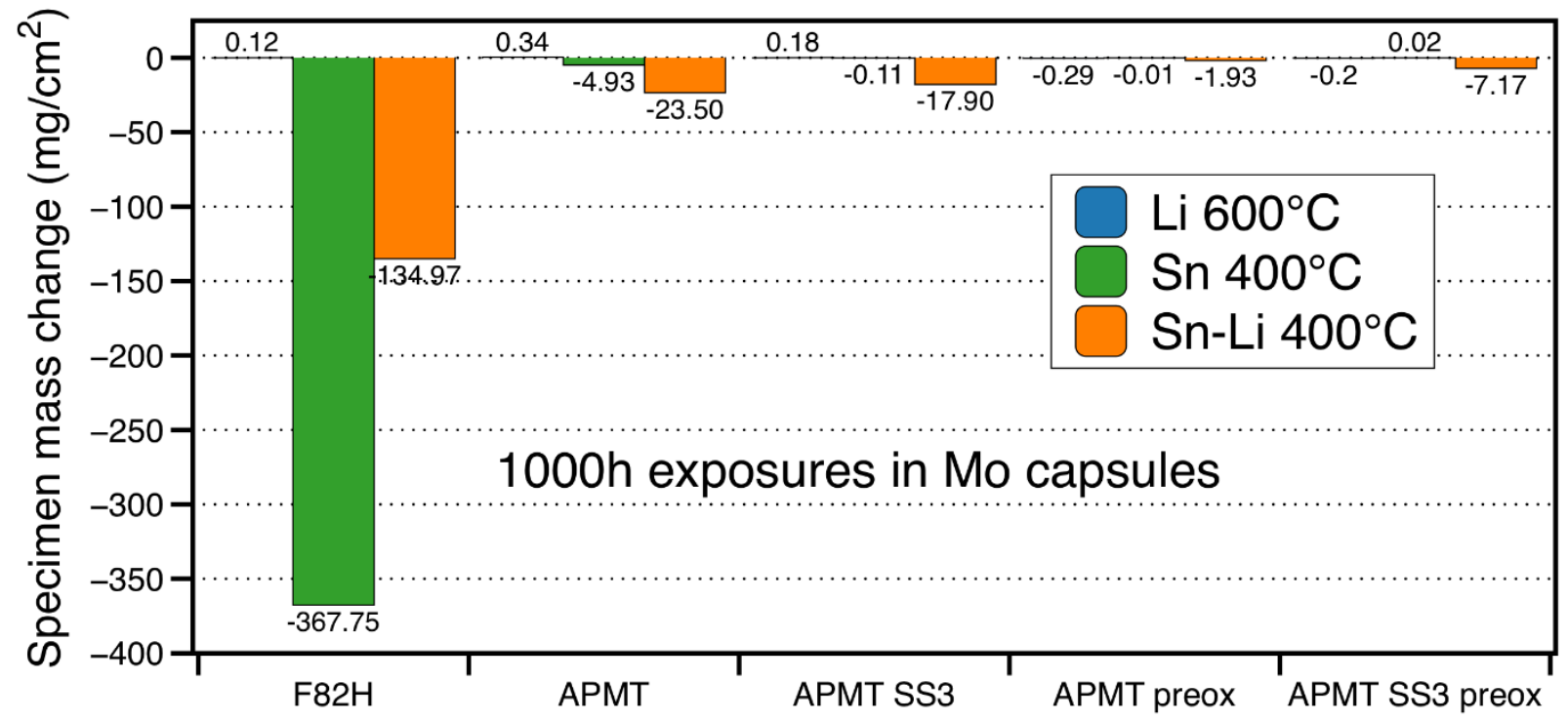

Figure 41. Specimen mass change data for specimens exposed for $1000 \mathrm{~h}$ in isothermal capsule experiments.

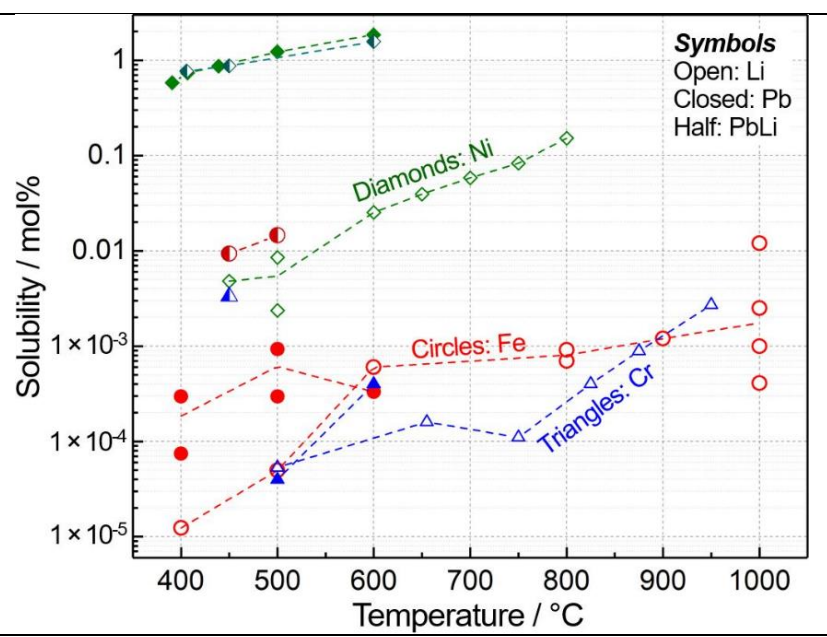

Figure 42. Solubility of $\mathrm{Fe}, \mathrm{Cr}$ and $\mathrm{Ni}$ in liquid $\mathrm{Li}, \mathrm{Pb}$ and $\mathrm{PbLi}$ up to $1000^{\circ} \mathrm{C}$. Dashed lines connect median solubilities.

\section{FUTURE PLANS}

The current task is concluding, and a review paper is being finalized to summarize the experimental findings in the context of the liquid metal literature. Future US-Japan collaborations will continue to study Sn and the use of pre-oxidation to minimize the interaction with Fe-based alloys. 


\section{EXPLORATORY, UNIQUE AND INNOVATIVE MATERIALS}

\subsection{PROPERTIES AND CHARACTERIZATION OF NOVEL COPPER ALLOYS FOR FUSION ENERGY APPLICATIONS}

Ying Yang (yangying@ornl.gov), Ling Wang (University of Tennessee), and Steven J. Zinkle (U T and ORNL)

\section{OBJECTIVE}

This study aims at developing high strength, high conductivity $\mathrm{Cu}$ alloys with improved thermal creep strength for long pulse fusion high heat flux structures, through an accelerated approach of computational thermodynamics guided alloy design.

\section{SUMMARY}

Work performed during the reporting period attempted to reduce or eliminate Sn and Fe contamination from previous batches of $\mathrm{CuCrNbZr}$ alloys, and to evaluate the physical properties, mechanical properties, and microstructure of newly fabricated high-purity $\mathrm{CuCrNbZr}$ alloys.

\section{PROGRESS AND STATUS}

We successfully fabricated and evaluated the mechanical properties, electric resistance and microstructure of a high-purity $\mathrm{CuCrNbZr}\left(\mathrm{CCNZ} \_\mathrm{HP}\right)$ alloy.

By employing high-purity raw elemental materials and refining the protection atmosphere in the casting process, we eliminated the $\mathrm{Fe}$ and $\mathrm{Sn}$ contamination, and retained the designed $\mathrm{Cr}, \mathrm{Nb}$ and $\mathrm{Zr}$ content of the alloys. Confirmed by chemical analysis, the ingot chemistry is in very good agreement with the designed chemistry. The measured electrical conductivity of the CCNZ-HP heat is significantly higher than the $(\mathrm{Fe}+\mathrm{Sn})$-contaminated $\mathrm{CCNZ1}$ heat (76\% IACS vs. 58\% IACS) and slightly lower than that of the reference Kabelmetal-produced $\mathrm{CuCrZr}$ (CCZ) alloy (83.4\% IACS). Tensile and creep properties were measured at various temperatures in air. The yield strength of the CCNZ-HP heat vs temperature is shown in Figure 43 (a), which is on the upper limit of the available $\mathrm{CuCrZr}$ alloys from literature [1]. The creep test at $500^{\circ} \mathrm{C}$ under $90 \mathrm{MPa}$ in air shows the creep life of CCNZ HP heat is about $110 \mathrm{~h}$, which is about one third longer than that of the reference CCZ alloy, as shown in Figure 43(b). Significant oxidation occurred in both alloys during creep tests. Details on fabrication process, electrical resistance measurement, tensile test and creep test can be found in the semiannual report [2].

During the most recent quarter we devoted our effort to characterization of the microstructure of the CCNZ_HP alloy and the reference CCZ alloy and compared the two alloys.

Low and high-magnification optical micrographs of CCZ and CCNZ_HP alloys in the as-received condition are shown in Figure 44(a) (d). The as-received average grain size of CCNZ-HP alloy is $50 \pm 2 \mu \mathrm{m}$ compared to that of CCZ at $55 \pm 8 \mu \mathrm{m}$. Small spherical particles ranging from 1 to $2.5 \mu \mathrm{m}$ were observed in the grain interior and along the grain boundaries in both CCZ and CCNZ-HP alloys. SEM-EDS line scan in Figure 44(e) showed that these spherical shape particles are Cr precipitates. The major difference between the CCZ and the CCNZ-HP alloy is that clustered micron-scale and somewhat faceted precipitates ranging from 2 to $11 \mu \mathrm{m}$ were observed randomly located along grain boundaries in CCNZ-HP alloys. The chemical composition of these large-size precipitates were confirmed to be $\mathrm{Cr}, \mathrm{Nb}$ and $\mathrm{Zr}$ enriched precipitates in Figure 44(f). Based on TEM diffraction patterns, these precipitates correspond to the structure of $\mathrm{C} 14-\mathrm{Cr}_{2}(\mathrm{Nb}, \mathrm{Zr})$ laves phase. Based on thermodynamic calculation [3], 
these large-sized $\mathrm{C} 14-\mathrm{Cr}_{2}(\mathrm{Nb}, \mathrm{Zr})$ laves phase precipitates in the designed alloy is primarily formed from the liquid during solidification.

Microstructures of the CCZ and CCNZ-HP alloys in the tab ends of samples after $500^{\circ} \mathrm{C}$ creep tests (equivalent to thermal annealing at $500^{\circ} \mathrm{C}$ ) are shown in Figure $44(\mathrm{~g})$ (h). Note the creep life for the CCZ alloy is different from the CCNZ-HP alloy, i.e., 79 vs $113 \mathrm{~h}$, meaning the microstructure of the $\mathrm{CCZ}$ alloy shown in Figure $44(\mathrm{~g})$ has a longer annealing time than the CCNZ HP alloy in Figure 44(h). The bcc-Cr particle size in the $\mathrm{CCZ}$ alloy grew from $\sim 5 \mathrm{~nm}$ to $\sim 18 \mathrm{~nm}$, while that in the CCNZ-HP alloy grew from $\sim 5 \mathrm{~nm}$ to $\sim 26 \mathrm{~nm}$. The growth of particles is roughly in proportion to the square root of annealing time, suggesting that the $\mathrm{Nb}$ addition does not significantly change the diffusion kinetics. Vickers hardness of the CCNZ-HP alloy the as-received condition, was 137.9, comparable to the $\mathrm{CCZ}$ at 135.8; after the creep test at $500^{\circ} \mathrm{C}$ and $90 \mathrm{MPa}$, hardness values were reduced to 97 and 103.3, respectively. The greater reduction in the CCNZ alloy hardness is probably due to more coarsening during the longer creep test. Despite the coarser Cr matrix precipitates and reduced hardness (or matrix strength), the CCNZ-HP alloy shows a longer Creep life, which is primarily due to the pinning effect of large Laves$\mathrm{Cr}_{2}(\mathrm{Nb}, \mathrm{Zr})$ precipitates on the grain boundaries.
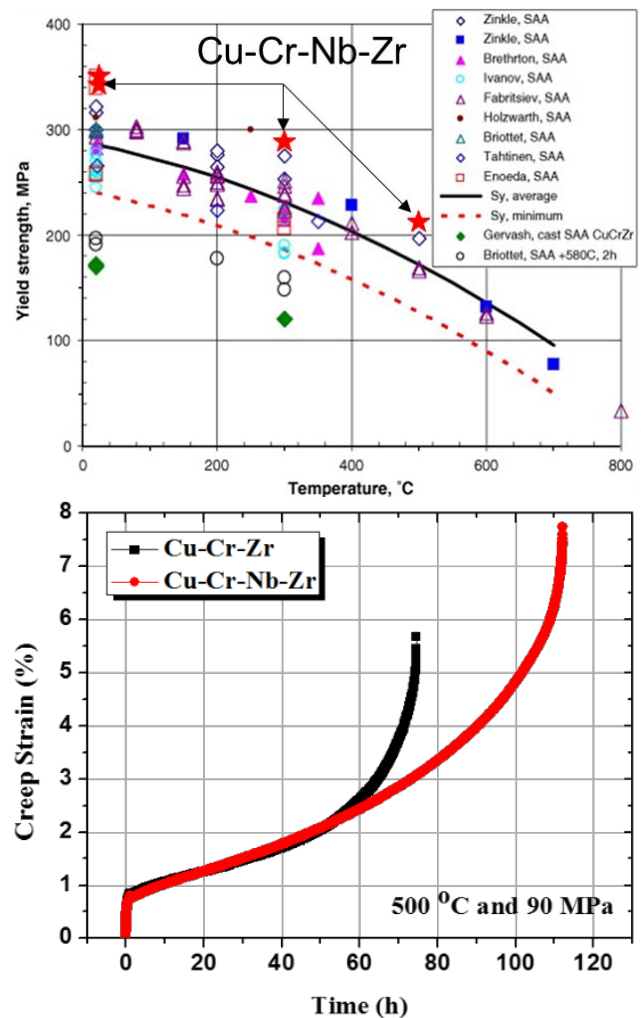

Figure 43. Yield strength (upper) and creep life (lower) of $\mathrm{Cu}-\mathrm{Cr}-\mathrm{Nb}-\mathrm{Zr}$ compared to $\mathrm{Cu}-\mathrm{Cr}-\mathrm{Zr}$ alloy literature values.

\section{FUTURE WORK}

1) Perform systematic creep tests under vacuum or argon protected atmosphere.

2) Fabricate high purity $\mathrm{Cu}-\mathrm{Cr}-\mathrm{Ta}-\mathrm{Zr}$ alloy and evaluate the electrical conductivity, mechanical properties and microstructure.

\section{REFERENCES}

[1] Barabash, V., A. Peacock, S. Fabritsiev, G. Kalinin, S. Zinkle, A. Rowcliffe, J-W. Rensman et al. "Materials challenges for ITER-Current status and future activities," Journal of Nuclear Materials 367 (2007) 21-32.

[2] Ying Yang, Ling Wang, Steven J. Zinkle and Lance Snead, "Properties and characterization of novel copper alloys for fusion energy applications," Section 4.1, pp. 62-65 in Fusion Materials Semiannual Progress Report for the Period Ending June 30, 2018, DOE-ER-0313/64 (Oak Ridge National Laboratory, September 2018)

[3] Y. Yang, L. Wang, L. Snead, S. J. Zinkle, "Development of novel Cu-Cr-Nb-Zr alloys with the aid of computational thermodynamics," Materials \& Design, 156 (2018) 370-380. 

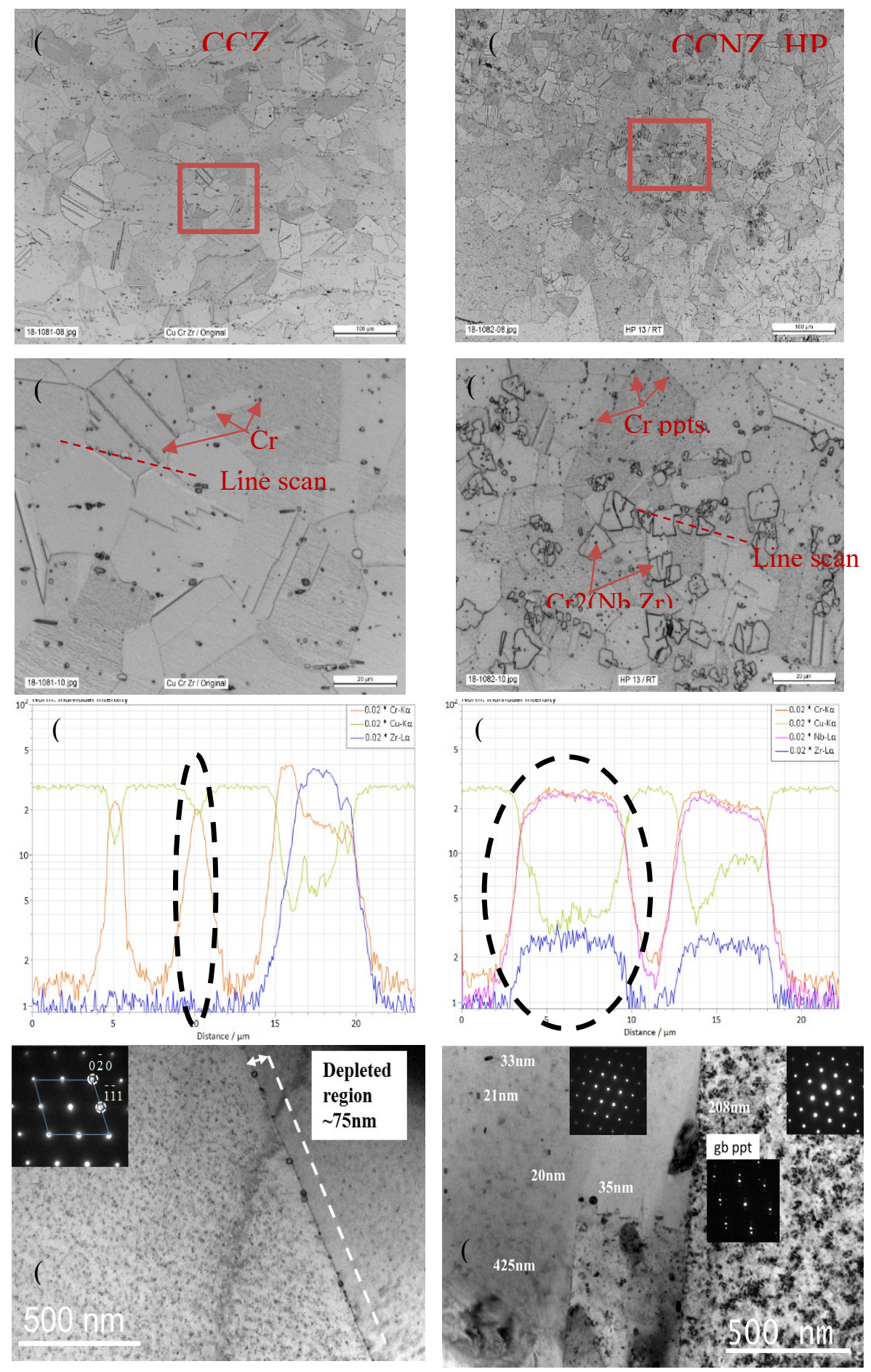

Figure 44. (a)-(b) Low magnification optical image of the CCZ and CCNZ alloys in the as-received condition. (c)-(d) High magnification optical image of the $\mathrm{CCZ}$ and $\mathrm{CCNZ}$ alloys in the as-received condition. (e) SEM-EDS on spherical particles in the CCZ alloy. (f) SEM-EDS on facet particles in the CCNZ alloy. (g) TEM image at the tab location of the creep-tested $\mathrm{CCZ}$ sample at $500^{\circ} \mathrm{C}, 90$ MP for $79 \mathrm{~h}$. (h) TEM image at the tab location of the creep-tested CCNZ sample at $500^{\circ} \mathrm{C}, 90 \mathrm{MP}$ for $113 \mathrm{~h}$. 


\title{
7.2 NEUTRON AND ION IRRADIATION EFFECTS IN 312 AND 211 Ti-BASED MAX PHASES
}

\author{
M. A. Tunes (Univ. Huddersfield, UK) and P. D. Edmondson (edmondsonpd@ornl.gov)
}

\section{OBJECTIVE}

The overarching objective of this work is to develop a fundamental understanding of the microstructural and property response of MAX phase materials to neutron irradiation to investigate their potential application to fusion energy systems.

\section{SUMMARY}

To investigate the potential use of MAX phases as radiation tolerant materials for fusion energy applications, a series of MAX phases have been neutron irradiated in HFIR over a range of temperatures and doses. Property and microstructure evaluations are ongoing to determine the extent and mechanisms of the observed changes in the material. Recently, the focus has been on the microstructural evaluations by Transmission Electron Microscopy (TEM) paying particular attention to the dislocation loop population and cavities.

\section{PROGRESS AND STATUS}

Post-irradiation examination (PIE) has been conducted using TEM on $\mathrm{Ti}_{3} \mathrm{SiC}_{2}$ and $\mathrm{Ti}_{2} \mathrm{AlC}$ MAX phases irradiated at $1273 \mathrm{~K}$ to doses of 2 and 10 displacements per atom (dpa). Additionally, a detailed examination on the unirradiated material has been conducted. The primary focus of the TEM investigations has been on the radiation induced dislocation loop populations, but has also included more general imaging to determine the extent of other damage, e.g. cavities, stacking faults, etc.

The characterization has shown that the neutron-irradiated specimens had a significant population of perfect basal dislocation loops of the <a>-type. Cavities were also observed in the neutron irradiated materials. Dislocation loops and cavities were also observed in the unirradiated materials but at significantly lower number densities (three specimens showed dislocations, only one showed cavities from a total of 17 TEM specimens characterized.) A manuscript describing the results of this study will be submitted to a journal soon.

Another research thrust has been in investigating the possibility of using ion beams as a proxy for neutrons to perform accelerated radiation effects studies. This effort in particular has focused on the use of ion irradiation in situ in a TEM thereby allowing the observation of damage formation and recovery in real time. A preliminary study of the thermal stability of the MAX phases was conducted in situ in the TEM to determine the maximum possible irradiation temperature for in situ experiments. This was done as it is had been observed that thin films of a thickness below $100 \mathrm{~nm}$ (as required for TEM analysis) melt and/or decompose at temperatures well below that of the bulk material. In this case, it was observed that decomposition occurred at a temperature near $973 \mathrm{~K}$. As a result this was chosen as the maximum irradiation temperature for the in situ ion irradiation study.

The in situ irradiations were conducted using the MIAMI-2 facility at the University of Huddersfield, using $700 \mathrm{keV} \mathrm{Kr}^{2+}$ ions. Irradiations were conducted on unirradiated materials, and on MAX phases that had previously been neutron-irradiated to 2 and $10 \mathrm{dpa}$ at $1273 \mathrm{~K}$. Initial results showed no incremental damage produced in the material due to the ion irradiations. It is suspected that the lack of damage production may be as a result of the electronic stopping power, but additional work is required. 


\section{FUTURE PLANS}

Additional in situ ion irradiations are to be conducted using different irradiation conditions.

Further dislocation loop characterization will be conducted on MAX phase specimens neutron-irradiated at lower temperatures. This is of interest as it is in the low irradiation temperature regime where significant swelling has previously been observed, raising the question of any potential differences in dislocation loop populations.

Following the detailed characterization of the low irradiation temperature materials, the same samples will also be heated in situ in the TEM to determine dislocation behavior at elevated temperatures. 


\subsection{EFFECT OF GAMMA IRRADIATION ON SECOND-GENERATION HIGH TEMPERATURE SUPERCONDUCTORS}

P.D.Edmondson (edmondsonpd@ornl.gov)

\section{OBJECTIVE}

The objective of this ongoing task is to evaluate the effects of gamma irradiation on the superconducting properties of second-generation high temperature superconductors (HTS) to explore the possibility of their use in future fusion applications.

\section{SUMMARY}

In order to explore the viability of the use of HTS materials for fusion applications, it is necessary to investigate and understand the effects of radiation on the functional properties of the HTS material. An ongoing campaign is investigating these effects on two second-generation high temperature superconductors based on the yttrium-barium-copper-oxide (YBCO) structure. The results will ultimately determine the potential applicability of YBCO-based HTS for fusion, and will also aid the design of local shielding. A neutron-irradiation campaign previously investigated the effects of particle irradiation; the focus of our current investigations is transitioning to the effects of gamma irradiation.

\section{PROGRESS AND STATUS}

Post-irradiation examination using advanced microscopy techniques (atom probe tomography) continues to be conducted on the samples previously irradiated in the neutron-irradiation campaign. These results are providing detailed data on the local compositional variations - particularly that of the oxygen - that is well known to have a strong effect on the superconducting properties of the material.

An irradiation vehicle has been constructed for irradiation of the HTS material in the gamma irradiation facility (GIF) in the HFIR pool at ORNL. This will expand our knowledge base on this class of HTS of interest for potential fusion applications.

\section{FUTURE PLANS}

A series of gamma irradiations of two second-generation HTS materials will be conducted in FY19, with the primary focus being determining the effects of gamma irradiation on the functional superconductivity. Post-irradiation examination of the microstructure of the materials will also be conducted on select specimens to investigate any microstructural changes that explain any property changes in the HTS materials, and will focus on defect generation and local compositional variations. These results will be compared and contrasted to the previous neutron-irradiation work. 


\section{COMPUTATIONAL MATERIALS SCIENCE}

\subsection{MECHANICAL PROPERTIES AND RADIATION EFFECTS IN MATERIALS FOR FUSION}

\section{Y.Osetskiy(osetskiyyn@ornl.gov)}

\section{OBJECTIVE}

The objective of this task is to obtain a better understanding of the atomic-scale mechanisms operating in fusion materials. Two main groups of effects are under consideration: mechanisms of radiation damage and properties of irradiated materials. The main materials studied are ferritic and stainless steels and tungsten-based alloys.

\section{SUMMARY}

\section{He-effects}

A new mechanism of He effects in radiation damage evolution is suggested. The main idea is that under irradiation He-filled bubbles may reach a strongly over-pressurized state and emit new interstitial atoms that affect microstructure evolution. The conditions when and how interstitial atoms can be emitted by He-bubbles were studied by atomistic modeling. It is demonstrated that interstitial atoms can be emitted as individual atoms as well as large dislocation loops with different Burgers vectors. A journal paper on this study has been.

\section{Mechanical properties}

Comparison of strengthening due to different radiation-induced microstructures was investigated by large-scale atomistic modeling. Voids, He-filled bubbles, $\mathrm{Cu}$-precipitates, and impenetrable obstacles imitating oxide particles, were modeled as obstacles to edge dislocation glide in a bcc Fe matrix. A wide range of model and environmental parameters was tested, including obstacles size and position relatively to the dislocation slip plane, ambient temperature and the dislocation speed. A number of conclusions was formulated, and conditions of maximum possible strengthening are suggested. Journal papers on this work were prepared.

\section{PROGRESS AND STATUS}

\section{Helium effects}

Helium effects in radiation damage evolution have long been observed and studied and the conventional effects include:

- He bubbles formation and accelerating radiation swelling

- He bubbles hardening due to pinning of gliding dislocations.

Analysis of He-bubble stability and interactions with point defects such as vacancy, interstitial atoms and He-atoms lead to the possibility of formation and growth of strongly over-pressurized He bubbles. This phenomenon produces newly considered effects - the role of over-pressurized He bubbles, including:

- Formation of new interstitial components due to bubble mechanical instability

- Formation of new interstitial components due to interactions with dislocations.

Our consideration of these effects showed that: 
- $\quad$ Over-pressurized bubbles are the source of new interstitial damage components - $\quad$ These may reduce the total swelling rate due to additional point defect recombination

- $\quad$ Strengthening due to over-pressurization is stronger than that due to equilibrium bubbles.

Some examples of interstitial loops punching from He bubble are presented in Figure $45.4 \mathrm{~nm}$ bubbles with He-to-vacancy ratio equal to 2 (that is 2891 vacancies and $5782 \mathrm{He}$-atoms) were inserted into a cubic bcc Fe crystal of size $100 \mathrm{a} \times 100 \mathrm{a} \times 100 \mathrm{a}(\mathrm{a}=0.2286 \mathrm{~nm}$ is lattice parameter) containing 2 million lattice sites. The crystal temperature was gradually increased until interstitials were punched out. After punching the configuration was annealed and then quenched for accurate analysis of newly produced microstructures. Note the large number of new interstitial atoms emitted to the bulk, from $\sim 300$ to $\sim 400$ interstitials, and the different crystallography and geometry of punched loops.
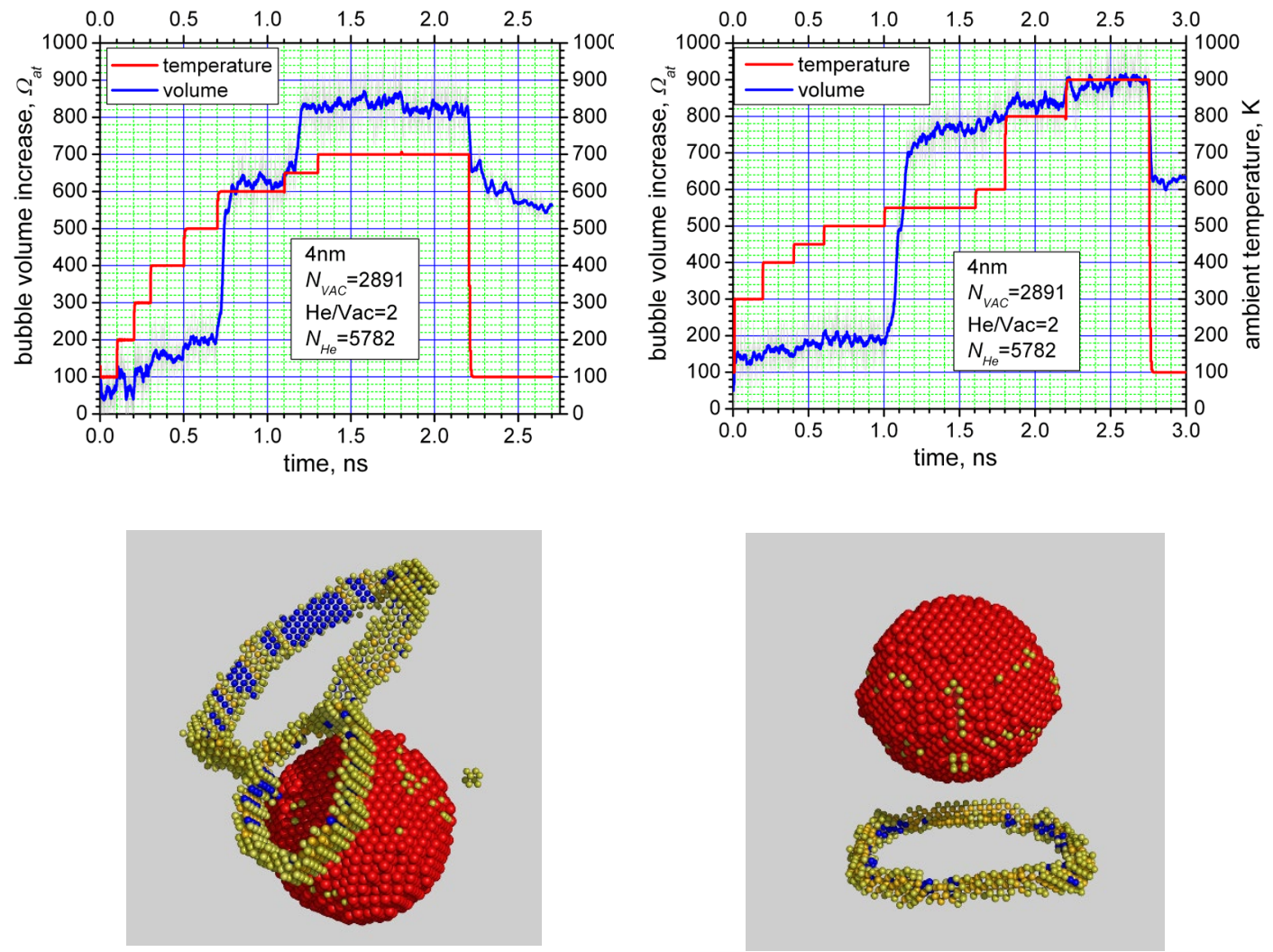

Figure 45. Aging of $4 \mathrm{~nm}$ He-bubble with initial $\mathrm{He} / \mathrm{VAC}=2$ : crystal temperature and bubble volume increase are plotted vs modeling time. Sudden volume increase occurred when bubble emits an interstitial loop. Formation and emitting of loops is a stochastic and random process and loops may have different shape and Burgers vector: Left - two segments of $1 / 2<111>$ loops of $\sim 450$ SIAs, Right $-<\mathbf{1 0 0}>$ loop of $\sim 530$ SIAs. This modeling is suggested for comparison with targeted in situ TEM experiments.

Another result of the high helium pressure is that additional interstitial components may appear due to interaction between gliding dislocations and the over-pressurized bubbles, depicted in Figure 46. 


\section{Mechanical properties}

Voids, He-filled bubbles, Cu-precipitates and impenetrable obstacles, imitating oxide particles, were modelled as obstacles to an edge dislocation glide in bcc Fe matrix. Large-scale atomistic approach considered up to $8 \mathrm{~nm}$ spherical obstacles modelled in up to $\sim 10$ million atoms systems over up to $\sim 30 \mathrm{~ns}$ time with dislocations moving down to $\sim 0.1 \mathrm{~m} / \mathrm{s}$ velocities. A number of conclusions was formulated, and conditions of maximum possible strengthening are suggested. Particular effect of dislocation-obstacle geometry is demonstrated in Figure 47 for the case of impenetrable, rigid inclusions imitating oxide particles embedded into bcc Fe matrix. Draft journal papers on this study was prepared in FY18.
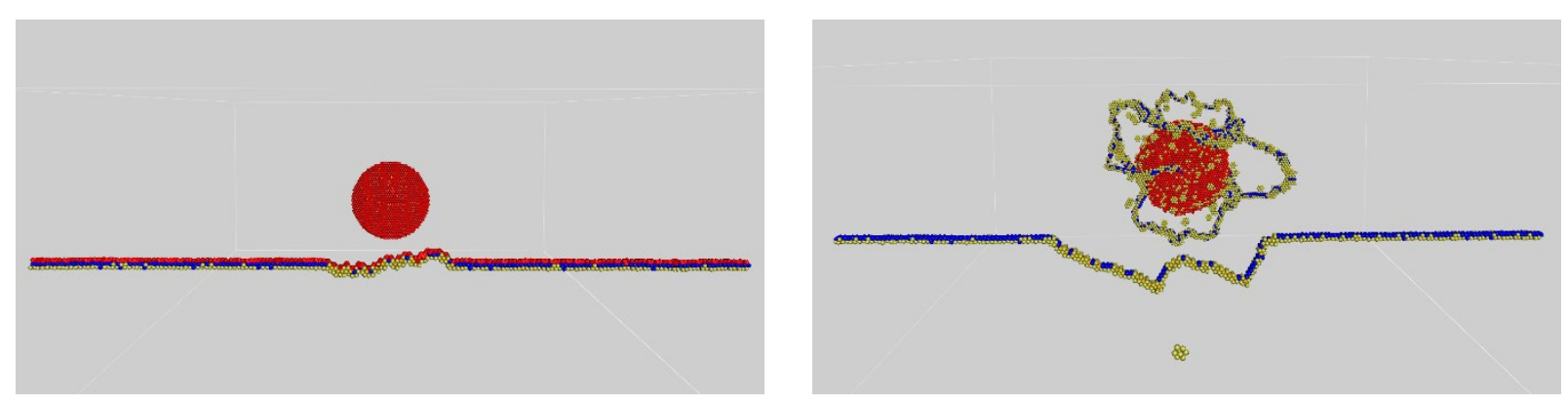

Figure 46. Near equilibrium (left) and over-pressurized (right) bubbles after interaction with a moving $1 / 2<111>$ edge dislocation in bec Fe. Note a significant increase in the total dislocation network after interaction with the over-pressurized bubble.
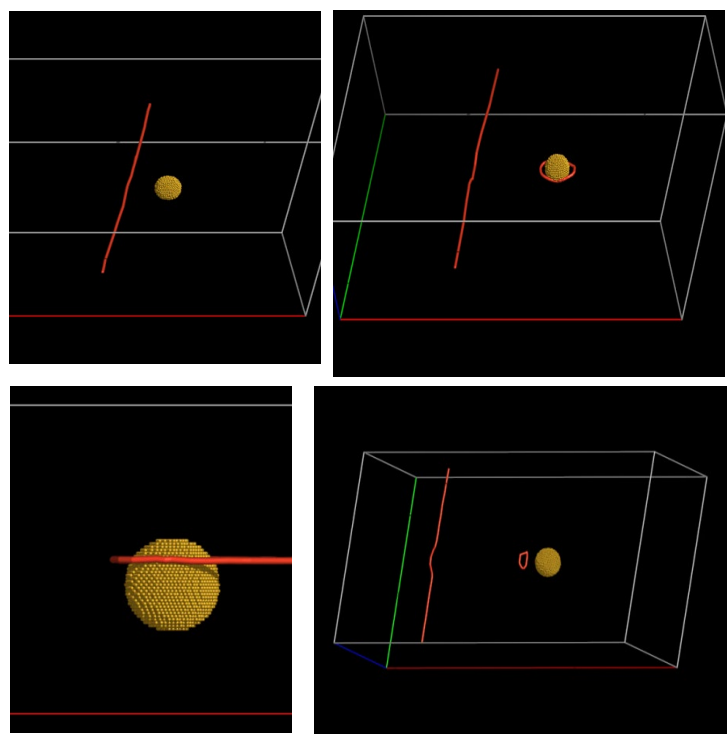

\section{FUTURE PLANS}

Figure 47. Interactions of $1 / 2<111>$ edge dislocation with $6 \mathrm{~nm}$ impenetrable, rigid inclusion for different interaction geometries. Top: dislocation slip plane intersects the inclusion along its equator. Shear Orowan is formed around the inclusion. This geometry results in near the maximum strengthening.

Bottom: dislocation slip plane intersects the inclusion at a half-radius distance above the equator. An interstitial loop and the corresponding superjog on the dislocation line are formed after the interaction.

Note: this interaction is asymmetric - when the dislocation slip plane intersects an inclusion below its equator a vacancy loop is formed and strengthening is weaker than in the above case.

The investigation of He effects and atomic scale mechanisms in irradiated fusion alloys will be extended to $\mathrm{W}$-based materials using the new interatomic potentials to be developed within the SEED money proposal "General framework for the development of predictive atomistic force fields and application to multicomponent alloys." The new atomic-scale mechanisms will be implemented into phenomenological and continuum models for predicting materials properties. 


\title{
8.2 ANALYSIS OF PHASE STABILITY OF PRECIPITATES IN TUNGSTEN ALLOYS
}

\author{
G. Samolyuk (samolyukgd@,ornl.gov) and Y. Osetskiy.
}

\section{OBJECTIVE}

The purpose of this research is to understand the phase stability of W-based materials under irradiation conditions. Microstructure features and phenomena such as precipitates, interfaces and their properties and effects on mechanical properties are the primary targets. The main methods applied are density functional theory (DFT) base modeling of microstructures and low-scale properties combined with atomistic modeling, depending on the available interatomic potentials

\section{SUMMARY}

The research on phase stability of W-based materials under irradiation conditions is in its initial stage. It was observed, that under irradiation conditions resulting in transmutation of $\mathrm{W}$ to Re and Os, precipitates that result are ordered in Laves phase structure with composition $\mathrm{WRe}_{0.6} \mathrm{Os}_{0.4}$ at lower doses and hexagonal structure with composition $\mathrm{ReOs}_{2} \mathrm{~W}$ at higher doses. We applied first principles methods to study energy of hep and $\chi$ optimized structures with composition $\mathrm{ReOs}_{2} \mathrm{~W}$. It was found that the hep structure has lower energy than $\chi$. This result agrees with experimental observations. It illustrated that this result could be understand within a simple virtual crystal approximation (VCA). This contradicts the observations that the ground state of precipitates with composition $\mathrm{WRe}_{0.6} \mathrm{Os}_{0.4}$ corresponds to the $\sigma$ phase. The stability of the $\mathrm{WRe}_{0.6} \mathrm{Os}_{0.4}$ precipitate in Laves phase structure is attributed to kinetic effects due to irradiation.

\section{PROGRESS AND STATUS}

The conventional view of precipitation in irradiated tungsten is that W-Re-Os precipitates in either $\sigma$ - or $\chi$-phases. However, a recent observation [1], found that most probable precipitate structure corresponds to the $\mathrm{Re}_{2} \mathrm{~W}$ Laves phase intermetallic. The actual composition of the precipitate is $\left(\operatorname{Re}_{\mathrm{y}} \mathrm{Os}_{1-\mathrm{y}}\right)_{1-\mathrm{x}} \mathrm{W}$, where $\mathrm{x}$ may be large. This excess $\mathrm{W}$ could be the result of $\mathrm{W}$ atoms or vacancies present in Re-Os sublattices. We are planning to calculate DFT-based formation energies of different type of defects in this phase. These results will be used as an input to the grand canonical formalism [2,3] based calculation of the defects equilibrium concentration as a function of $\mathrm{x}$ and $\mathrm{y}$ and temperature. Going further, this information will be used to investigate the defects influence on the lattice parameters of precipitates and to develop matrix-precipitate interface structure.

The formation energy of different phases in the W-Re-Os system was calculated by a series of DFT [4] calculations. Both volume of the super cell and the position of atoms were optimized. Based on the experimental observations, reported below, we studied the following combinations: hexagonal vs $\chi$ and Laves vs $\sigma$ using the corresponding modeling setup.

Hexagonal vs $\chi$. In current calculation the random solid solutions have been modeled, i.e. $\mathrm{W}, \mathrm{Re}$ and Os atoms were randomly distributed between 96 or 232 possible lattice sites of hexagonal or $\chi-$ structure supercells, respectively, Figure 48.

Laves $\boldsymbol{v s} \boldsymbol{\sigma}$. The Laves and $\sigma$ phases solid solusions were modeled in supercells containing 216 or 240 atoms, respectively, Figure 49. 
According to the results we obtained the hexagonal structure has lower energy by $0.12 \mathrm{eV}$ per atom than the $\chi$ structure. While, it was found that $\sigma$ phase is more stable than Laves by $0.23 \mathrm{eV}$ per atom, this simple thermodynamic approach is not adequate to explain the stability of the Laves phase.
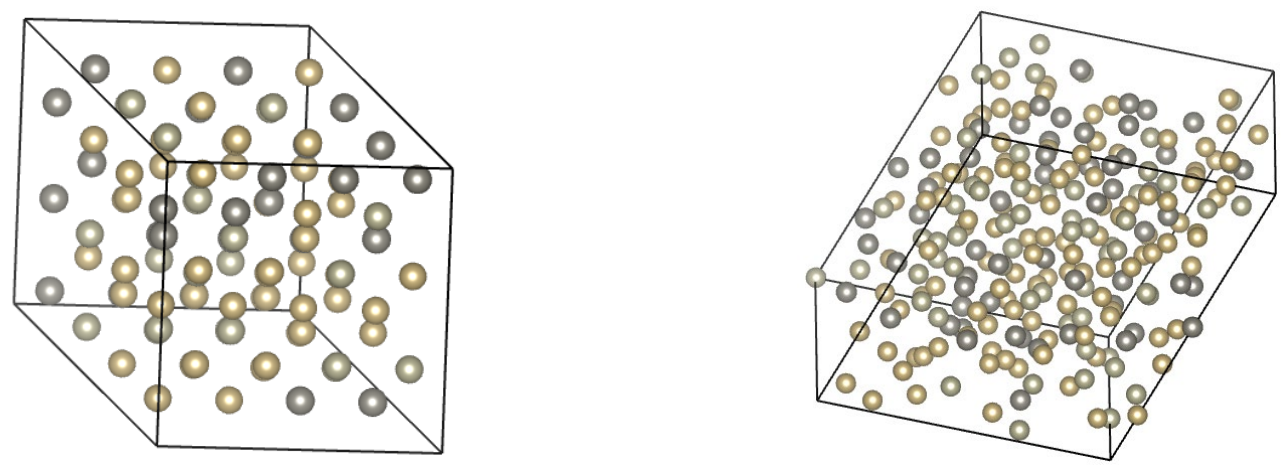

Figure 48. Hexagonal and $\chi-$ structure supercells.
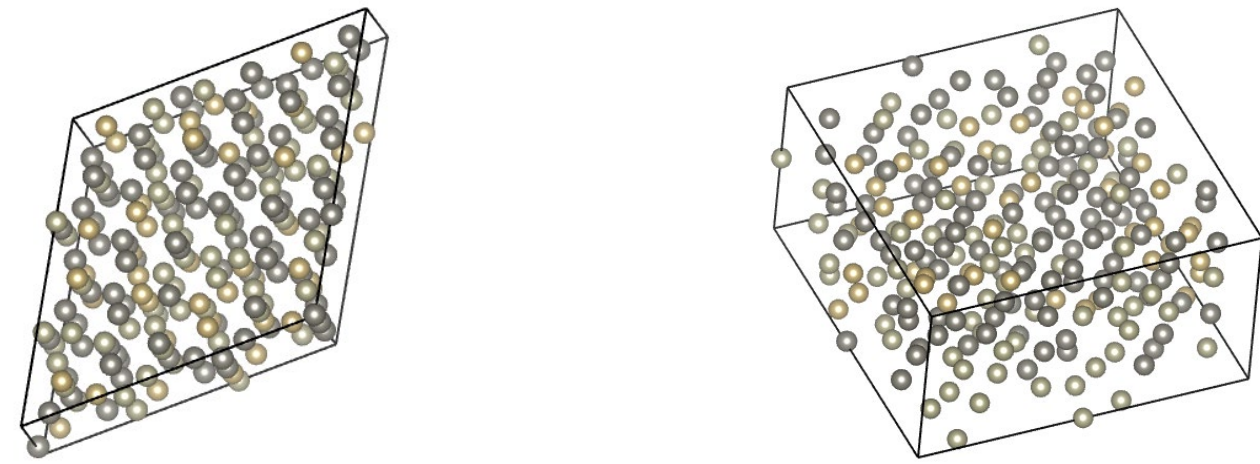

Figure 49. Laves and $\sigma-$ structure supercells.

\section{FUTURE PLANS}

The DFT-based study of phase stability in W-based alloys will be extended to more complicated cases to consider local strain/stress fields and radiation defects. The investigation of phase stability, precipitation and mass transport in $\mathrm{W}$-based materials under irradiation conditions will be extended to larger scale atomistic modeling using the new interatomic potentials to be developed within the SEED money proposal "General framework for the development of predictive atomistic force fields and application to multicomponent alloys."

\section{REFERENCES}

[1.] Chad Parish, unpublished, TMS talk.

[2.] G. D. Samolyuk; B. Ujfalussy; G.M. Stocks; "The distribution alloying elements in alnico 8 and 9 magnets: Site preference of ternary $\mathrm{Ti}, \mathrm{Fe}, \mathrm{Co}$, and $\mathrm{Ni}$ additions in $\mathrm{DO}_{3} \mathrm{Fe}_{3} \mathrm{Al}, \mathrm{Co}_{3} \mathrm{Al}$, and $\mathrm{Ni}_{3} \mathrm{Al}$ based intermetallic phases", J. Appl. Phys., 116 (2014) 173908.

[3.] G. D. Samolyuk; Y. N. Osetsky; "Thermodynamic approach to the stability of multi-phase systems: application to the $\mathrm{Y}_{2} \mathrm{O}_{3}$-Fe system", J. Phys-Cond. Matter, 27 (2015) 305001

[4.] W. Kohn, L. J. Sham, Phys. Rev. 140 (1965) A1133-A1138 


\title{
8.3 THERMODYNAMICS OF COMPLEX MULTI-PHASE FUSION ALLOYS
}

\author{
G. Samolyuk (samolyukgd@ornl.gov) and Y. Osetskiy.
}

\section{OBJECTIVE}

The objective of this task is determining the phase stability and thermodynamic properties of complex multi-phase, multi-component oxide-metal systems, especially ODS steels.

\section{SUMMARY}

Enhancing the preferential adsorption of radiation produced defects at interfaces is one of the most promising approaches to the development of radiation resistant materials. A practical realization of this idea is in oxide-metal systems (OMSs), such as ODS steels. OMSs materials demonstrate both radiation tolerance and improved mechanical properties. We recently proposed a thermodynamic approach to study equilibrium in multiphase systems. We estimate the thermodynamic equilibrium by minimizing the free energy of the whole multiphase system using a limited set of defects and microstructural features for which the properties are calculated by DFT. The initial approach has now been extended and directly includes defects in the interface. The new approach allows investigation of defect concentration as a function of both precipitate volume fraction and size distribution; it also includes the specific orientation of the precipitate-matrix interface.

\section{PROGRESS AND STATUS}

We began this task by considering $\mathrm{Y}_{2} \mathrm{O}_{3}+$ bcc Fe with vacancies in both the $\mathrm{Y}_{2} \mathrm{O}_{3}$ and bcc $\mathrm{Fe}$ phases, $\mathrm{Y}$ substitutions and $\mathrm{O}$ interstitials in $\mathrm{Fe}, \mathrm{Fe}$ impurities and antisite defects in $\mathrm{Y}_{2} \mathrm{O}_{3}$. Special attention is devoted to the role of vacancies in the stability of the $\mathrm{Y}_{2} \mathrm{O}_{3}$ precipitates. We have finished developing the thermodynamic model for multi-phase multi-component systems to study defects equilibrium in complex oxide-metal systems. This thermodynamic model will be extended to include precipitate-matrix interfaces as an additional region, with specific defect properties calculated in the corresponding DFT studies. This allows us to:

- consider specific orientation of the oxide-matrix interface,

- account more precise composition effects, especially down to lower element concentrations,

- consider statistics of the component distributions, and

- include point defects such as vacancies and interstitial atoms in phase stability calculations.

At the current stage the formal part of the new modification related to oxide-matrix interfaces is finished and the project is at the stage of code testing. A draft journal paper on this study has been prepared.

\section{FUTURE PLANS}

The new approach to thermodynamic stability of multi-phase systems will be extended to study defect concentration as a function of both precipitate volume fraction and size distribution and to consider specific orientations of the precipitate-matrix interface. 


\section{INTERNATIONAL COLLABORATIONS}

\subsection{US-JAPAN COLLABORATIONS ON STRUCTURAL MATERIALS}

J.W. Geringer (geringerjw@ornl.gov), X. Cheng, K. Field, Y. Katoh (ORNL), H. Tanigawa, M. Ando, D. Hamaguchi, T. Nozawa, H. Sakasegawa, T. Hirose (QST, Japan),

\section{OBJECTIVE}

This collaboration between the Department of Energy (DOE) and the National Institutes for Quantum and Radiological Science and Technology (QST), Japan jointly pursues activities using the advanced capabilities for materials irradiation and post-irradiated examination at ORNL, especially the HFIR and hot cells. The focus is on ferritic steels and other advanced materials, especially the development of the materials database for the design of facilities beyond ITER. The goals include achieving DEMO-relevant performance data on structural materials neutron irradiated in HFIR to high levels of displacement damage.

\section{SUMMARY}

The DOE-QST collaboration continues to make steady progress in building the materials data bases for the reduced activation ferritic martensitic (RAFM) that include F82H, ODS and Eurofer97 steels and other materials such as nuclear grade $\mathrm{SiC}$ composites and copper alloys. This database on $\mathrm{F} 82 \mathrm{H}$, being developed by QST and ORNL researchers, is being used by QST to predict changes in mechanical performance of $\mathrm{F} 82 \mathrm{H}$ for various components of a DEMO fusion reactor.

\section{PROGRESS AND STATUS}

During FY18 a series of irradiated RAFM steel specimens - designed to evaluate the He effect on the damage mechanisms in the high dose regime (up to $80 \mathrm{dpa}$ ) - have been tested followed by microstructural examination to not only elucidate the mechanical response at varying $\mathrm{He}$ accumulations in the same dose-temperature regime but to also correlate this response to the development of the microstructure including bubble formation and coarsening mechanisms in the alloy.

Other progress includes the investigation of large area mapping of carbide stability and segregation phenomena in Eurofer97 (Figure 50) and ODS steels irradiated up to 72 dpa at 573K using highefficiency Scanning Transmission Electron Microscopy (STEM) Energy Dispersive X-ray Spectroscopy (EDS) techniques. The high-efficiency STEM-EDS evaluation of Eurofer97 is the highest dose specimen advanced microscopy completed in the ORNL LAMDA facility. Similar investigation of F82H variant steels is continuing.

Additional pre-irradiation activities that were accomplished this year include the characterization of fracture toughness of $\mathrm{F} 82 \mathrm{H}$ steels in the T-S orientation. Figure 51 and Figure 52 show the general layout of the test setup and the fixture used in the tests. The tested alloys were F82H-IEA, F82H-Mod3, $\mathrm{F} 82 \mathrm{H}+1.4 \% \mathrm{Ni} 58$ and $\mathrm{F} 82 \mathrm{H}+1.4 \% \mathrm{Ni60}$. These results establish the Master Curve basis for determining the transition temperature shift in the irradiated steel irradiation experiments (JP26-29).

Current HFIR irradiation experiments include the F13-rabbit series housing F82H specimens, the SCFand JCR-rabbit series that includes SiC specimens continue under irradiation. Other planned FMP-rabbit series will contain several materials including RAFM steels, $\mathrm{SiC}$ and $\mathrm{Cu}$ alloys. 


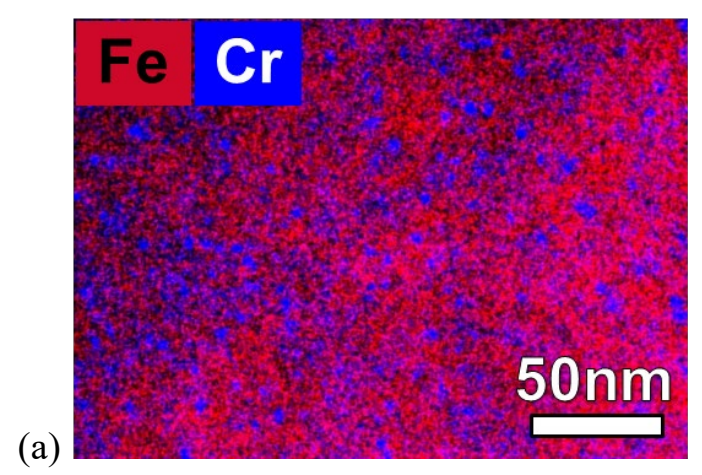

(b)
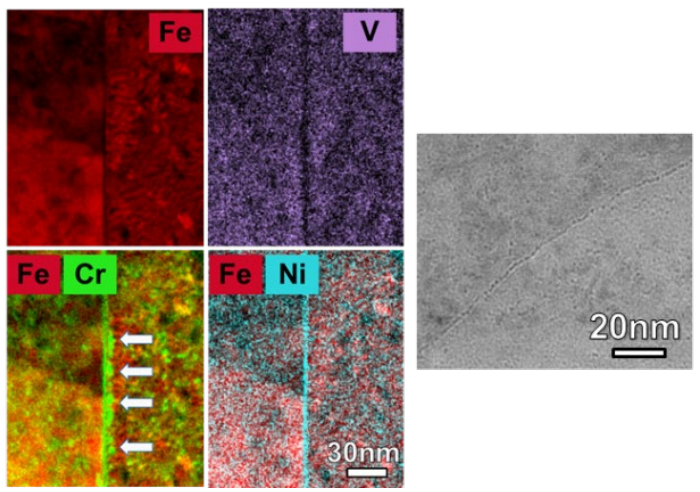

Figure 50. Eurofer97: (a) Cr-rich clusters distributed in the matrix, with an average size of $3.1 \pm 0.8$ $\mathrm{nm}$ and number density of $1.7 \times 10^{23} \mathrm{~m}^{-3}$, (b) Elemental segregation $(\mathrm{Cr}$ and Ni enrichment, $\mathrm{Fe}$ and $\mathrm{V}$ depletion) and helium bubbles were observed at the lath boundaries.

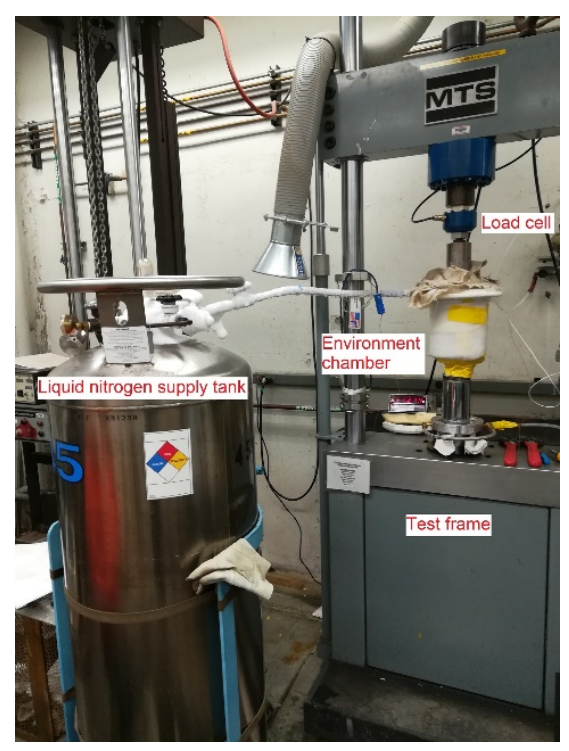

Figure 51. General layout of fracture toughness test setup.

Effort on testing equipment and techniques have included the optical non-contact extensometer installed on the new Instron, the high temperature tensile test frame with furnace which is now deployed at the ORNL Irradiation Materials Examination and Testing (IMET) facility. The new test frame has been prepared and tested in a clean area and is scheduled for installation during FY19. Additional equipment prepared for installation include a new Mitutoyo HV-120B Vickers hardness tester and a new Cressington 208C High Vacuum Carbon Coater facility that has been installed in LAMDA.

These techniques and the subsequent database on $\mathrm{F} 82 \mathrm{H}$, the product of the collaboration between QST and ORNL researchers, have enabled QST to predict the mechanical performance of F82H for DEMO fusion reactor components. 

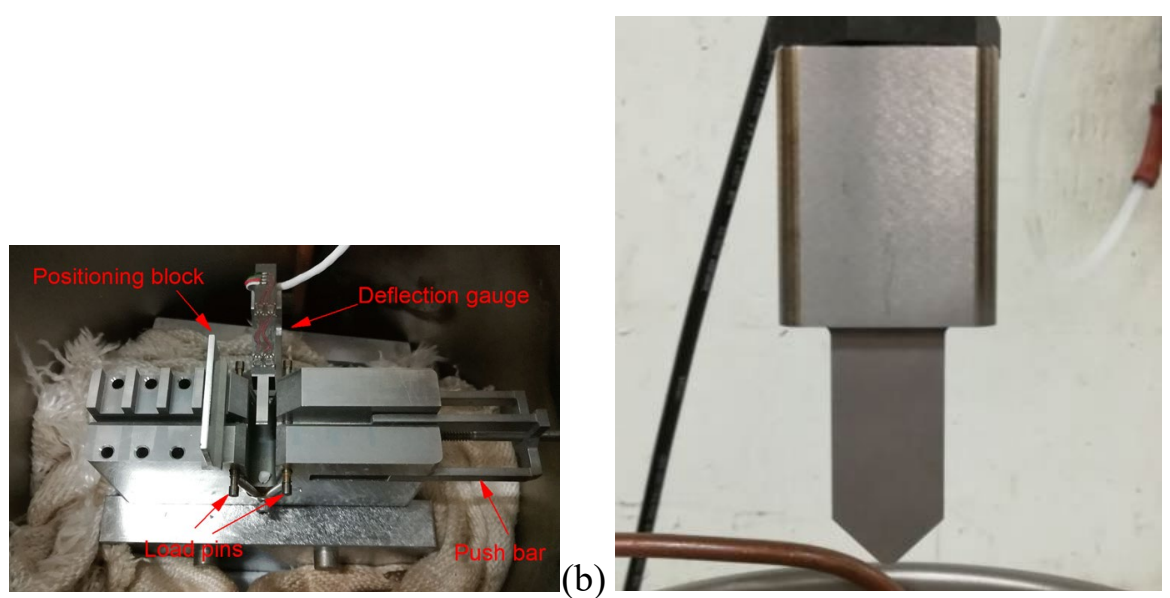

Figure 52. (a) M5CVN multi-notch bend bar test fixture and (b) a close up photo of the indenter.

\section{FUTURE PLANS}

The future main focus of the DOE-QST collaboration will be on mechanical and fracture toughness testing at temperatures above $573 \mathrm{~K}$ on the remaining specimens from the high dose HFIR capsules JP28/29 and then continue with similar testing on lower dose specimens from the HFIR JP30/31 experiments.

Testing procedure for the $\mathrm{F} 82 \mathrm{H}$ pressurized creep tubes irradiated at lower temperatures and doses relevant to ITER-TBM operating conditions will be developed.

PIE of the high dose SiC specimens is scheduled to start during the first quarter of FY19.

Irradiation of $\mathrm{Cu}$ alloys is scheduled for in the first half of FY19, directed at supporting an ITER tungsten diverter prototype design. 


\subsection{US-JAPAN PHENIX PROGRAM}

\section{J.W. Geringer (geringerjw@ornl.gov), L.M. Garrison, A.S. Sabau, Y. Katoh}

\section{OBJECTIVE}

The PHENIX Project on Technological Assessment of Plasma Facing Components for DEMO Reactors is the current US/Japan Fusion Research Collaboration Project that started in April 2013. The goal of the project is to evaluate critical issues on plasma-facing components (PFCs) under divertor conditions of fusion reactors, including: (1) heat transfer, (2) mechanical properties, (3) neutron irradiation effects, and (4) tritium retention and permeation. The project participants are ORNL, Idaho National Laboratory, Sandia National Laboratory, Georgia Institute of Technology, National Institute for Fusion Science of Japan, and various Japanese universities. The role of ORNL is to participate in Task 1 on high heat flux testing, Task 2 on neutron irradiation effects, and to provide neutron irradiation in HFIR in support of all research tasks.

\section{SUMMARY}

In FY18 the HFIR-RB-19J instrumented capsule that contained $\sim 1100$ tungsten specimens was transported to the 3525 hot cell facilities, where the large sleeve components were removed and the specimen holders were recovered. The specimen holders were individually transferred to Irradiation Materials Experiment and Testing (IMET), the $3025 \mathrm{E}$ hot cell facilities where the $800^{\circ} \mathrm{C}, 500^{\circ} \mathrm{C}$ and then $1200^{\circ} \mathrm{C}$ holders (in that order of priority), were disassembled. The specimens were then transferred to LAMDA, sorted and inventoried using a special glovebox prepared to accommodate the high beta source specimens. Temperature monitors from the $800^{\circ} \mathrm{C}$ and $500^{\circ} \mathrm{C}$ holders were measured and analysis gave results for the mean irradiation temperatures over the length of the holder of $785^{\circ} \mathrm{C}$ and $549^{\circ} \mathrm{C}$. The specimen inventory and temperature analysis of the $1200^{\circ} \mathrm{C}$ specimens are near completion.

The testing of specimens from two companion HFIR rabbit capsules, PXW2 and PXW5, was completed testing in LAMDA. The specimens have been shipped to the various end destinations.

Several shipments of 19J specimens were made to other laboratories including PNNL and INL, for dosimetry analysis and to continue with Task 3 collaboration work.

The plasma arc lamp facility needed for PHENIX Task 1 experiments was upgraded with a new fabricated reflector to maximize the heat flux. The facility can now achieve a target heat flux of 12 $\mathrm{MW} / \mathrm{m}^{2}$ (incident) or $6 \mathrm{MW} / \mathrm{m}^{2}$ (absorbed in W) over a $2 \times 15 \mathrm{~cm}^{2}$ area.

\section{PHENIX Task 1. High heat flux testing of W-based specimens}

The new reflector was received and installed during this reporting period. After preliminary testing, that included direct temperature measurement and characterization of test material, the heat load test for RB$19 \mathrm{~J}$ irradiated materials commenced with heat flux levels expected to reach $12 \mathrm{MW} / \mathrm{m}^{2}$. Several tests were completed on the non-irradiated specimens.

The test facility was prepared to accommodate irradiated materials testing by developing Laboratory work and safety procedures and certain facility setup changes to ensure the readiness for 19J test specimens. 


\section{PHENIX Task 2. Effects of neutron irradiation}

A May 2018 workshop on the post-irradiation examination (PIE) defined the FY18 focus on efforts to ship and disassemble the RB-19J capsule consisting of disc, tensile, fracture toughness, and torsion specimens.

Several instruments were procured and prepared to enable the post-irradiation testing efforts. These include the Netzsch LFA 467 HT HyperFlash instrument, to perform thermal diffusivity measurements on $3 \mathrm{~mm}$ disc tungsten specimens and the Horiba GD-Profiler-2 for Glow Discharge Optical Emission Spectrometer (GDOES) to perform elemental analysis on the $6 \mathrm{~mm}$ disc tungsten specimens. The procurement of a new high temperature tensile frame is also in process. That latter system will provide LAMDA with capability to perform temperature testing up to $1300^{\circ} \mathrm{C}$ with $5 \mathrm{kN}$ and $2 \mathrm{kN}$ tensile load capacities.

Testing of the companion unirradiated materials proceeded. Micro hardness, torsion, tensile and thermal diffusivity testing on the $800^{\circ} \mathrm{C}$ and $500^{\circ} \mathrm{C}$ irradiated specimens were performed on both US and Japanese materials. Scanning electron microscopy was used to observe specimen surface areas for the purpose of analyzing the pre- and post-irradiation grain structures. Additionally, a standard W-Re-Os material with several test specimens was prepared for the GDOES system to commence elemental analysis on the irradiated $\mathrm{W}$ specimens.

New test techniques under development for the specimens from RB-19J include miniature fracture toughness. A three-point bend fixture was designed for the tungsten bend bars with dimensions $4 \mathrm{x} 2 \mathrm{x}$ $10 \mathrm{~mm}$. New procedures are being adapted for these small specimens.

\section{FUTURE PLANS}

PIE on the irradiated specimens will continue until closeout of this program.

All technical tasks will continue through FY-19. ORNL will contribute to the project by providing project management, participating in personnel exchanges and workshops, and publishing and presenting the results, in addition to the continuing research planned for FY19. 


\subsection{US-EUROFUSION PROJECT}

KoryLinton(lintonkd@ornl.gov), R. Harris, J.W. Geringer, Y. Katoh

\section{BACKGROUND}

The Karlsruhe Institute of Technology (KIT), as a EUROfusion project seeks to provide blanket, baseline, design-relevant data and basic material properties evaluation of EUROFER material variants. ORNL is under contract to assist the Neutron Irradiation and Material Data task by preparation, irradiation and PIE of these steels to determine their suitability for use in fusion energy systems. This requires the use of several unique ORNL facilities including the High Flux Isotope Reactor (HFIR) and Irradiated Materials Examination and Testing (IMET) hot cell facility.

\section{PROGRESS}

In FY18 ORNL completed design and fabrication of the 21 irradiation vehicles (known as "rabbit" capsules) loaded with Eurofer-97 alloys provided by KIT and EUROfusion program collaborators. Of the 21 rabbits, 14 began irradiation with a target of 20 dpa ( $\sim 12$ cycles) at nominal target temperatures ranging from $220^{\circ} \mathrm{C}$ to $375^{\circ} \mathrm{C}$ while the other seven rabbits were achieved a $2.5 \mathrm{dpa}$ ( 2 cycles) irradiation at a nominal target temperature of $300^{\circ} \mathrm{C}$. The 20 dpa irradiation began in May 2018 and will finish in late 2019. The 7 rabbits which completed a 2.5 dpa irradiation in 2018 were shipped to the IMET hot cell facility where they were disassembled. Post-irradiation examination in FY19 will include elevated temperature mechanical tests, microstructural characterization and analysis of passive thermometry to verify irradiation temperatures.

In addition to preparing and initiating the irradiation experiments, ORNL completed pre-irradiation mechanical property and microstructural characterization of Eurofer97 steel variants. A report entitled "Mechanical Properties and Microstructure Characterization of unirradiated Eurofer-97 steel variants for the EUROfusion project" (Bhattacharya, et al, ORNL/SPR-2018/882, June 2018) contain the results of mechanical tests including Vickers hardness indentation measurements, uniaxial tensile tests and fracture toughness tests. Microstructure characterization in the report consisted of light optical microscopy (LOM), transmission electron microscopy (TEM) in both conventional TEM and scanning TEM (STEM) mode, energy dispersive X-ray spectroscopy (EDX) in STEM mode, study of the fracture surfaces after room temperature tensile tests, and general microstructure observations using SEM.

Sections 2.2 and 12.2 summarize limited details related to this Project. 


\subsection{IAEA - STANDARDIZATION OF SSTT FOR FUSION APPLICATIONS}

\section{M.A.Sokolov(sokolovm@ornl.gov),X.Chen}

\section{OBJECTIVE}

The International Atomic Energy Agency (IAEA) Coordinated Research Project (CRP) for the standardization of small specimen test techniques (SSTT) for fusion applications aims for harmonizing and coordinating world-wide development and acceptance of SSTT for fusion applications. ORNL participates in this project with contributions in to two areas: fracture toughness and fatigue crack growth rate.

\section{SUMMARY}

The IAEA CRP for the standardization of SSTT for fusion applications aims to address the following main tasks:

- Analysis of SSTT results focusing on fusion structural reference materials (RAFM steels).

- Analysis of SSTT: for measuring tensile, creep, low cycle fatigue, fracture toughness, fatigue crack growth rate.

- Definition of a strategy for meaningful Round Robin tests establishing best practices in the field.

- Establishment of guidelines for common practices in the use of SSTT.

ORNL participation in this project will focus on rationalizing the specimen size effects on fracture toughness and fatigue crack growth rate properties of RAFM steels. Recommendations will be made for the limitation of specimen downsizing as well as for best practices for using SSTT for fusion materials development and data base applications.

\section{PROGRESS AND STATUS}

The first-year activities of the IAEA CRP included producing a report on reference guidelines for fracture mechanics testing using SSTT for fusion structural steels, including specimen needs, specimen drawings and fabrication details, and explanation of the proposed approaches providing specific step-by-step guidelines. In addition, we will draft a literature review on the size effects in fatigue crack growth measurements. Results will be presented during the Second Research Coordination Meeting for the IAEA CRP in January 2019 at the IAEA headquarters in Vienna, Austria. 


\section{MATERIALS ENGINEERING}

\subsection{MATERIALS ENGINEERING SUPPORTING THE FNSF CONCEPTUAL DESIGN}

\section{OBJECTIVE}

The objective of this task is to identify potential materials solutions for the FNSF power core components and extraction systems and for lifetime components such as the vacuum vessel structural ring and the low temperature shield. In addition, the suitability of a subset of these structural materials as candidate substrate materials for liquid metal plasma facing component (LM-PFC) concepts is being evaluated.

\section{PROGRESS AND STATUS}

There is a strong interdependence between the evolution of the conceptual design of FNSF components and fusion materials research. A wide range of materials issues have been identified during the on-going design studies and a sub-set of these issues has been identified which could be usefully addressed within the scope of the current US Fusion Materials Program. R\&D opportunities were identified related to the investigation of helium-induced intergranular fracture regimes in RAFMs, neutron radiation damage in 3Cr-3WV bainitic steels, development of Al-bearing RAFM and ODS alloys, and materials development to support novel high heat flux/particle solutions for the FW. An example of the materials R\&D needs related to the response of the FNSF vacuum vessel to system loss-of cooling events is illustrated in Figure 53.

ISSUE:

- Preliminary analysis of a LOCA indicates that the vacuum vessel temperature could reach $\sim 640 \mathrm{C}$ and remain $>600^{\circ} \mathrm{C}$ for $\sim 12$ days.

- The vacuum vessel is a safety class component; integrity must be maintained throughout a LOCA and during subsequent operations

\section{FNSF-RELEVANT R\&D:}

- Establish thermal response of bainitic microstructure of $3 \mathrm{Cr}-3 \mathrm{WV}$ steel and weldments to simulated LOCA temperature-time cycles

- Determine microstructural stability of neutron-irradiated material; radiation damage annealing; mechanical behavior/fracture toughness

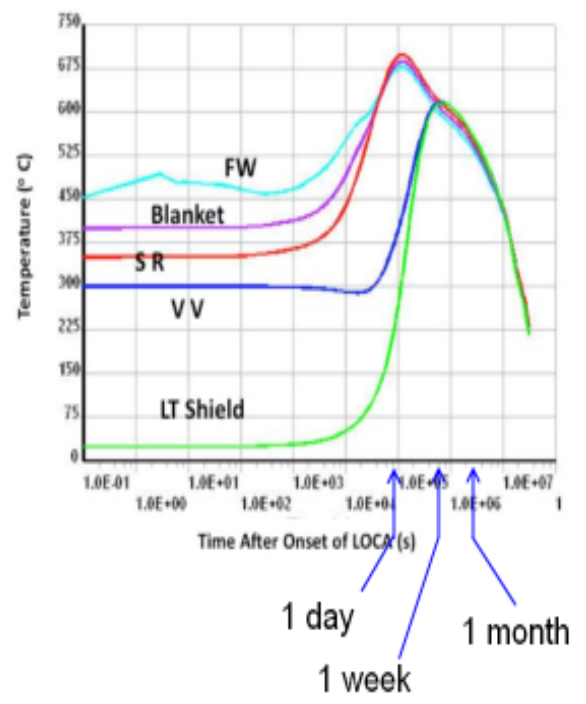

Figure 53. Temperature response of major reactor components to loss-of-cooling event, and vacuum vessel materials issues that could be tackled in the Fusion Materials research program.

As part of the assessment of substrate materials for LM-PCs, the data base on the Pb-Li corrosion behavior of ferritic-martensitic steels in flowing $\mathrm{Pb}-\mathrm{Li}$ with the application of a magnetic field was evaluated. The data are restricted to two experiments carried out in a flowing $\mathrm{Pb}-\mathrm{Li}$ loop containing a test section passing through a magnetic field with $\mathrm{B}=1.7 \mathrm{~T}$. An initial set of measurements was carried out on flat-plate EUROFER samples exposed for 2000 hours with a flow rate of $5 \mathrm{~cm} \cdot \mathrm{s}^{-1}$. At $550^{\circ} \mathrm{C}$ a 2 to 3 times higher corrosion rate was measured for surfaces oriented perpendicular to the applied B-field [1]. Similar 
results were obtained in subsequent experiments using FM steel P91 exposed for 1000 hours [2]. Both experiments and independent confirmation [3] revealed a major change in the $\mathrm{Pb}-\mathrm{Li}$ corrosion mechanism. The specimens perpendicular to the applied magnetic field developed a uniform array of striations (70-80 $\mu \mathrm{m}$ deep and 350-1400 $\mu \mathrm{m}$ wavelength) running parallel to the LM flow direction. The implications of this phenomenon for the DCLL Pb-Li blanket lifetime require further evaluation. It is not known if this behavior is limited to the ferromagnetic FM steel $/ \mathrm{Pb}-\mathrm{Li}$ system or whether it is a general phenomenon which could impact the LM/substrate systems currently being evaluated in the LM-PFC project where flow rates and B-fields are significantly higher.

\section{REFERENCES}

[1] E. Platacis, I. Bucenieks, F. Muktupavel, A. Shisko, "Corrosion phenomena of EUROFER steel in PbLi stationary flow at magnetic field," Proc. of ICONE14, International Conference on Nuclear Engineering, July 17-20, 2006 Miami Florida.

[2] E. Platacis, A. Ziks, A. Poznjak, F. Muktepavela, A. Shisko, S. Sarada, P. Chakraborty, K. Sanjay, M. Vrushank, R. Fotedar, E.K. Rajendra, A.K. Suri, "Investigation of the Li-Pb flow corrosion on the attack on the surface of P91 steel in the presence of magnetic field," Magnetohydrodynamics 48 (2012) 343-350.

[3] René Moreau*, Yves Bréchet, Laurent Maniguet, "Eurofer corrosion by the flow of the eutectic alloy $\mathrm{Pb}-\mathrm{Li}$ in the presence of a strong magnetic field," Fusion Engineering and Design 86 (2011) 106-1. 


\section{EXPERIMENTAL TECHNIQUES AND LABORATORY SYSTEMS}

\subsection{MECHANICAL TEST SYSTEMS FOR IMET HOT CELLS (Building 3025E)}

X. Chen (chenx2@ornl.gov), C. Stevens, K.D. Linton, J.W. Geringer, H. Sakasegawa (QST), M. Ando (QST), D. Hamaguchi (QST)

\section{PROGRESS AND STATUS}

We have completed out-of-cell setup and verification testing of the high temperature vacuum chamber on the Instron test frame shown in Figure 54. The test chamber showed satisfactory vacuum performance (achieved $\sim 7 \times 10^{-8}$ torr at $800^{\circ} \mathrm{C}$ ) and high temperature test capability (up to $1200^{\circ} \mathrm{C}$ ). It is also equipped with a video extensometer for non-contact deformation measurement. The test frame is currently being installed in cell 1 of the Irradiated Materials Examination and Testing Facility (IMET) at ORNL with an expected installation date of late December 2018 and operation in the new year.

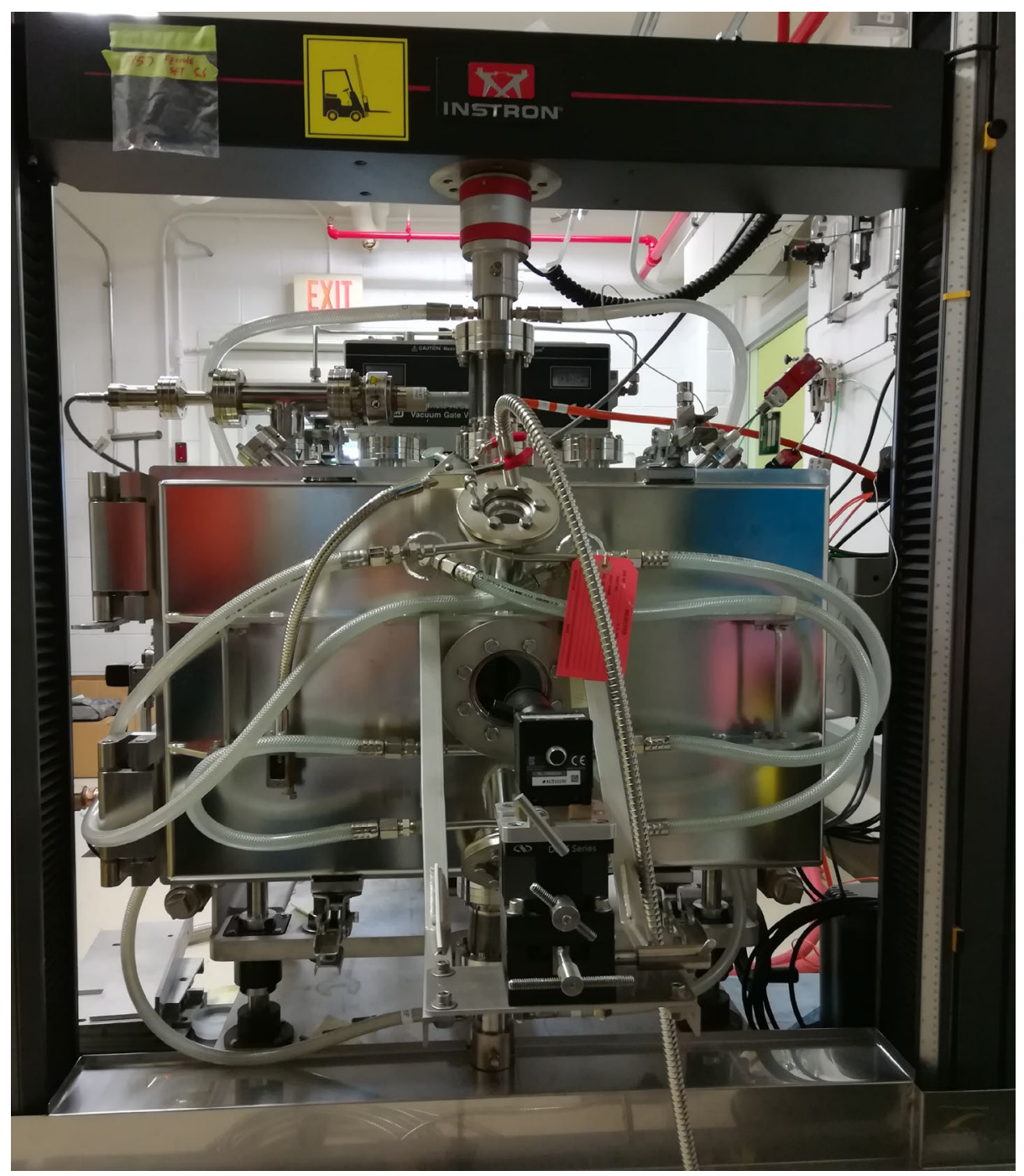

Figure 54. Front view of the high temperature vacuum test frame ready for installation in the IMET hot cells of ORNL Building 3025E. 
A new Mitutoyo HV-120B Vickers hardness tester was purchased to replace an identical model hardness tester which was inoperable after service in the hot cell, likely due to the high radiation field. The hardness tester, shown in Figure 55, has completed out-of-cell installation and calibration and is currently being installed in cell \#4 of IMET at ORNL with expected installation before the end of the year.

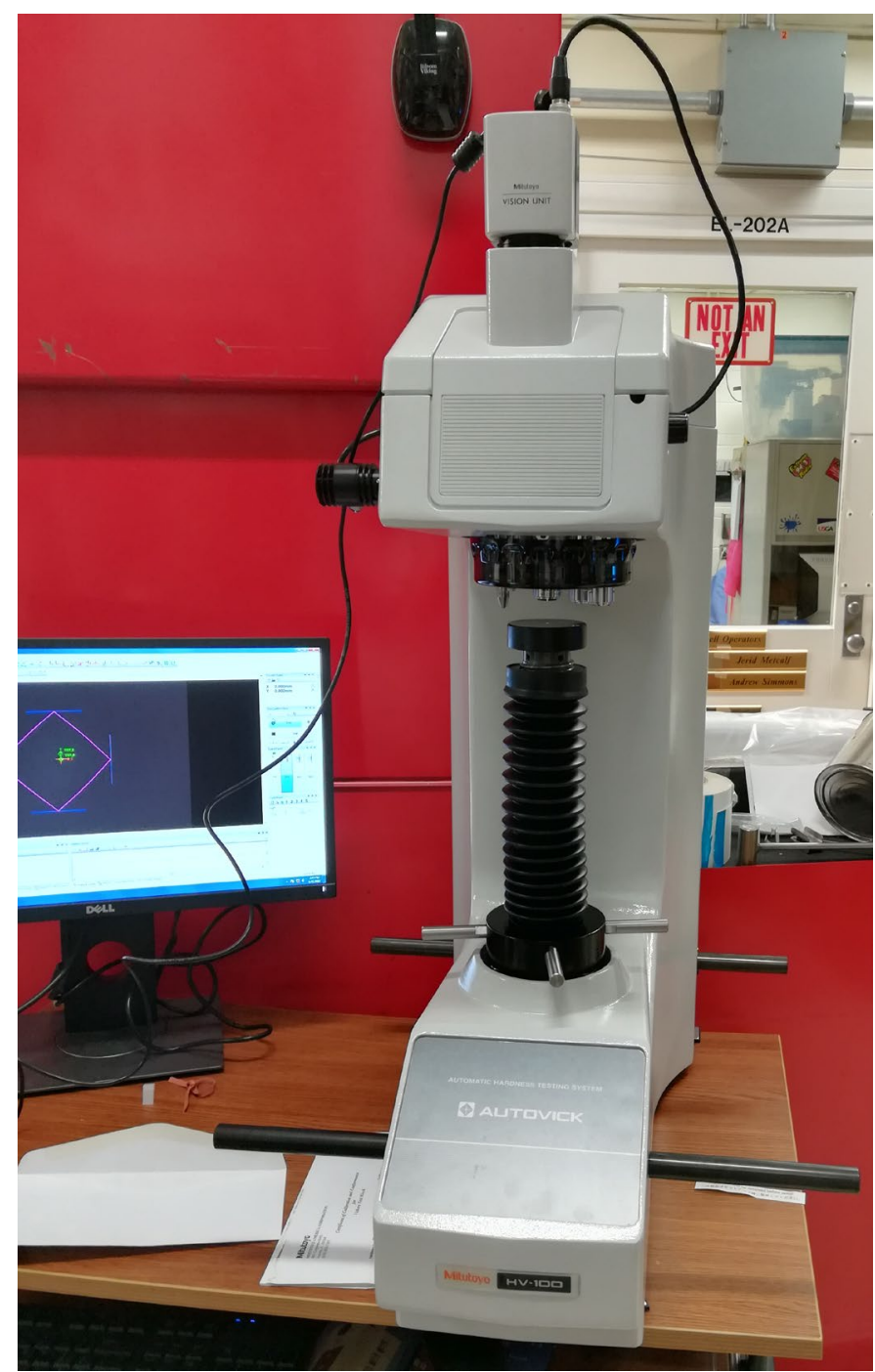

Figure 55. New Mitutoyo HV-120B Vickers hardness tester for installation in the Building 3025E hot cells. 


\subsection{FINITE ELEMENT ANALYSIS OF TUNGSTEN COMPOSITE TENSILE SPECIMENS}

\section{M. Garrison (garrisonlm@ornl.gov), A. Hayes (University of Illinois)}

\section{OBJECTIVE}

A finite element analysis of tungsten composite tensile specimens is needed to understand the properties measured in tensile tests.

\section{SUMMARY}

As a first step toward modeling tungsten composites, simplified tensile tests of individual tungsten foils were simulated in the finite element analysis (FEA) program ANSYS. Then, several tungsten-steel laminate variations were modeled in tension. This project is exploring the impact of variations in input parameters, geometry, mesh fineness, and force application location and rate. The basis of the model has been developed, but further refinement is needed to match experimental results.

\section{PROGRESS AND STATUS}

There is strong interest in tungsten composites for fusion applications, but their behavior under relevant fusion conditions is not yet predictable. For instance, initial tests of tungsten copper laminate composite had good unirradiated tensile ductility, but little to no ductility after neutron irradiation. Of the tungsten composites considered, the laminate composite was chosen to model first. To properly model a laminate with such complex interface properties, individual tungsten, steel, and copper foils must be accurately simulated to reduce error in modeling the composite material. Foils of varying thicknesses can then be combined using the ANSYS Composite PrepPost (ACP) software to model laminates.

Experimentally measured stress-strain data from uniaxial tensile tests was imported into the program. These tests were at room temperature on unirradiated tensile specimens machined from 250, 100, or 25 $\mu \mathrm{m}$ thick tungsten and steel foils. Strength, elasticity, and other relevant material properties were defined for foil as well. A mesh consisting of 4806 elements was generated by ANSYS across a solid body geometry and a fixed support was applied to one end face. Several boundary conditions of applied force or applied extension rate were simulated. A finite element analysis of the uniaxial tensile test solved for the stress, strain, and deformation in ANSYS. Individual foils and a variety of laminates will be modeled in tension to compare material and mechanical properties.

Initially the entire tensile specimen was simulated. To improve calculation time, this model is limited to the $5 \mathrm{~mm}$ segment between the gauge marks. There are no natural impurities in the modeled material for crack propagation to initiate, so necking is encouraged by artificially decreasing the width in the middle with a circle of radius $100 \mathrm{~mm}$ (Figure 56). An example of the results for a $100 \mu \mathrm{m}$ tungsten foil are shown in Figure 57.

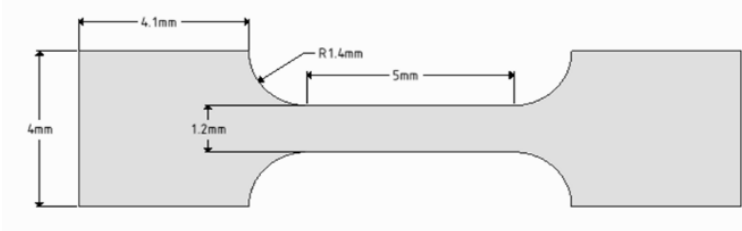

Experimental geometry

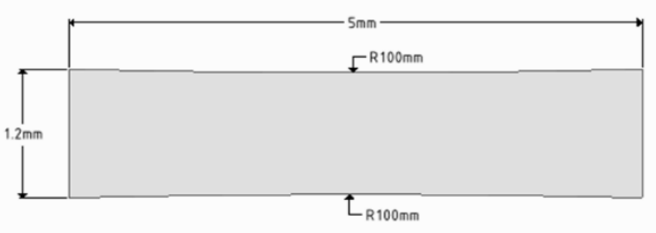

Modelled geometry

Figure 56. Tests use the SSJ-2 samples (left), and the FEA model focuses on the gauge section (right). 


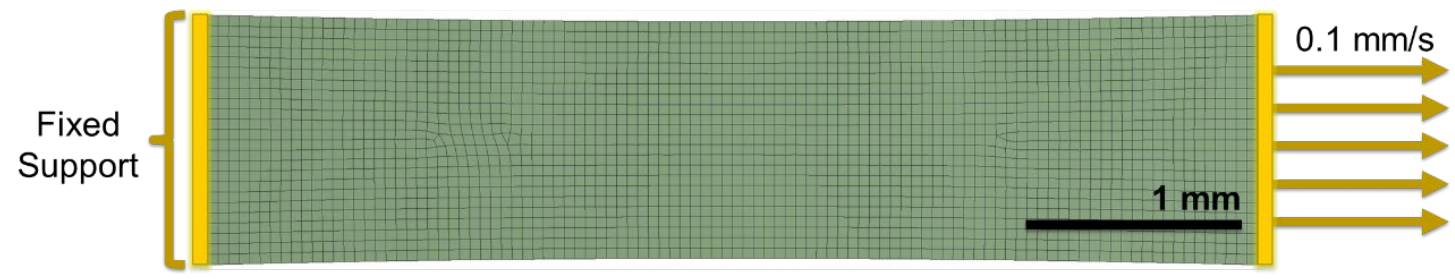

Standardized mesh and model conditions

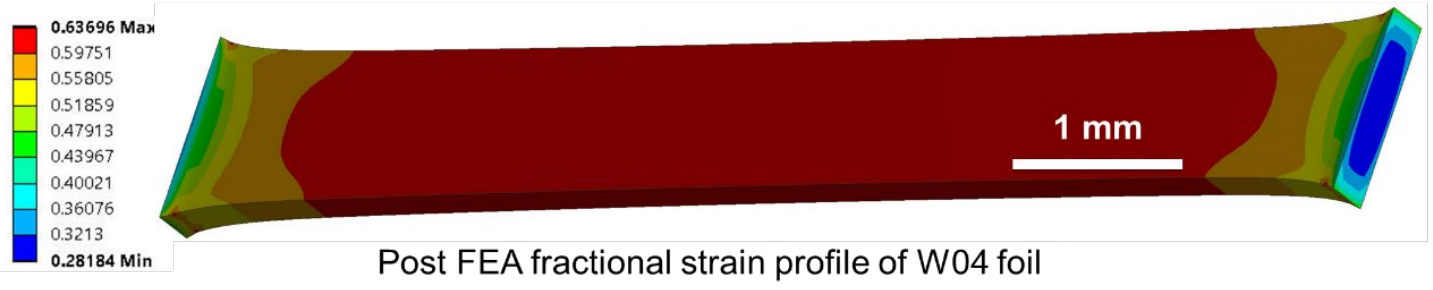

Figure 57. Example of tungsten foil modeled with a fixed support and induced motion on one end (top), and the resulting strain profile (bottom).

Six varieties of tungsten-steel laminate composites were modelled by stacking combinations of the foils. The stacking direction is normal to the face of the tensile specimen. Each laminate consisted of five alternating layers of one type of tungsten foil and one type of steel foil (Figure 58). The real composites were roll bonded, so the thickness of each layer in the composite was reduced compared to the starting foil thicknesses. The average measured after-fabrication thickness of each layer was used in the laminate model. The model of the composite under tension was able to reproduce the elastic region, but could not converge after yielding.

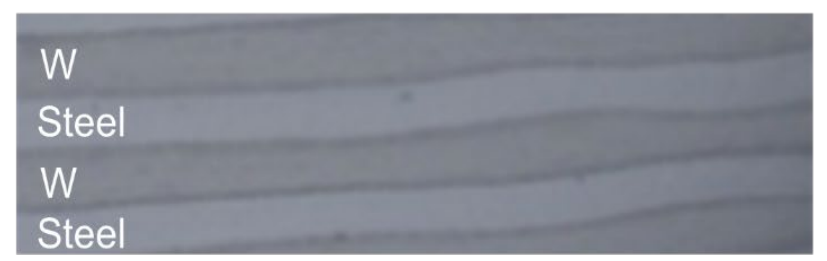

Cross section image of W04-S04 layers

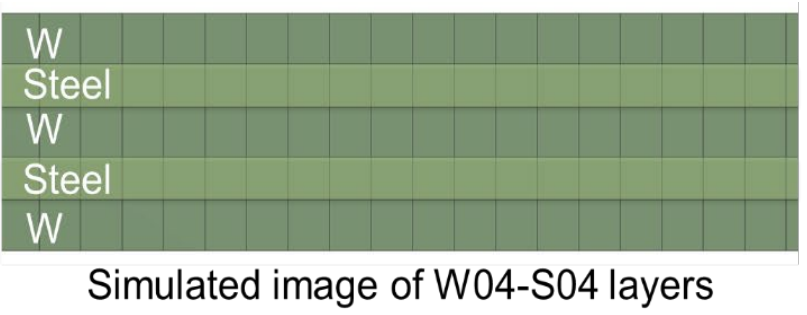

Simulated image of W04-S04 layers

Figure 58. Cross section of experimental tungsten-steel laminate (left). Simulated tungsten-steel laminate layers with $57 \mu \mathrm{m}$ individual layer thickness (right).

\section{FUTURE PLANS}

Further improvements will be made to the model to be able to reliably reproduce the experimentally observed behavior. Once a baseline is confirmed, the model will be used to simulate a wide variety of laminate composite variables to search for optimal combinations. Selected laminates with optimized parameters may then be fabricated and tested. 


\subsection{THE GD-OES TECHNIQUE TO MEASURE THE COMPOSITION OF TUNGSTEN MATERIALS}

\section{L.M. Garrison (garrisonlm@ornl.gov), N.Reid}

\section{OBJECTIVE}

The aim of this work is to use the GD-OES technique to analyze impurities, alloying elements, and transmutation elements in neutron irradiated tungsten.

\section{SUMMARY}

Glow discharge optical emission spectroscopy (GD-OES) is a technique that can analyze the elemental composition of materials with depth resolution. It will be useful with tungsten, since tungsten transmutes to $\mathrm{Re}$ and Os under neutron irradiation, and these elements are important for determining its microstructure, thermal, and mechanical properties. Moreover, GD-OES can be used to determine impurities from fuel, elements injected for cooling the plasma, elements eroded from other areas of the device, and more, that end up in or on plasma facing components. To prepare this technique for irradiated tungsten samples, a mounting system was designed and machined. The technique will be used on the irradiated tungsten materials.

\section{PROGRESS AND STATUS}

In the GD-OES system metallic samples are used as a cathode in a direct current plasma. From the surface, the sample is removed in layers by sputtering with argon ions. The removed atoms pass into the plasma by diffusion. Photons are emitted with excited waves and have characteristic wavelengths which are recorded by means of a downstream spectrometer and subsequently quantified.

The ORNL GDOES has a $2 \mathrm{~mm}$ and a $4 \mathrm{~mm}$ anode, and the samples of interest include $3 \mathrm{~mm}$ discs, broken tensile tabs, $6 \mathrm{~mm}$ discs, and larger samples. In some cases it is possible to position a $6 \mathrm{~mm}$ disc over the anode without a mount, but this has a high probability of giving noisy GDOES results or not igniting the plasma. Additionally, for irradiated samples, a mounting method that reduces radiation exposure to the operator is desired. The mounting system for the GDOES instrument consists of square aluminum sample mounting tabs with indents for different sized samples and a centering disk to position each sample precisely over the anode (Figure 59). Samples were superglued into mounts. A conductive silver coating was used to flush the sample with the surface and fill in gaps in the fixture (Figure 60).

The mounting system was used to test all the types of necessary samples. However, any initial misalignment in the sample in the mount is propagated through the sputtered crater (Figure 61). All the material eroded at one depth relative to the plasma is averaged into the measured GDOES signal. Thus, for depth or surface sensitive measurements, the depth resolution is only as good as how flat, smooth and correctly aligned in mounting the initial sample surface is. 


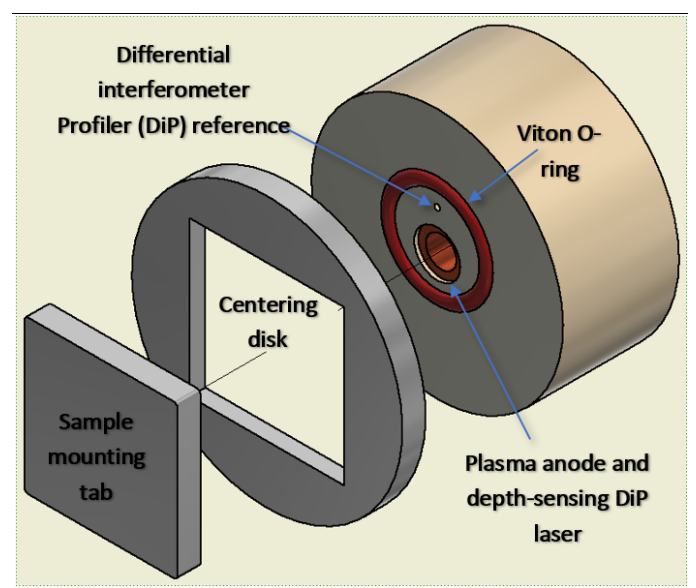

Figure 59. Exploded view of centering ring and sample mount on GD-OES 4mm anode with DiP.

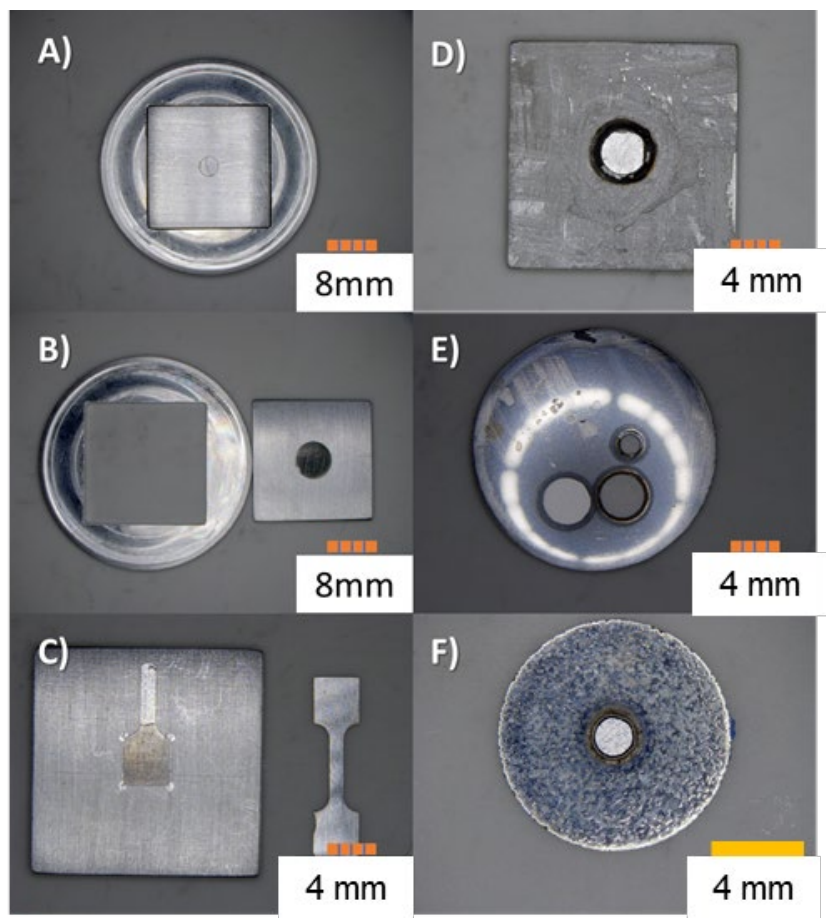

Figure 60. Examples of several sample types for GDOES are shown: (a) $3 \mathrm{~mm}$ disc in square sample mounting tab shown with the centering ring, (b) $6 \mathrm{~mm}$ sample in mounting tab, (c) tensile bar, (d) silver paint coated mount, (e) $\mathrm{W} \mathrm{ZrC}$ material with two $4 \mathrm{~mm}$ and one $2 \mathrm{~mm}$ craters, (f) $10 \mathrm{~mm}$ disc of W PIM material with a 2 mm crater. 


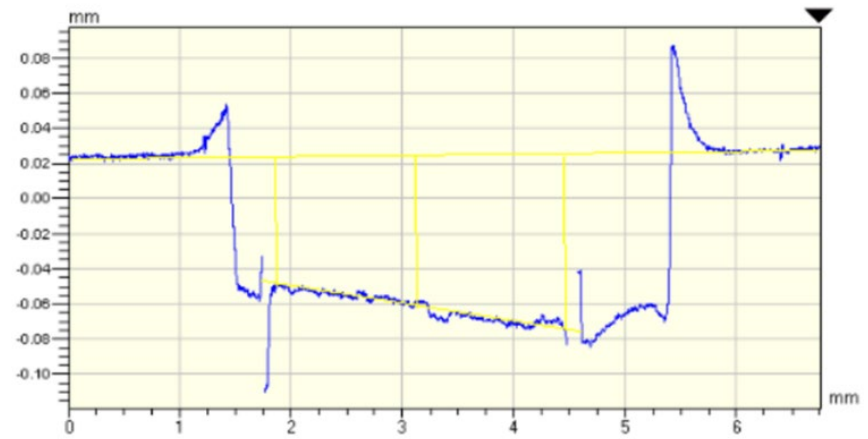

Figure 61. Example of sputtered crater depth profile. The slope at the bottom of the crater was because the original sample was not mounted flat in the mount.

A material with composition $\mathrm{W}-10 \% \mathrm{ZrC}$ was measured with the $2 \mathrm{~mm}$ and $4 \mathrm{~mm}$ GD-OES anodes at the same power $(40 \mathrm{~W})$ and pressure $(700 \mathrm{~Pa})$, but different RF impedances (Figure 62). It takes at least $60 \mathrm{~s}$ for the signals to approach the bulk concentrations. Zr has a higher sensitivity than $\mathrm{C}$, and both of their relative intensities are higher for the $2 \mathrm{~mm}$ anode than the $4 \mathrm{~mm}$ anode. The total intensity of $\mathrm{Zr}$ is about the same for both and is less for $\mathrm{C}$ on the $4 \mathrm{~mm}$ anode. This highlights the importance of calibrating and having standards for any anode size that will be used for measurements, because the signals of different anodes using the same material are different.

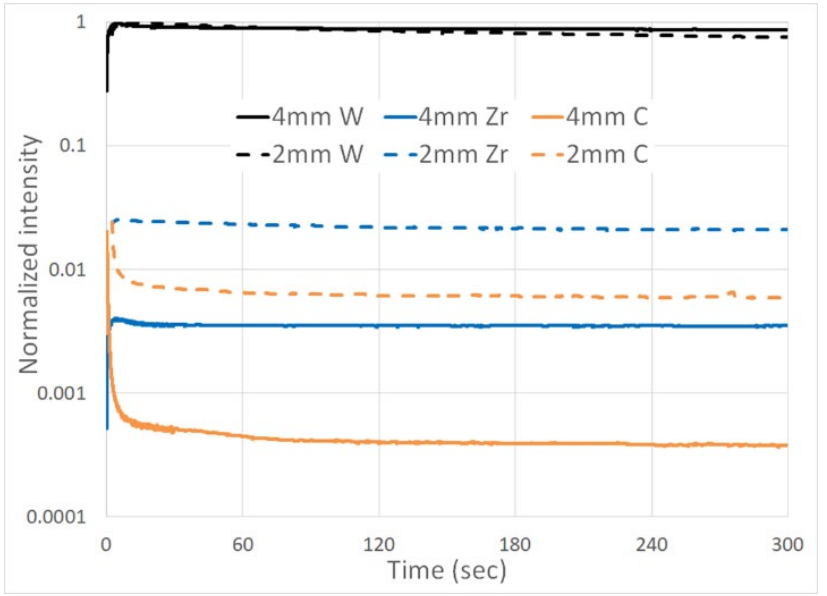

Figure 62. The same material, $\mathrm{W}-10 \% \mathrm{ZrC}$, was measured with the $2 \mathrm{~mm}$ and $4 \mathrm{~mm}$ anodes on the GDOES.

One of the main goals of using the GDOES instrument for irradiated tungsten studied in the PHENIX program is to measure the amount of transmuted Re and Os. An unirradiated model alloy of W- $0.4 \% \mathrm{Re}$ was measured (Figure 63). This is the lowest concentration of model alloy that was included in the program, and the Re still gives a strong signal. Re at $0.4 \%$ concentration has a sensitivity much higher than that seen for $\mathrm{C}$ in the $10 \% \mathrm{ZrC}$ sample. The raw intensity (in volts) is background subtracted. This value is $\sim 30 \mathrm{x}$ larger than the background signal by itself. The amount of $0.4 \% \mathrm{Re}$ was separately measured quantitatively by the ICP-OES method by the company EAG, so can be used to calibrate the GDOES sensor for Re. 


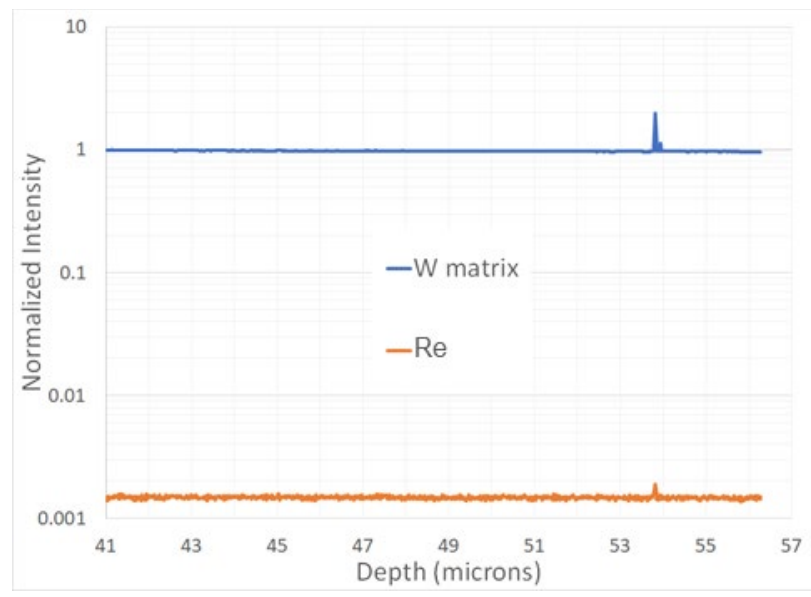

Figure 63. GDOES measurement of an unirradiated W-0.4\%Re sample.

\section{FUTURE PLANS}

Using the mounting system, calibrated element measurements, and anode size differences, the unirradiated and irradiated tungsten materials in the PHENIX program will be measured with the GDOES. 


\title{
12. HFIR IRRADIATION PROGRAM
}

\subsection{FUSION 2018 IRRADIATION CAPSULE DESIGN}

\author{
R.Howard(howardrh@ornl.gov), Y.Katoh, and K.Linton
}

\section{OBJECTIVE}

The Fusion 2018 Irradiation program plans to irradiate more than 20 capsules with design temperatures that range from 100 to $1000^{\circ} \mathrm{C}$. Loading will include several materials and specimen types to meet objectives of the Fusion Materials program.

\section{SUMMARY}

The Fusion 2018 Irradiation program has broad requirements for a rather larger number of capsules and specimen materials. As such, a general capsule design for metal specimens was needed to easily identify irradiation locations in HFIR and support such a challenging effort. Researchers at ORNL have developed two generic irradiation capsule formats, called the GENTEN and GENBEN designs, to facilitate the ability to rapidly design capsules for a wide range of temperatures, specimen composition, and irradiation location in HFIR.

\section{PROGRESS AND STATUS}

The GENTEN and GENBEN irradiation capsule formats describe versatile general capsule designs for either SSJ/MPC (tensile/coupon) type specimens or M4PCCVN (multi-notch bend bar) toughness specimens, respectively. Modern finite element analysis software and solution methods allowed generation of flexible models that have effectively mapped the HFIR flux trap such that one can rapidly design a capsule to meet specific specimen temperatures as a function of specimen holder diameter and axial irradiation location. See Figure 64 for a graphical representative core mapping that corresponds to GENTEN capsules with F82H specimen materials. These models have currently been technically reviewed and were used to produce capsule designs for the Fusion 2018 Irradiation capsules with target specimen temperatures ranging from 200 to $1000^{\circ} \mathrm{C}$.

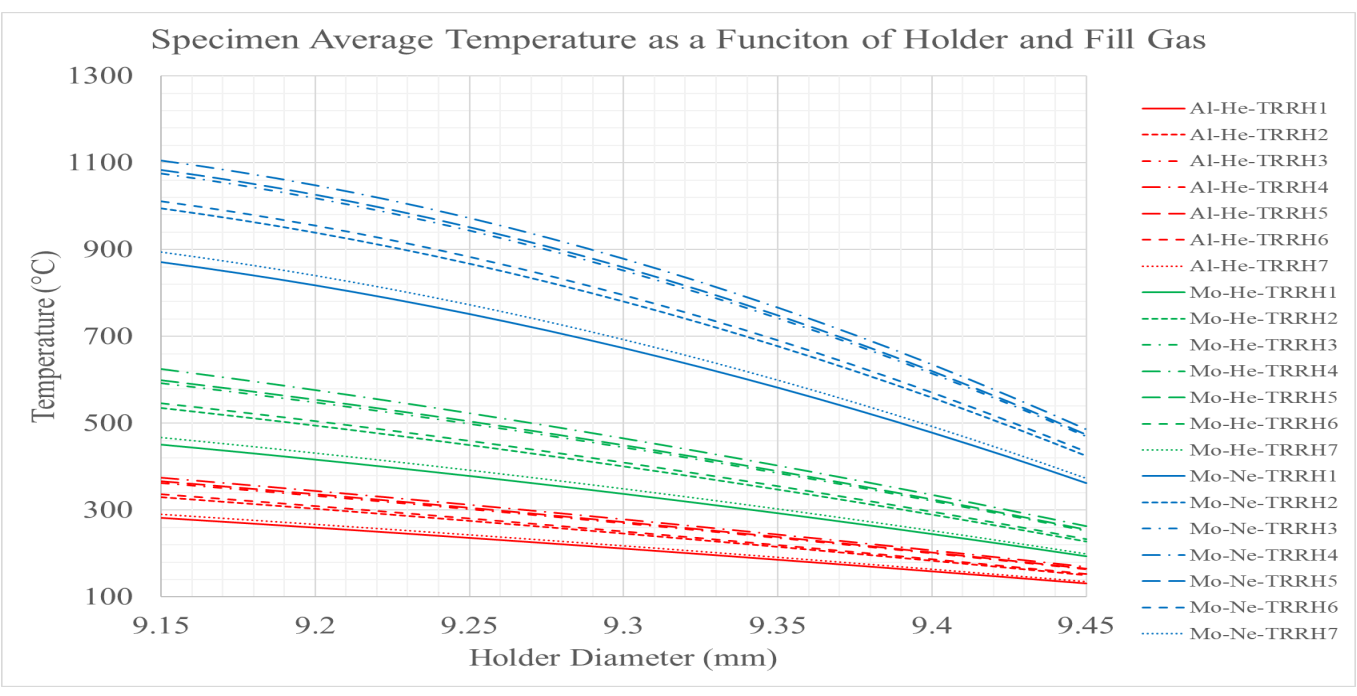

Figure 64. Core mapping of the GENTEN capsule format with F82H specimens. 


\subsection{THE EUROFER HFIR IRRADIATION CAMPAIGN}

\section{R.Howard(howardrh@ornl.gov),Y.Katoh, and K.Linton}

\section{OBJECTIVE}

This work focused on establishing an irradiation capsule design set appropriate for both SSJ tensile specimens and M4PCVVN bend bar toughness specimens at temperatures ranging between 200 and $380^{\circ} \mathrm{C}$. This work was specifically directed to support the Eurofer 97 irradiations under contract with the Karlsruhe Institute of Technology (KIT).

\section{SUMMARY}

This irradiation campaign required 21 capsules ( 7 low dose capsules to compare alloy variations and 14 high dose capsules with a reference Eurofer97) for HFIR irradiation. These capsules were designed to be irradiated at various temperatures between $200-380^{\circ} \mathrm{C}$ and were planned for near centerline HFIR flux trap positions. Images of representative SSJ tensile specimen format and toughness specimen capsules are shown in Figure 65.

\section{PROGRESS AND STATUS}

The initial seven alloy variation capsules were assembled and submitted to HFIR for irradiation Dec 2017 (cycle 477). These capsules received a nominal dose of 2.5 dpa over two cycles of irradiation. The remaining 14 capsules were submitted to HFIR by June 2018 (for cycle 480). These capsules are scheduled to receive nominally 20 dpa over twelve HFIR cycles. The low does screening capsules have completed their irradiation schedule and post irradiation examination (PIE) is underway. PIE for the high dose capsules is expected to begin in late FY19 or early FY20.
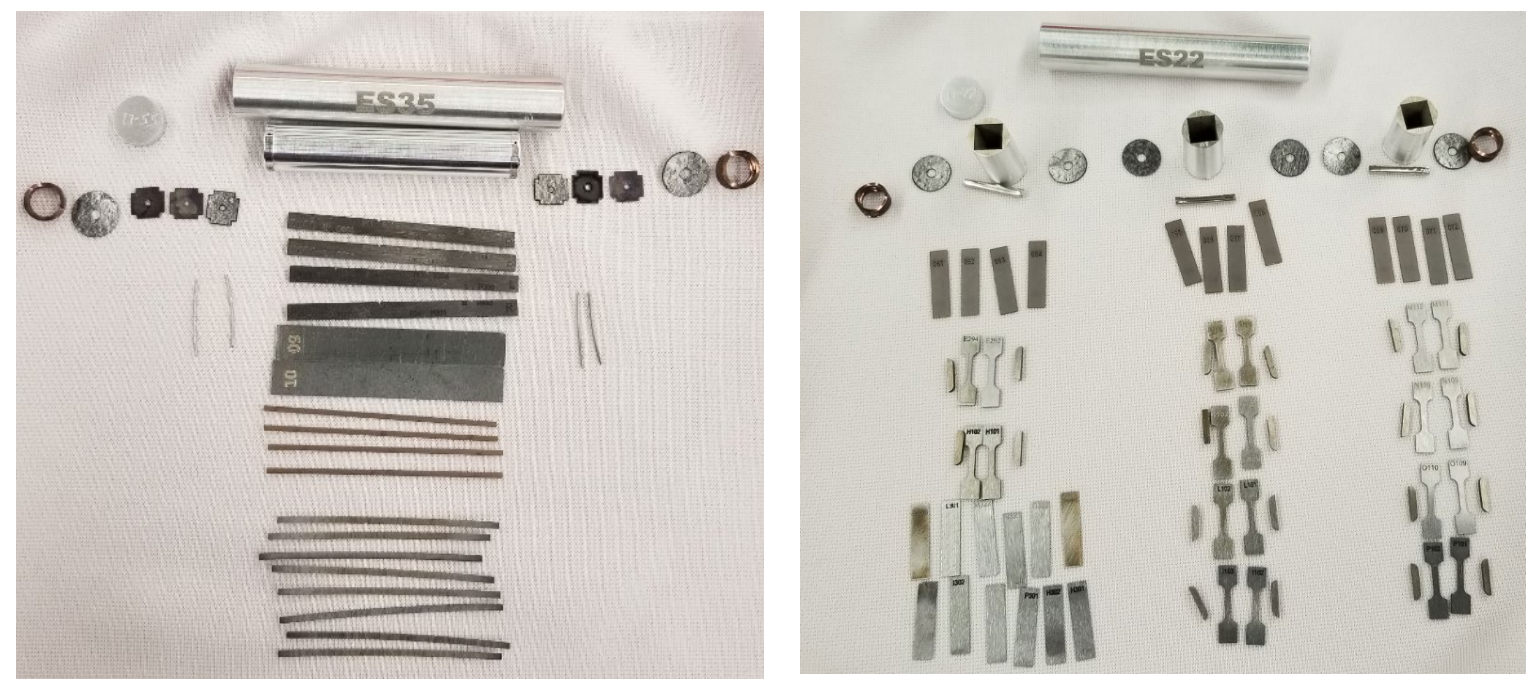

Figure 65. Representative layouts of EUROfusion-KIT toughness specimen capsule (left - ES35) and SSJ/MPC specimen capsule (right - ES22) to irradiate Eurofer 97 in HFIR. 


\title{
12.3 A HYDROGEN-CHARGED IRRADIATION CAPSULE FOR HFIR
}

\author{
N.O. Cetiner (cetinerno@ornl.gov), Joel L McDuffee, Yuji Hatano, S. Dan Ilas, Yutai Katoh, J. Wilna
} Geringer

\section{OBJECTIVE}

The objective of this work is to design a first-of a kind capsule for HFIR that allows neutron irradiation of plasma facing component (PFC) materials in a hydrogen environment. A first use will develop data on the modification of microstructures and physicochemical properties of tungsten metal irradiated in hydrogen.

\section{SUMMARY}

Most studies of hydrogen migration in irradiated metals have used a sequential approach of exposing preirradiated specimens to hydrogen. However, the presence of hydrogen in a metal affects vacancy migration during irradiation and modifies the resulting microstructures, implies that a sequential ion irradiation approach is less desirable than a simultaneous irradiation scheme. To confirm this effect, it is necessary to irradiate tungsten metal specimens in a hydrogen environment. However, filling and seal welding a capsule in hydrogen is difficult due to the hydrogen extreme flammability in air. Filling a weld chamber with hydrogen and then performing an arc weld in that environment presents safety concerns that, while ultimately manageable, require a high degree of planning, as well as the development and construction of additional engineering safeguards, and all at a high cost.

A novel irradiation experiment was designed to allows the safe irradiation of tungsten, graphite other PFC material specimens in a hydrogen environment. The design uses vanadium disks charged with hydrogen. The hydrogen in solution in the metal matrix is stable at room temperature, so the capsule can be hermetically welded without significant release of hydrogen. The hydrogen is released into the capsule environment during irradiation as the $\mathrm{V}-\mathrm{H}$ specimens are heated. At the $400^{\circ} \mathrm{C}$ design temperature, the hydrogen mole fraction is about $40 \%$. This experiment, to be conducted in HFIR, is designed to expose tungsten, $\mathrm{SiC}$, and graphite disks to hydrogen during neutron irradiation in a sealed rabbit capsule.

\section{PROGRESS AND STATUS}

A neutronic analysis calculation was performed to estimate the peak (reactor core midplane) heat generation rates of various materials in the capsule to support thermal design calculations.

Thermal analyses were performed using the ANSYS finite element software package to predict temperature distributions inside the capsule. These analyses use material-dependent heat generation rates (heat per unit mass) determined in neutronics analyses.

This experiment is designed to be irradiated in the hydraulic tube facility of HFIR. The irradiation capsule design uses a standard aluminum large bore rabbit housing, an aluminum end cap, and a Dispal aluminum alloy cylindrical holder to enclose the specimens. To ensure that specimens stay centered inside the housing, steel thimbles are used on either end. Various disk-shaped specimens are stacked into a circular cutout in the holder and supported by a $6.4 \mathrm{~mm}$ thick silicon carbide spacer and molybdenum foil. The specimens are $0.5 \mathrm{~mm}$ thick tungsten, $1 \mathrm{~mm}$ thick silicon carbide, (some of which can be used for passive thermometry), $1 \mathrm{~mm}$ thick hydrogen-vanadium, $0.25 \mathrm{~mm}$ thick vanadium, and $1 \mathrm{~mm}$ thick graphite disks. At each end of the holder, a centering thimble is secured with $0.5 \mathrm{~mm}$ diameter molybdenum wires. The axial heat loss is minimized by using grafoil disks at the bottom of the holder assembly inside the aluminum housing. Quartz wool is used to fill the space at the top of the specimens to keep the parts in place. The capsule design and specimen stack configuration are shown schematically in Figure 66 and a 
layout photo of the capsule components and specimens to be loaded in Figure 67. The holder has four $0.25 \mathrm{~mm}$ wide slots down the axial length to facilitate disassembly in the hot cell. Cuts at the ends of the holder will allow easy removal of the irradiated specimens without damage to the specimens.

Four capsules were built. Two capsules include the hydrogen charged vanadium specimens, the other two capsules include non-hydrided vanadium specimens. All capsules, designed to achieve $400^{\circ} \mathrm{C}$ on the specimens, will be irradiated to dose levels of 0.1 and $0.02 \mathrm{dpa}$.

\section{FUTURE PLANS}

The capsules will be irradiated in HFIR during 2019.

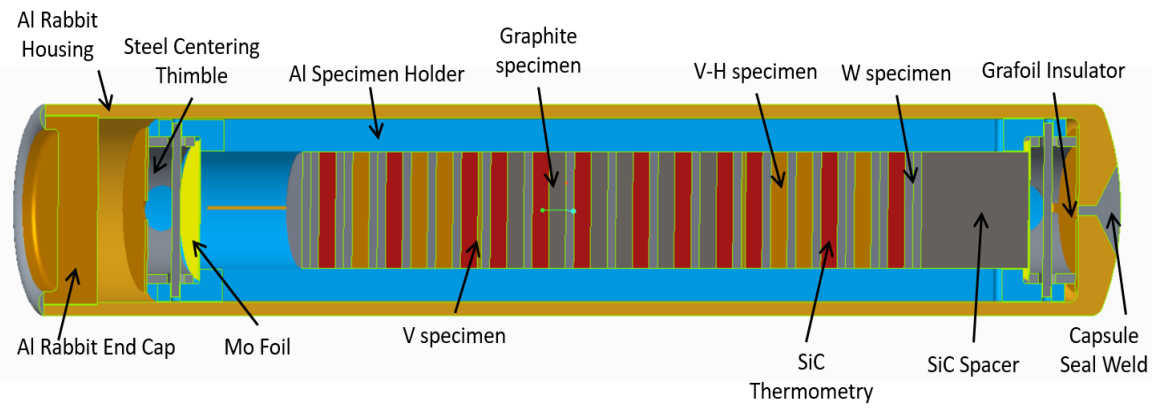

Figure 66. Schematic of capsule design and specimen loading.

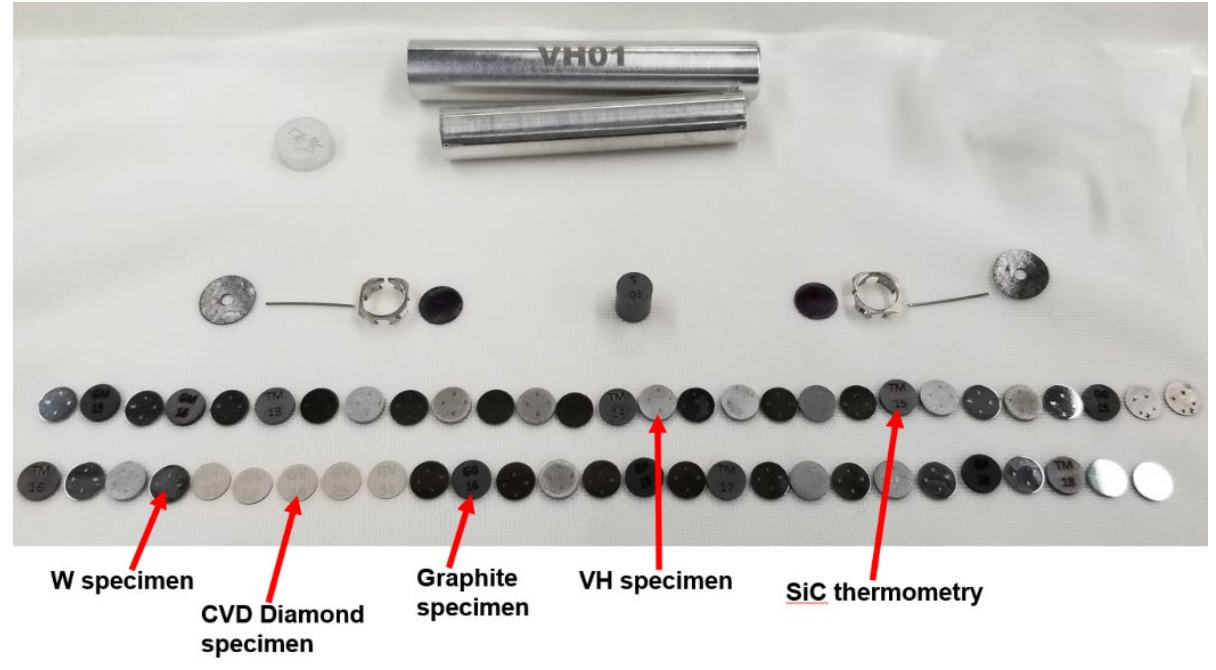

Figure 67. Layout of components and specimens for HFIR capsule VH01. 


\subsection{HFIR IRRADIATION EXPERIMENTS}

Y. Katoh (katohy@ornl.gov), J.L. McDuffee, C. Bryan, J.P. Robertson

\section{SUMMARY}

Neutron irradiation experiments were performed in support of the ORNL Fusion Materials Program using various materials irradiation facilities in the High Flux Isotope Reactor (HFIR).

The HFIR operated for seven cycles in FY-2018, cycles 476 through 482, accumulating a total of 14,358 MWD, as shown in Table 6.

Table 6. Summary of HFIR operation in FY2018

\begin{tabular}{|c|c|c|c|c|c|c|c|c|}
\hline & \multicolumn{9}{|c|}{ HFIR Cycle Number } \\
\hline & 476 & $477 \mathrm{~A}$ & $477 \mathrm{~B}$ & 478 & 479 & 480 & 481 & 482 \\
\hline Cycle & $11 / 14 / 2017$ & $1 / 9 / 2018$ & $1 / 15 / 2018$ & $2 / 20 / 2018$ & $5 / 1 / 2018$ & $6 / 12 / 2018$ & $7 / 24 / 2018$ & $9 / 4 / 2018$ \\
dates & to & to & to & to & to & to & to & to \\
& $12 / 8 / 2017$ & $1 / 13 / 2018$ & $2 / 4 / 2018$ & $3 / 16 / 2018$ & $5 / 24 / 2018$ & $7 / 6 / 2018$ & $8 / 17 / 2018$ & $9 / 28 / 2018$ \\
\hline MWD & 2051.05 & 353.19 & 1673.3 & 2036.33 & 2033.77 & 2042.7 & 2088.38 & 2079.28 \\
\hline
\end{tabular}

During FY-2018, 12 target zone rabbit capsules completed HFIR irradiation, achieving the target neutron fluences. Those capsules are listed in Table 7 along with condensed information on material, specimen type, temperature, fluence, and period of irradiation. At the end of FY-2018, 22 target zone rabbit capsules are continuing irradiation in HFIR toward their target neutron fluences. Those capsules are listed in Table 8 along with the information on materials, specimen types, and irradiation parameters.

Table 7. Fusion materials program rabbits that completed HFIR irradiation in FY-2018

\begin{tabular}{|c|c|c|c|c|c|c|}
\hline $\begin{array}{c}\text { Experiment } \\
\text { Designations }\end{array}$ & $\begin{array}{c}\text { Primary } \\
\text { Materials }\end{array}$ & $\begin{array}{c}\text { Specimen } \\
\text { Types }\end{array}$ & $\begin{array}{c}\text { Irradiation } \\
\text { Temperature } \\
\left({ }^{\circ} \mathrm{C}\right)\end{array}$ & $\begin{array}{c}\text { Max } \\
\text { Exposure } \\
(\mathrm{dpa})\end{array}$ & $\begin{array}{c}\text { Number of } \\
\text { Reactor } \\
\text { Cycles }\end{array}$ & $\begin{array}{c}\text { HFIR Cycles } \\
\text { Start }- \text { End }\end{array}$ \\
\hline F13A6 & $\begin{array}{c}\text { FeCrAlY } \\
\text { Steel }\end{array}$ & Bend bar & 300 & 50 & 29 & 451 \\
\hline $\begin{array}{c}\text { FHC series } \\
4 \text { capsules }\end{array}$ & F82H Steel & Creep Tube & 300 & 3.7 & 2 & 475 \\
\hline $\begin{array}{c}\text { ES21 to ES22 } \\
2 \text { tensile } \\
\text { capsules }\end{array}$ & $\begin{array}{c}\text { EUROFER } \\
\text { alloy variants }\end{array}$ & Tensile/MPC* & 300 & 2.5 & 2 & 477 \\
\hline $\begin{array}{c}\text { ES31 to ES35 } \\
5 \text { bend bar } \\
\text { capsules }\end{array}$ & $\begin{array}{c}\text { EUROFER } \\
\text { alloy variants }\end{array}$ & Bend Bar & 300 & 2.5 & 2 & 477 \\
\hline
\end{tabular}

*MPC is a Multi-Purpose Coupon, with the same outer dimensions as a tensile specimen. 
Table 8. HFIR fusion materials program rabbit capsules continuing irradiation beyond FY-2018

\begin{tabular}{|c|c|c|c|c|c|c|c|}
\hline $\begin{array}{c}\text { Experiment } \\
\text { Designations }\end{array}$ & $\begin{array}{l}\text { Primary } \\
\text { Materials }\end{array}$ & $\begin{array}{l}\text { Specimen } \\
\text { Types }\end{array}$ & $\begin{array}{c}\text { Irradiation } \\
\text { Temperatures } \\
\left({ }^{\circ} \mathrm{C}\right)\end{array}$ & $\begin{array}{c}\text { Max } \\
\text { Exposure } \\
\text { (dpa) }\end{array}$ & $\begin{array}{l}\text { Number } \\
\text { of Reactor } \\
\text { Cycles }\end{array}$ & & $\begin{array}{l}\text { irst } \\
\text { IFIR } \\
\text { ycle }\end{array}$ \\
\hline F13A5 & $\begin{array}{c}\text { FeCrAlY } \\
\text { Steel }\end{array}$ & Bend bar & 300 & 28 & 16 & 451 & \\
\hline F13B4 & $\begin{array}{c}\text { FeCrAlY } \\
\text { Steel }\end{array}$ & Tensile & 300 & 50 & 29 & 451 & \\
\hline JCR11-05 & $\mathrm{SiC} / \mathrm{SiC}$ & bend bars & 950 & 200 & 115 & 444 & \\
\hline JCR11-07 & $\mathrm{SiC} / \mathrm{SiC}$ & Mini bend bars & 950 & 100 & 47 & 444 & \\
\hline JCR11-08 & $\mathrm{SiC} / \mathrm{SiC}$ & Mini bend bars & 950 & 200 & 115 & 444 & \\
\hline SCF8 & $\mathrm{SiC} / \mathrm{SiC}$ & $\begin{array}{c}\text { Miniature flexure } \\
\text { bar }\end{array}$ & 600 & 100 & 45 & 457 & \\
\hline SCF9 & $\mathrm{SiC} / \mathrm{SiC}$ & $\begin{array}{c}\text { Miniature flexure } \\
\text { bar }\end{array}$ & 600 & 200 & 90 & 457 & \\
\hline SCF11 & $\mathrm{SiC} / \mathrm{SiC}$ & $\begin{array}{c}\text { Miniature flexure } \\
\text { bar }\end{array}$ & 950 & 100 & 57 & 458 & \\
\hline $\begin{array}{c}\text { ES01 to ES07 } \\
7 \text { tensile } \\
\text { capsules }\end{array}$ & $\begin{array}{c}\text { EUROFER } \\
97\end{array}$ & Tensile/MPC* & $\begin{array}{c}220 \\
\text { to } \\
375\end{array}$ & 20 & 12 & 479 & \\
\hline $\begin{array}{c}\text { ES11 to ES17 } \\
7 \text { bend bar } \\
\text { capsules }\end{array}$ & $\begin{array}{c}\text { EUROFER } \\
97\end{array}$ & Bend bars & $\begin{array}{c}220 \\
\text { to } \\
375 \\
\end{array}$ & 20 & 12 & 479 & \\
\hline
\end{tabular}

*MPC is a Multi-Purpose Coupon, with the same outer dimensions as a tensile specimen. 


\section{PUBLICATION AND PRESENTATION RECORD}

\subsection{PAPERS PUBLISHED IN FY 2018 (Alphabetical by first $\underline{\text { ORNL author) }}$}

Arunodaya Bhattacharya, Estelle Meslin, Jean Henry, Brigitte Décamps \& Alain Barbu, "Dramatic reduction of void swelling by helium in ion-irradiated high purity $\alpha$-iron," Materials Research Letters, 6 (2018) 372-377, DOI: 10.1080/21663831.2018.1462266

X. Chen, M.A. Sokolov, Y. Katoh, M. Rieth, L. Clowers, "Master curve fracture toughness characterization of EUROFER97 using miniature multi-notch bend bar specimens for fusion applications," Proceedings of the ASME 2018 Pressure Vessels and Piping Conference, July 15-20, 2018, Prague, Czech Republic, PVP2018-85065

H. Sakasegawa, X. Chen, and T. Kato, H. Tanigawa, M. Ando, J.W. Geringer, S. Ukai, S. Ohtsuka, "Strain evaluation using a non-contact deformation measurement system in tensile tests of irradiated $\mathrm{F} 82 \mathrm{H}$ and $9 \mathrm{Cr}$ ODS steels," Nuclear Materials and Energy, 16 (2018) 108-113

Lauren M. Garrison, Gerald L. Kulcinski, Greg Hilmas, William Fahrenholtz, and Harry M. Meyer III, "The Response of $\mathrm{ZrB}_{2}$ to Simulated Plasma-Facing Material Conditions of He Irradiation at High Temperature," Journal of Nuclear Materials, 507 (2018) 112-125

L. M. Garrison, F. W. Meyer, M. E. Bannister, "The Influence of Microstructure on Deuterium Retention in Polycrystalline Tungsten," Fusion Science and Technology 72 (2017) 574-580

Xunxiang Hu, Takaaki Koyanagi, Jiangtao Zhao, Takuya Yamamoto, Yutai Katoh, "Microstructural evolution of 3C-SiC exposed to simultaneous neutron irradiation and helium implantation," Journal of Nuclear Materials, 509 (2018) 366-376. doi:10.1016/j.jnucmat.2018.07.007

Y. Katoh, Q. Huang, Y.H. Han, S. Risbud, "Viewpoint Set on Nuclear Materials Science," Scripta Materialia 143 (2018) 126-128. doi:10.1016/j.scriptamat.2017.08.028

Y. Katoh, T. Koyanagi, J. L. McDuffee, L. L. Snead, and K. Yueh, "Dimensional stability and anisotropy of $\mathrm{SiC}$ and $\mathrm{SiC}$-based composites in transition swelling regime," Journal of Nuclear Materials, 499 (Jan. 2018) 471-479

M. Ando, H. Tanigawa, H. Kurotaki, Y. Katoh, "Mechanical properties of neutron irradiated F82H using micro-tensile testing," Nuclear Materials and Energy, 16 (2018) 258-262

V. Casalegno, S. Kondo, T. Hinoki, M. Salvo, A. Czyrska-Filemonowicz, T. Moskalewicz, Y. Katoh, M. Ferraris, "CaO-A12O3 glass-ceramic as a joining material for $\mathrm{SiC}$ based components: A microstructural study of the effect of Si-ion irradiation," Journal of Nuclear Materials 501 (2018) 172-180. doi:10.1016/j.jnucmat.2018.01.033

J. Kabel, P. Hosemann, Y. Zayachuk, D.E.J. Armstrong, T. Koyanagi, Y. Katoh, C. Deck, “Ceramic composites: A review of toughening mechanisms and demonstration of micropillar compression for interface property extraction," J. Mater. Res. 33 (2018) 424-439. doi:10.1557/jmr.2017.473

T. Koyanagi, T. Nozawa, Y. Katoh, L.L. Snead, "Mechanical property degradation of high crystalline SiC fiber-reinforced SiC matrix composite neutron irradiated to 100 displacements per atom," Journal of the European Ceramic Society 38 (2018) 1087-1094 
Padhraic L. Mulligan, Hideo Sakasegawa, Hiroyasu Tanigawa, Christian M. Petrie, Joel L. McDuffee, Yutai Katoh, "An F82H steel pressurized tube creep capsule for irradiation in HFIR," Nuclear Materials and Energy, 15 (2018) 254-260 [ISSN 2352-1791; doi: https://doi.org/10.1016/j.nme.2018.05.011]

C.M. Parish, K. Wang, P.D. Edmondson, "Viewpoint: Nanoscale chemistry and crystallography are both the obstacle and pathway to advanced radiation-tolerant materials," Scripta Materialia, 143 (2018) 169

D. Donovan, D. Buchenauer, J. Whaley, G. Wright, C. M. Parish, X. Hu, "Characterization of He-Induced Bubble Formation in Tungsten due to Exposure from an Electron Cyclotron Resonance Plasma Source," Fusion Science and Technology, 72 (2017) 337-346

A.F. Rowcliffe, C.E. Kessel, Y. Katoh, L.M. Garrison, L. Tan, Y. Yamamoto, F.W. Wiffen, "Materialsengineering challenges for the fusion core and lifetime components of the fusion nuclear science facility," Nuclear Materials and Energy 16 (2018) 82-87

K. Ibano, A.S. Sabau, K. Tokunaga, M. Akiyoshi, J.O. Kiggans, C.R. Schaich, Y. Katoh, and Y. Ueda, "Surface morphology of Tungsten-F82H after High-Heat Flux Testing using Plasma-Arc Lamps," Nuclear Materials and Energy, 16 (2018) 128-132

L. Tan, C.M. Parish, X. Hu, "Microstructure and property tailoring of castable nanostructured alloys through thermomechanical treatments," Journal of Nuclear Materials 509 (2018) 267-275

K. Wang, R.P. Doerner, M.J. Baldwin, and C.M. Parish, "Nucleation and growth of tungsten nanotendrils grown under divertor-like conditions," Journal of Nuclear Materials 509 (2018) 679-686

K. Wang, R.P. Doerner, M.J. Baldwin, and C.M. Parish, "Flux and fluence dependent helium plasmamaterials interaction in hot-rolled and recrystallized tungsten," Journal of Nuclear Materials 510 (2018) 80-82

Ying Yang, Ling Wang, Lance Snead, Steven J. Zinkle, "Development of Novel Cu-Cr-Nb-Zr alloys with the Aid of Computational Thermodynamics," Materials \& Design 156 (2018) 370-380. https://doi.org/10.1016/j.matdes.2018.07.003

S.J. Zinkle and L.L. Snead, "Opportunities and limitations for ion beams in radiation effects studies: Bridging critical gaps between charged particle and neutron irradiations," Scripta Materialia 143 (Jan. 2018) 154-160

T. Yang, S. Xia, W. Guo, R. Hu, J.D. Poplawsky, G. Sha, Y. Fang, Z. Yan, C. Wang, C. Li, Y. Zhang,

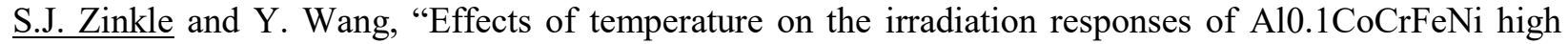
entropy alloy," Scripta Materialia 144 (2018) 31-35

P.J. Doyle, K.M. Benensky and S.J. Zinkle, "Modeling of dislocation channel width evolution in irradiated metals," Journal of Nuclear Materials 499 (2018) 47-64 


\subsection{REPORTS ISSUED IN FY 2018}

Arunodaya Bhattacharya, Xiang Chen, Kory Linton, Yukinori Yamamoto, Mikhail Sokolov, Logan Clowers, Yutai Katoh, "Mechanical Properties and Microstructure Characterization of Unirradiated Eurofer-97 Steel Variants for the EUROfusion Project," ORNL/SPR-2018/882, June 2018

X. Chen, M.A. Sokolov, K.D. Linton, L. Clowers, Y. Katoh, "Transition Fracture Toughness Characterization of Eurofe97 Steel using Pre-Cracked Miniature Multi-Notch Bend Bar Specimens," ORNL/LTR-2017/532, November 2017

F.W. Wiffen, Y. Katoh, S. Melton, "Fusion Materials Research at Oak Ridge National Laboratory in Fiscal Year 2017," ORNL/TM-2017/732, November 2017

"Fusion Materials Semiannual Progress Report for the Period Ending December 31, 2017," DOE-ER0313/63, March 2018

"Fusion Materials Semiannual Progress Report for the Period Ending June 30, 2018," DOE-ER-0313/64, March 2018 


\subsection{PAPERS SUBMITTED IN FY 2018 (Alphabetical by first ORNL author; Currently awaiting publication)}

Arunodaya Bhattacharya, Chad Parish, Jean Henry, and Yutai Katoh, "High throughput modern electron microscopy characterization of nanosize precipitates with unprecedented statistics," submitted to Nature Communications

Arunodaya Bhattacharya, Chad Parish, Takaaki Koyanagi, Derek King (MUST), Greg Hilmas (MUST), William Fahrenholtz (MUST), Steve Zinkle and Yutai Katoh, "Nanoscale microstructure damage by neutron irradiations in a novel Boron-11 enriched $\mathrm{TiB}_{2}$ ultra-high temperature ceramic," submitted to Acta Materialia

Lauren M. Garrison, Y. Katoh, N.A.P. Kiran Kumar, "Mechanical Properties of Single-Crystal Tungsten Irradiated in a Mixed Spectrum Fission Reactor," submitted to Journal of Nuclear Materials

C.E. Kessel, J.P. Blanchard, A. Davis, L. El-Guebaly, L.M. Garrison, N.M. Ghoniem, P.W. Humrickhouse, Y. Huang, Y. Katoh, A. Khodak, E.P. Marriott, S. Malang, N.B. Morley, G.H. Neilson, J. Rapp, M.E. Rensink, T.D. Rognlien, A.F. Rowcliffe, S. Smolentsev, L.L. Snead, M.S. Tillack, P. Titus, L.M. Waganer, G.M. Wallace, S.J. Wukitch, A. Ying, K. Young, Y. Zhai, "Overview of the fusion nuclear science facility, a credible break-in step on the path to fusion energy," in press Fusion Engineering and Design

M. Shimada, Y. Oya, W.R. Wampler, Y. Yamauchi, C.N. Taylor, L.M. Garrison, D.A. Buchenauer, and Y. Hatano, "Deuterium Retention in Neutron-Irradiated Single-Crystal and Polycrystalline Tungsten," accepted by Fusion Engineering and Design

Masafumi Akiyoshi, Ryuta Kasada, Yuko Ishibashi, Lauren M. Garrison, Josina W. Geringer, Wallace D. Porter, and Yutai Katoh, "Validation of miniature test specimens for post-irradiation thermal diffusivity measurement," accepted by Fusion Engineering and Design

Xunxiang Hu, Takaaki Koyanagi, Jiangtao Zhao, Takuya Yamamoto, Yutai Katoh, "Microstructural evolution of 3C-SiC exposed to simultaneous neutron irradiation and helium implantation," accepted by Journal of Nuclear Materials

Xunxiang Hu, Lizhen Tan, Kun Wang, Caleb P. Massey, David T. Hoelzer, Yutai Katoh, "Dueterium retention in advanced steels for fusion reactor structural application," submitted to Journal of Nuclear Materials

Xunxiang Hu, Chad Parish, Kun Wang, Takaaki Koyanagi, Benjamin P. Eftink, Yutai Katoh, "Transmutation-induced precipitation in tungsten irradiated with a mixed energy neutron spectrum," submitted to Acta Materialia

Katherine Haynes, Xunxiang Hu, Brian Wirth, Christopher Hatem, and Kevin Jones, "Defect Evolution in Ultralow Energy, High Dose Helium Implants of Silicon Performed at Elevated Temperatures," submitted to Journal of Applied Physics

T. Koyanagi, Y. Katoh, T. Nozawa, L.L. Snead, S. Kondo, C.H. Henager Jr., M. Ferraris, T. Hinoki, Q. Huang, "Recent progress in the development of $\mathrm{SiC}$ composites for nuclear fusion applications," in press at Journal of Nuclear Materials 
Takaaki Koyanagi, Yutai Katoh, Caen Ang (ORNL), Derek King, Greg E. Hilmas, William G. Fahrenholtz (Missouri University of Science and Technology), "Response of isotopically tailored titanium and zirconium diborides to neutron irradiation," submitted to Journal of the American Ceramic Society

T. Koyanagi, Y. Katoh, M.J. Lance, "Raman spectroscopy of neutron irradiated silicon carbide: correlation among Raman spectra, swelling and irradiation temperature," submitted to Journal of the Raman Spectroscopy

C. Massey, S. Dryepondt, P. Edmonson, K.A. Terrani and S. Zinkle, "Influence of Mechanical Alloying and Extrusion Conditions on the Microstructure and Tensile Properties of Low-Cr ODS FeCrAl Alloy," accepted by Journal of Nuclear Materials

Joel L. McDuffee, Nesrin Cetiner, Yuji Hatano, S. Dan Ilas, Yutai Katoh, J. Wilna Geringer, "A Hydrogen-Charged, Tungsten Irradiation Capsule for HFIR," (Not yet accepted by Nuclear Materials and Energy)

L. Tan, Y. Katoh, L.L. Snead, "Development of castable nanostructured alloys as a new generation RAFM steels," accepted by Journal of Nuclear Materials (2018), https://doi.org/10.1016/j.jnucmat.2018.05.024

Kun Wang, R. P. Doerner, M. J. Baldwin, Chad M. Parish, "Flux and fluence dependent helium plasmamaterials interaction in hot-rolled and recrystallized tungsten," submitted to Journal of Nuclear Materials

Kun Wang, F.W. Meyer, M.E. Bannister, Chad M. Parish, "Surface roughness and exposure energy effect on the surface nanofuzz growth of tungsten," submitted to Journal of Nuclear Materials

K. Nordlund, S.J. Zinkle, A.E. Sand, F. Granberg, R.S. Averback, R. Stoller, T. Suzudo, L. Malerba, F. Banhart, W.J. Weber, F. Willaime, S. Dudarev and D. Simeone, "Primary radiation damage: A review of current understanding and models" (invited), Journal of Nuclear Materials, submitted July 2018 


\subsection{PRESENTATIONS DELIVERED IN FY 2018 (OFES-funded ORNL Presenting Authors, by} date presented)

At the Materials Science \& Technology 2017, Pittsburgh, PA, October 9-12, 2017

\section{Symposium on Materials for Nuclear Energy Applications}

C.K. Ang, S.J. Zinkle, C. Shih, P.D. Edmondson and Y. Katoh, "Effects of increasing neutron dose on the stability of MAX phase Ti3AlC2 /Ti3SiC2 ceramics and MX/MA impurity phases"

C. Massey, P.D. Edmondson, S. Dryepondt, K. Terrani and S.J. Zinkle, "Atom Probe Tomography and Transmission Electron Microscopy Investigations of Nano-precipitate Nucleation in ODS FeCrAl Alloys"

S.J. Zinkle, "Promise and Limitations of Ion Irradiations for Understanding High Dose Radiation Effects in Materials"

\section{American Ceramic Society Edward Orton, Jr. Memorial Lecture}

S.J. Zinkle, "What's New in Nuclear Reactors?"

At the American Nuclear Society Winter Meeting, Washington, DC, November 1, 2017

S.J. Zinkle, "High Performance Nanostructured Materials for Fission and Fusion Energy Applications," (Panel on Research Opportunities in Advanced Fission and Fusion Materials)

At the 18th International Conference on Fusion Reactor Materials, Aomori, Japan, November 5-10, 2017

\section{Oral presentations}

Sebastien Dryepondt, Caleb Massey, Kinga A. Unocic, David T Hoelzer, Phil Edmonson and Bruce A. Pint, "New Creep Resistant ODS FeCrAl(Zr) Alloys With Improved Pb-Li Compatibility"

Philip D. Edmondson, Keith J. Leonard, "Microstructural and conductivity of second generation high temperature superconductors irradiated in HFIR"

Kevin G. Field, Kun Wang, David Hoelzer, Hideo Sakasegawa, Hiroyasu Tanigawa, Takanori Hirose, Lizhen Tan, Yutai Katoh, "Mechanical properties of oxide dispersion strengthened steels after neutron irradiations up to $64 \mathrm{dpa"}$

D.T. Hoelzer, C.P. Massey, M. Li and R.L. Klueh, "High-Temperature Creep of MA957"

Xunxiang Hu, Kevin G. Field, Takaaki Koyanagi, Jie Qiu, Brian D. Wirth, Yutai Katoh, "Helium interactions with displacement defects in neutron irradiated materials"

Yutai Katoh, Lance L. Snead, Lauren M. Garrison, Xunxiang Hu, Takaaki Koyanagi, Chad M. Parish, Phil D. Edmondson, Makoto Fukuda, and Akira Hasegawa, "Understanding the response of tungsten to mixed spectrum neutrons" 
T. Koyanagi, Y. Katoh, T. Nozawa, L.L. Snead, T. Hinoki, S. Kondo, C.H. Henager Jr., M.Ferraris, Q. Huang, "Recent progress in the development of SiC composites for fusion"

Chad M. Parish, Kun Wang, Xunxiang Hu, Lauren Garrison, Philip Edmondson, David T. Hoelzer, Steven J. Zinkle, and Yutai Katoh, "Applying Advanced Electron Microscopy to Fusion Studies of Plasma-Exposure and Neutron-Irradiation"

B. A. Pint, J. Jun, and S. J. Pawel, "Compatibility of Alumina-Forming Steel in Flowing PbLi at $450^{\circ}-650^{\circ} \mathrm{C}$ with Temperature Gradients"

A.F. Rowcliffe, C.E. Kessel, Y. Katoh, L.M. Garrison, L. Tan, Y. Yamamoto, F.W. Wiffen, "Materials-Engineering Challenges for the Fusion Core and Lifetime Components of the Fusion Nuclear Science Facility"

Lizhen Tan, Yutai Katoh, Lance L. Snead, "Development of castable nanostructured alloys as a new generation of RAFM steels"

Kun Wang, Kevin G. Field, Chad M. Parish, Lizhen Tan, Hideo Sakasegawa, Hiroyasu Tanigawa, Takanori Hirose, Xiang Chen, Josina W. Geringer, Yutai Katoh, "Dose, Composition, and Helium Effects on Mechanical Properties of Neutron Irradiated Reduced-Activation Ferritic/Martensitic Steels"

Yukinori Yamamoto, Arthur Rowcliffe, "Advanced Bainitic Steels for Large Fusion Structures"

S.J. Zinkle, "Fundamentals of Radiation Effects in Materials," (ICFRM tutorial)

S.J. Zinkle, L.L. Snead and Y. Yang, "Prospects for Designing High Performance Copper Alloys for High Heat Flux Structural Applications"

\section{Poster presentations}

C. Ang, S.J. Zinkle, C. Shih, P. Edmondson, Y. Katoh, "Effects of Irradiation on Max Phase Ceramics"

Anne A. Campbell, J.D. Arregui-Mena, Y.Katoh, "Using Raman Microscopy to Predict Tritium Retention in Neutron Irradiated Graphite"

X. Chen, H. Sakasegawa, M.A. Sokolov, L.N. Clowers, J.W. Geringer, Y. Katoh, H. Tanigawa, "Fracture Toughness of F82H Steel after High Dose Irradiation"

Philip D Edmondson, Mark Gilbert, Yutai Katoh, "Atom probe characterization of precipitates in neutron-irradiated tungsten"

Lauren M. Garrison, Yutai Katoh, Chad Parish, Kun Wang, Jens Reiser, Michael Rieth, "Interface characteristics of tungsten-copper laminate composites after neutron irradiation"

Lauren M. Garrison, Yutai Katoh, Chad Parish, Kun Wang, Lance Snead, "Neutron irradiation response of ductile phase toughened tungsten-copper composite" 
Josina W. Geringer, Joel L. McDuffee, Charles R. Daily, Nesrin O. Cetiner, Christian M. Petrie, Richard H. Howard, Frank D. Riley, Jr., Tatsuya Hinoki, Hiroyasu Tanigawa, and Yutai Katoh, "The MFE-RB-19J experiment to irradiate tungsten and steel in HFIR"

Maxim Gussev, Kevin G. Field, Richard H. Howard, Philip D. Edmondson, Brian Eckhart, "Advanced methods for evaluating mechanical performance of neutron irradiated alloys"

D.T. Hoelzer and C.P. Massey, "Development of Phase Transformable ODS Fe-10Cr Ferritic Alloys for Fusion Reactors"

Xunxiang Hu, Takaaki Koyanagi, Makoto Fukuda, N.A.P. Kiran Kumar, Lance. L. Snead, Brian D. Wirth, Yutai Katoh, "Neutron irradiation hardening of tungsten"

Y. Katoh, L.M. Garrison. T. Koyanagi, C.M. Parish, P.D. Edmondson, S.J. Zinkle, D.S. King, G.E. Hilmas and W.G. Fahrenholtz, "Potential of ultra-high temperature ceramics as fusion invessel component materials"

T. Koyanagi, X. Hu, D.J. Sprouster, L.E. Ecker, M.J. Lance, Y. Katoh, "Characterization of atomic scale defects in neutron irradiated silicon carbide"

Joel McDuffee, Yuji Hatano, S. Dan Ilas, Yutai Katoh, J. Wilna Geringer, “A hydrogen-charged tungsten irradiation capsule for HFIR"

Padhraic L. Mulligan, Hideo Sakasegawa, Hiroyasu Tanigawa, Christian M. Petrie, Joel L. McDuffee, Yutai Katoh, "An F82H Steel Pressurized Tube Creep Capsule for Irradiation in HFIR"

Padhraic L. Mulligan, Christian Petrie, Joel L. McDuffee, Yutai Katoh, "HFIR Irradiation Capabilities for Fusion Materials Research"

Yuri Osetsky, Roger Stoller, "Atomic-scale assessment of the role of edge dislocations in inclusion strengthened iron"

Yuri Osetsky, Roger Stoller, "Geometric effects in hardening mechanisms applicable to irradiated iron"

Chad M. Parish, Kun Wang, Mark Bannister, Fred Meyer, Russell Doerner, Matt Baldwin, and David Donovan, "Defect Analysis in Plasma-Materials Interactions"

A.S. Sabau, K. Ibano, J.O. Kiggans, C.R. Schaich, Y. Ueda, and Y. Katoh, High-Heat Flux Testing of Tungsten and Tungsten-SiC using Plasma-Arc Lamps

Hideo Sakasegawa, Xiang Chen, Taichiro Kato, Hiroyasu Tanigawa, Masami Ando and Josina W. Geringer, "Strain evaluation using a non-contact deformation measurement system in tensile tests of irradiated F-82H steel"

G.D. Samolyuk, Y.N. Osetsky, "Thermodynamic approach to defect equilibrium distribution at the interface: application to the $\mathrm{Y}_{2} \mathrm{O}_{3}-\mathrm{Fe}$ system" 
M.A. Sokolov, H. Tanigawa, S.M. Gonzalez-de-Vicente, J. Aktaa, R. Heidinger, T. Nagasaka, S. Nogami, M. Serrano, Y. Shen, X. Chen, "IAEA coordinated research project on small specimen test techniques for fusion applications"

Roger E. Stoller, Yuri Osetsky, Alexander Barashev, "Mechanisms of helium effects under irradiation"

Lizhen Tan, Chad M. Parish, "Tailoring the microstructure and mechanical properties of castable nanostructured alloys through thermomechanical treatments"

K. Wang, C.M. Parish, R.P. Doerner, M.J. Baldwin, "Flux, fluence, and microstructure effects on helium disposition in tungsten PFCs"

Y. Yamamoto, X. Chen, K.G. Field, R.H. Howard, L.L. Snead, and M. Rieth, "54Fe Isotope Containing RAFM Steels Produced For Accelerated Helium Production in HFIR"

Y. Yang, S.J. Zinkle and L.L. Snead, "Advanced copper alloys from computational thermodynamics and microstructural screening"

T. Yang, C. Li, Y. Wang and S.J. Zinkle, "Irradiation responses of a high entropy alloy A10.1CoCrFeNi at elevated temperatures"

T. Yang, C.J. Beers, L. Wang, J. Hu, Z. Shen, Y. Fang and S.J. Zinkle, "Plasma exposure behavior of molybdenum and graphite in the EAST tokamak"

C. Li, X. Hu, T. Yang, M. Stocks, S.J. Zinkle and B.D. Wirth, "Evaluation of the radiation effects in a Co-free high entropy alloy"

L. Wang and S.J. Zinkle, "Microstructural Evaluation of Ion Irradiated Model Binary Alloys"

At the MRS Fall Meeting \& Exhibition, Boston, MA, November 26-December 1, 2017

Xunxiang $\mathrm{Hu}$, Chad Parish, Kun Wang, Yutai Katoh, "Transmutation-induced precipitation in neutron-irradiated tungsten"

C.P. Massey, P.D. Edmondson, S.N. Dryepondt, A. Kini, B. Gault, K.A. Terrani and S.J. Zinkle, "Analyzing the Effect of Milling Intensity on the Nano-precipitate Evolution in ODS FeCrAl Alloys using Atom Probe Tomography"

At the Fusion Power Associates 38th annual meeting and symposium, Washington, DC, December 6-7, 2017

S.J. Zinkle, "Technology issues for fusion power"

At the 42nd International Conference and Exposition on Advanced Ceramics and Composites, Daytona Beach, FL, January 21 - 26, 2018

A. Bhattacharya, T. Koyanagi, C. Parish, Y. Katoh, D. King, G. Hilmas, "Effect of neutron irradiation on microstructure evolution of isotopically-controlled titanium diboride $\left(\mathrm{Ti}_{11} \mathrm{~B}_{2}\right)$ "

Y. Katoh, T. Koyanagi, T. Nozawa, L. Snead," High dose neutron irradiation response of nuclear grade $\mathrm{SiC} / \mathrm{SiC}$ composites" 
S. Agarwal, Y. Zhao, S.J. Zinkle and W.J. Weber, "Raman spectroscopy experiments to characterize radiation induced defects in $\mathrm{SiC} / \mathrm{SiC}$ composites"

S.J. Zinkle and Y. Katoh, "Advances in ceramic composites for fission and fusion energy applications"

At the Workshop of ORNL-Chinese fusion materials community collaboration, Beijing, March 7, 2018

X. Hu, "Nuclear materials research at Oak Ridge National Laboratory"

At TMS 2018, Phoenix, AZ, March 11-15, 2018

C. Li, X. Hu, T. Yang, B.D. Wirth and S.J. Zinkle, "Ion and neutron irradiation effects in a Cofree high entropy alloy"

Yutai Katoh, Takaaki Koyanagi, Gyanender Singh, Ken Yueh, "Transient Swelling of SiC/SiC Composites and its Implications to Fuels and Core Designs"

Caleb P. Massey, Sebastien N. Dryepondt, Philip D. Edmondson, Anoop Kini, Baptiste Gault, Kurt A. Terrani, and Steven J. Zinkle, "ODS FeCrAl Fabrication Methodology for Optimizing Ductility and Sink Strength"

Caleb P. Massey, Sebastien N. Dryepondt, Philip D. Edmondson, Matthew G. Frith, Anoop Kini, Baptiste Gault, Kinga Unocic, Kenneth Littrell, Kurt A. Terrani and Steven J. Zinkle " In-situ Characterization of Dispersoid Evolution during Annealing of ODS FeCrAl Mechanical Alloyed Powders"

Kun Wang, Kevin G. Field, Chad M. Parish, Josina W. Geringer, Yutai Katoh, "High-dose Neutron Irradiation Induced Evolution of Mechanical Properties and Microstructure of Ferritic/Martensitic Steels"

Kun Wang, Chad M. Parish, R.P. Doerner, M.J. Baldwin, F.W. Meyer, M.E. Bannister, D.C. Donovan, Y. Katoh, "Investigation on the damage mechanism of Plasma-materials interface by using multi-scale electron microscopy"

J. Brechtl, L. Mora, M. Crespillo, Y. Zhang, H. Wang, H. Bei, J. Neuefeind, W. Dmowski, T. Egami and S.J. Zinkle, "Effects of Annealing and Irradiation on the Mechanical and Microstructural Properties of Bulk Metallic Glass Alloys"

\section{Invited talk at UC Berkeley April 23, 2018}

Xunxiang $\mathrm{Hu}$, "Microstructure and mechanical properties of tungsten neutron irradiated with a mixed energy spectrum"

At Electron Backscatter Diffraction 2018, Ann Arbor, MI, May 23-25, 2018

C. M. Parish, K. Wang, A. Bhattacharaya, Y. Katoh, R. Doerner, M. Baldwin, C. Layton, "Preparation of Atypical Sample Geometries for Transmission Kikuchi Diffraction and Scanning Transmission Electron Microscopy" 
At CIMTEC 2018 -Forum of New Materials, Perugia, Italy, June 10-15, 2018

Yutai Katoh, Caen Ang, Philip D. Edmondson, Takaaki Koyanagi, "Response of Commercial MAX-phases to Neutron Irradiation to Intermediate Fluences"

At the American Nuclear Society Annual Meeting, Philadelphia, PA June 17-21, 2018

Xunxiang $\mathrm{Hu}$, Takaaki Koyanagi, Jiangtao Zhao, Takuya Yamamoto, Yutai Katoh, "Microstructural evolution of 3C-SiC exposed to simultaneous neutron irradiation and helium implantation"

Yutai Katoh, "Recent Development in SiC Composite Technologies for Nuclear Energy Applications"

Yutai Katoh, T. Koyanagi, X. Hu, G. Singh, K.A. Terrani, J.W. Geringer, A.L. Qualls, Y. Lee, S. Raiman (ORNL), L.L. Snead (SUNY/SBU), B.D. Wirth (UTK), C. Deck (GA), P. Xu (WEC), C. Sauder (CEA), S. Gonczy(GMT), M. Jenkins (CSU Fresno), "Recent Development in SiC Composite Technologies for Nuclear Energy Applications"

S.J. Zinkle, "Fundamental Aspects of Radiation Effects in Materials"

At the International Conference on Plasma Surface Interactions in Controlled Fusion Devices, Princeton University, NJ, June 17-22, 2018

Xunxiang $\mathrm{Hu}$, Kun Wang, Chad Parish, Russell P. Doerner, Matthew Baldwin, Yutai Katoh, "Thermal stability of tungsten nanotendril fuzz grown under divertor-like conditions"

K. Wang, C.M. Parish, G. Tynan, Yongqiang Wang, "TEM Analysis of Ion-Irradiation Damage in Cu-Implanted Tungsten"

C.M. Parish, K. Wang, R.P. Doerner, M. Baldwin, F. Meyer, M. Bannister, D.N. Leonard, X. Hu, and D. Donovan, "Advanced Electron Microscopy Method Development to Improve Characterization of Plasma-Surface Interactions"

At the 14th international Workshop on Hydrogen Isotopes in Fusion Reactor Materials, University of Tennessee, Knoxville, TN June 25-27, 2018

Xunxiang Hu, Guin Shaw, Brian D. Wirth, Yutai Katoh, "Experimental Techniques Used for Investigating Hydrogen Isotope Retention in Fusion Reactor Materials"

Xunxiang Hu, Lizhen Tan, Sebastien N. Dryepondt, Caleb Massey, David T. Hoelzer, Yutai Katoh, "Deuterium Trapping Capability of Nanostructures in Steels for Fusion Reactor Structural Application"

Xunxiang Hu, Wendy Garcia, Brian Wirth, Yutai Katoh, "Deuterium Retention in Neutron Irradiated Tungsten"

At 2018 ASME Pressure Vessel \& Piping Conference, Prague, Czech Republic, July 15-20, 2018

Xiang Chen, Mikhail A. Sokolov, Yutai Katoh, Logan N. Clowers, Michael Rieth, "Master Curve Fracture Toughness Characterization of Eurofer97 Using Miniature Multi-Notch Bend Bar Specimens for Fusion Applications" 
At the 25th Conference on Application of Accelerators in Research and Industry, Grapevine, Texas, August $12^{\text {th }}-17^{\text {th }}, 2018$

Kun Wang, Chad M. Parish, Kevin G. Field, Russell P. Doerner, Matthew J. Baldwin, Yutai Katoh, "Multi-scale electron microscopy study on the damage mechanisms of materials under fusion irradiation environments"

At the $30^{\text {th }}$ Symposium on Fusion Technology (SOFT-2018), Giardine Naxo, Sicily-Italy, September 16-21, 2018

Arunodaya Bhattacharya, Chad Parish, Yutai Katoh, "Transmission Kikuchi diffraction on carbon extraction replicas: a novel high statistics precipitate characterization pathway for Eurofer-97 steel"

Xiang Chen, Arunodaya Bhattacharya, Mikhail A. Sokolov, Logan N. Clowers, Yukinori Yamamoto, Yutai Katoh, Kory D. Linton, Michael Rieth, Tim Graening, "Fracture Toughness Characterization of Eurofer97 Steels in EUROfusion using Miniature Multi-Notch Bend Bar Specimens" 